\title{
Fungi consortia in situ biodegradation of xenobiotic, military shooting range, Kachia, Kaduna, Nigeria
}

\section{Graphical abstract}

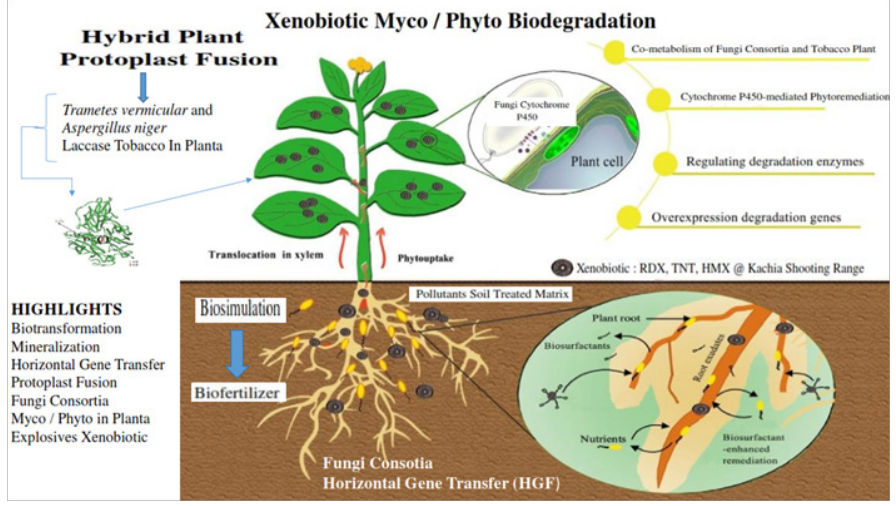

Volume 7 Issue 6 - 2020

\author{
Ayodele A Otaiku,' Al Alhaji ${ }^{2}$ \\ 'PhD Scholar, Department of Geography / Environmental \\ Management, Faculty of Arts and Science, Nigerian Defence \\ Academy, Nigeria \\ ${ }^{2}$ Department of Biological Science, Faculty of Science, Nigerian \\ Defence Academy, Nigeria
}

Correspondence: Ayodele A Otaiku, PhD Scholar, Department of Geography / Environmental Management, Faculty of Arts and Science, Nigerian Defence Academy, Kaduna, Nigeria, Tel +2348033721219,

Email aotaiku@gmail.com/otaiku.ajayiayodele@nda.edu.ng

Received: June 08, 2020 | Published: December 28, 2020

\begin{abstract}
A major limitation of the white-rot fungus is its sensitivity during biodegradation of mixed matrix explosive pollutants and the scale of Kachia military shooting since 1967, Nigeria. The amplified 16S rRNA gene of each microbial isolate was processed for sequencing and characterization with Gene Bank database. Fungal species heavy metal reduction in increasing order of Aspergillus niger $>$ Trametes versicolor $>$ Rhizopus spp $>$ Phanorochate chrysoporium $>$ Penicillium spp were identified. The total explosive contents shows a significant difference for all locations in both dry and wet seasons $(\mathrm{P}<0.05)$ using Anova test. Microbial fungi consortium (MFC) bioremediate heavy metal significantly at $61.7 \%$ relative to isolated fungi species because of the lateral gene transfer/co-metabolism, where Trametes versicolor and Aspergillus niger act as gene mediators. MFC growth in 1\% mineral salt medium munitions was significance than fungal species isolate. Deploying Myco Bio-augmentation / Phytoremediation/Biosimulation (Myco B-P-B) techniques to optimize the RDX and HMX characterized by a higher Nitrogen/Carbon ratio since fungi lack the beta-glucuronidase (GUS) gene to utilize carbon source directly. Pollutants biostimulation will enhances co-metabolism by MFC. Plant detoxification capabilities can be improved using fungi genes laccases and cytochrome P450 monooxygenase expressed effectively in plants using protoplast fusion.
\end{abstract}

Keywords: PC3R technology, explosives, enzymes, heavy metals, white rot fungi, peroxidase co-metabolism, biofertilizer, bioremediation, entophytes, phytoremediation, tobacco, xenobiotic myco B-P-B techniques and microbial fungi consortium

\section{Introduction}

Xenobiotic waste streams constituents from explosives military shooting ranges operations globally results in the soil contamination are nitroaromatics and Nitra mines including TNT $(2,4,6$ trinitrotolueness), RDX (Hexahydro-1,3,5-trinitro-1,3,5-Triazine), HMX (Octahydro-1,3,5,7-tetranitro-1,3,5,7-tetrazocine), Picric Acid (2,4,6-trinitrophenol) Tetryl (Methyl-2,4,6 trinitro-phenylnitramine), PETN (Pentaerythritol tetranitrate), TATB (Triaminotrini-trobenzene). The impurities and degradation products from military shooting ranges includes: 2,4-DNT (2,4-dinitrotoluene), 2,6-DNT (2,6 dinitrotoluene), 4A-2,6-DNT (4-amino-2,6-dinitrotoluene), 2A-4, 6-DNT(2amino-4,6-dinitrotoluene), TNB (1,3,5-trinitrobenzene), DNB (1,3 dinitrobenzene), NB (Nitrobenzene), Picramic Acid (2-amino-4,6dinitrophenol) was reported. ${ }^{1-79}$ Microbial biodegradation using microbes is optimized when interact within their niche, under the most favourable conditions. ${ }^{80-279}$ Microbial bioremediation consortium techniques that occurs simultaneously during explosive biodegradation are: bio-stimulation, bio-augmentation, bio-accumulation was reported; ${ }^{356,280-372}$ bio-sorption ${ }^{136}$ the use of biofilms. ${ }^{318,320}$

Pollutants bioremediation involves a number of species of microbes having different mechanisms depending upon the environmental factors and the nature of chemicals ${ }^{45}$ either to degrade or to remove the toxic contaminants from the environment. Elevated ambient atmospheric temperature (a climate change factor) may have impacts on the microbial activity, ${ }^{214}$ especially on the upper layers of soils. Explosives which are sufficiently sensitive to be detonated by a local hotspot or shock are called primary explosives (lead azide and lead styphnate) secondary (TNT, RDX) explosives less sensitive materials, which require an explosive shock wave for detonation can use primary explosives for detonation. ${ }^{117}$ Soil contamination by energetics at manufacturing sites, conflict areas, and military ranges is an international concern. Energetic compounds may enter 
the soil environment via numerous avenues ${ }^{31,24,333,215,216}$ including the following:

i. Ammunition production facilities, for example, wastewater lagoons, filtration pits;

ii. Packing or warehouse facilities;

iii. Waste disposal and destruction facilities, for example, open dumps, burn pits, incinerators;

iv. Weapons firing ranges; and

v. Weapon impact areas. ${ }^{372-412}$

RDX is reportedly the most important military high explosive currently in use, being about $40 \%$ more powerful than TNT. Approximately $85 \%$ of all landmines contain TNT. ${ }^{166}$ At elevated $\mathrm{CO}_{2}$ microbe's exhibit increased ability to decompose soil organic matter where soil microbial community plays an important role in cycling of carbon. ${ }^{246}$ The microbial biodegradation processes, the challenges are:

a. Physicochemical characteristics of environment or the abiotic factors,

\section{b. Biological factors or biotic factors}

c. Climatic conditions whereby physicochemical and climatic conditions are among the major factors affecting the metabolic rates in microbes.

A fluo-spot approach, ${ }^{382}$ which can be employed for in situ detection of trace amount of explosives. The fluorescence molecule used is 4-(dicyanomethylene)-2-methyl-6-(4-dimethylaminostyryl)$4 \mathrm{H}-$ pyran) (DCM). DCM is featured by its high fluorescence quantum yield $(15 \%$ in solid state, measured over the DCM deposited on a polytetra-fluoroethylene film) and unique electronic push-pull structure. The sensor reaction mechanism push-pull structure is a widely used design strategy for organic fluorescent molecules, as both the fluorescence efficiency and wavelength are very sensitive to the position and ability of the electron withdrawing or donating groups, which in turn can be changed by reacting with the analyses species (Figure 1). ${ }^{185,399}$

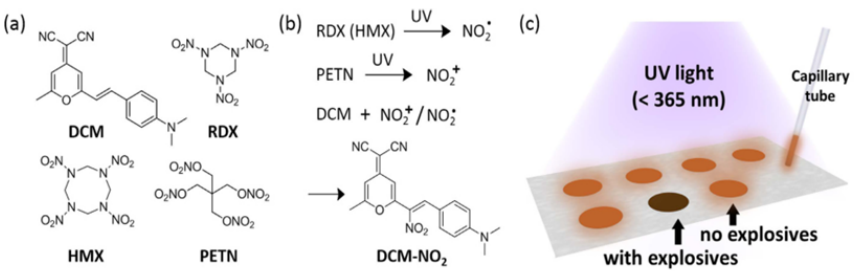

Figure I (a) Molecular structures of the fluorescence sensor, DCM, and the explosive compounds, RDX, HMX and PETN. (b) UV photolysis of RDX and PETN produces $\mathrm{NO}_{2}$ - and $\mathrm{NO}_{2}{ }^{+}$respectively; these reactive species can then be captured by DCM to produce the adduct $\mathrm{DCM}-\mathrm{NO}_{2}$, leading to complete fluorescence quenching of DCM. (c) Scheme of the fluo-spot detection method adapted. ${ }^{382}$

\section{Fungi biodegradation of TNT, RDX and HMX}

Explosives environmental impacts on humans shows that $\mathrm{RDX}$ affects the central nervous system, and classified as class $\mathrm{C}$ carcinogens. ${ }^{289} \mathrm{HMX}$ exists as $\alpha$ (orthorhombic), $\beta$ (monoclinic), $\gamma$ (monoclinic) and $\delta$ (hexagonal) forms, of which ' $\beta$ ' form is the least sensitive to impact and the most stable. HMX affects rats, aquatic organisms, bacteria, earthworm reproduction test and classified as
Class D carcinogenic. ${ }^{289,348}$ White rot fungi are able to transform or mineralize TNT using nonspecific extracellular enzyme systems such as lignin peroxidase, manganese peroxidase, laccase. The findings asserted that micromycetous fungi like Alternaria spp., Aspergillus terreus, Fusarium spp., Mucor mucedo, Penicillum spp., Rhizoctoniai spp are able to transform TNT but do not mineralize it. ${ }^{409}$ Agaricus aestivalis, Agrocybe praecox and Clitocybeodora transform TNT, with degree of mineralization ranging from 5 to $15 \%$ reported. ${ }^{172,175}$ The white rot fungus $P$. chrysosporium degrade TNT with complete transformation $10-40 \%$ mineralization was reported. ${ }^{409}$ In a study reported $^{313}$ that Phanerochaete Chrysosporium degraded RDX where it removed RDX $(62 \mathrm{mg} / \mathrm{L})$ from liquid medium containing glycerol as the main carbon source, Figures $2 \& 3$. Approximately $53 \%$ of the molecule was mineralized, and the major by product $(62 \%)$ of the degradation was $\mathrm{N}_{2} \mathrm{O}$. HMX was observed to be reduced from $61 \pm 20 \mathrm{mg} / \mathrm{kg}$ to $18 \pm 7 \mathrm{mg} / \mathrm{kg}$ during 62 days of incubation using P.chrysosporium. Under nitrogen-limiting conditions Phanerochaete chrysosporium mineralized HMX was reported ${ }^{113}$ After 25 days of incubation, $97 \%$ of HMX was removed via reduction with the accumulation of 4-nitro-2,4-diazabutanal was reported ${ }^{209}$ that the presence of glucose enhanced the degradation of HMX in marine sediment from a military UXO disposal and in which after 50 days, the HMX concentration in the aqueous phase $(1.2 \mathrm{mg} / \mathrm{L})$ was reduced by $50 \%$. The disappearance of HMX was accompanied by the formation of a mononitroso derivative.

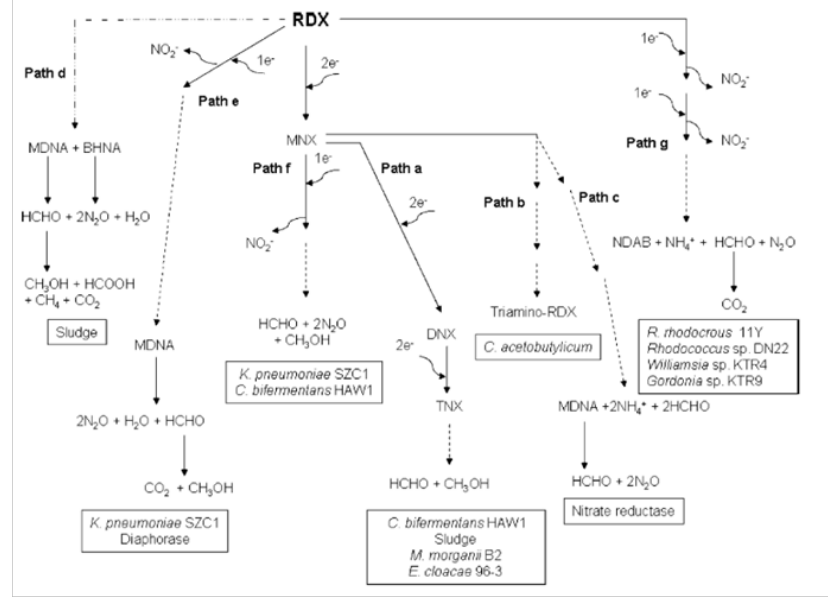

Figure 2 Proposed biodegradation pathways for hexahydro-I,3,5-trinitroI,3,5-triazine (RDX). Path a Reduction of RDX to nitres' derivatives before ring cleavage. ${ }^{221}$ Path b Reduction of RDX to I,3,5-triamino-I,3,5-triazine. ${ }^{408}$ Path c Reduction of RDX via Aspergillus niger nitrate oxidoreductase enzyme. ${ }^{34}$ Dashed arrows Multiple pathway steps based on hypothetical intermediates, which are not shown. Dashed plus dotted arrows hypothetical enzyme reactions.

\section{Xenobiotic biodegradation treatments construct}

Explosives biodegradation occurs in sequential incomplete process, potentially leading to the accumulation of toxic metabolites that can be further introduced into the food chain. ${ }^{366}$ This necessitate the convergence of bioremediation, phytoremediation and applied ecology xenobiotic degradation protocol called PC3R technology (Pollution Construct, Remediation, Restoration and Reuse) reported. ${ }^{256}$ Pollution construct (xenobiotic bioavailability in terrestrial environments for biodegradation) techniques (in situ or ex situ) Figure 4 soils/water contaminants for pesticides, herbicides, hydrocarbon, produced water, munitions, heavy metals and others for Remediation via microbial, phytoremediation and mineralization. Restoration ecosystems for 
zero pollutants footprints for sustainable re-generative Reuse of post treated soils site bio stimulated with biofertilizer for bioenergy crops (rice, soy bean or maize) and tobacco cultivation converted to biofuel production (ethanol). Rhizosphere remediation (plant-microbes interactions) by application for microbial biofertilizer (bacteria, fungi, etcs) to improves crop plant growth, soil ecosystem and biodiversity of the post-treated site.

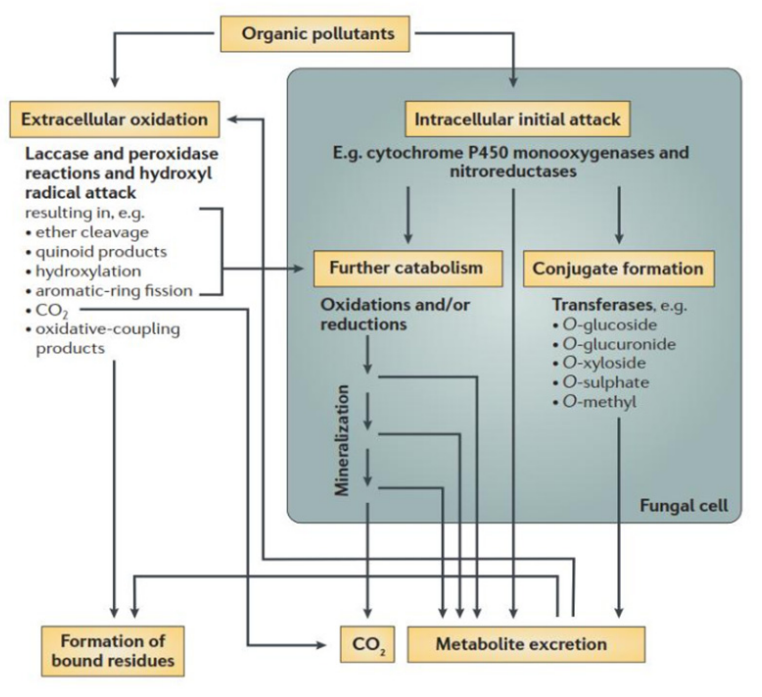

Figure 3 Principal methods used by fungi to degrade organic chemicals. Although fungi primarily co-metabolize organic pollutants, they do grow volatile organics62, 27I ,169, 249,229 via pollutant attack may occur extracellularly or intracellularly adapted. ${ }^{147}$

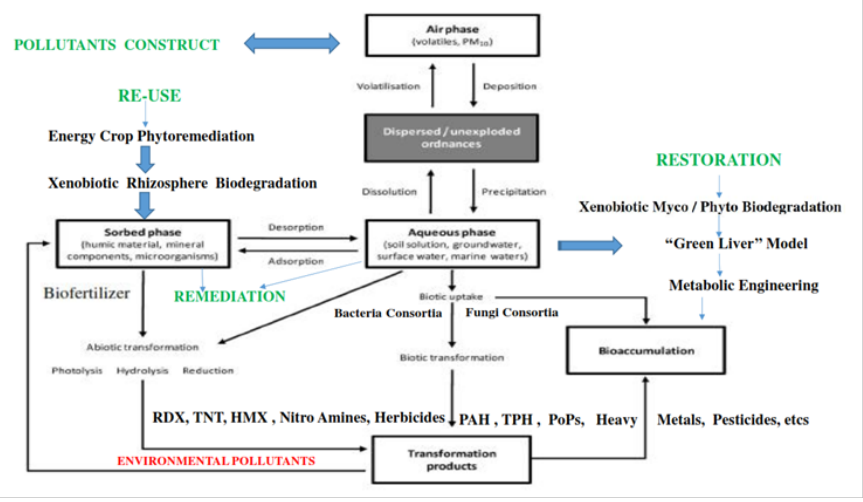

Figure 4 Xenobiotic biodegradation treatments construct called PC3R Technology adapted from Brannon and Myers ${ }^{50}$ and illustrated in Figures I3, 14,15 and 16 respectively below.

\section{PC3R technology}

\section{Pollution construct}

Laboratory studies reports that, most nitro-substituted explosives were found to be toxic for all classes of organisms, including bacteria, algae, plants, invertebrates, and mammals ${ }^{156,198,288,348}$ TNT and RDX are listed as 'priority pollutants' and 'possible human carcinogens' by the U.S. Environmental Protection Agency (EPA) reported. ${ }^{198,181}$ Phytoremediation, or the use of plants for cleaning up pollution ${ }^{304,308}$ metabolizing toxic pesticides. ${ }^{74,303}$ Environmental pollutants compounds may enter the environment during their production (wastewater lagoons), disposal (burn pits), storage, or usage (dispersed or unexploded ordnance), hydrocarbon and agriculture resulting in contamination of groundwater, surface water, marine, and terrestrial environments, and abiotic and biotic processes will influence the fate of explosive compounds. ${ }^{263,172}$ Physico-chemical properties of the compounds impacts on rate and extent of transport and transformation with environmental and biological factors including the presence and/ or absence of explosives-degrading microorganisms Biodegradation pollutants construct solution become a requirement for the sustainable management of xenobiotic with converged technologies, Figure 4. Pollutants fate of compounds driven by: a). Processes that influence transport dissolution, volatilization adsorption b). Processes that influence transformation, photolysis, hydrolysis, reduction and biodegradation. Manufacture of explosives, testing and firing on military ranges, and decommission of ammunition stocks have generated toxic wastes, leading to large-scale contamination of soils and groundwater. ${ }^{146}$

\section{Microbial remediation}

Microbial bioremediation using microorganisms for the treatment of explosive-contaminated sites and range of contamination ${ }^{142}$ now the 'top ten technologies for improving human health..$^{83}$ Different classes of microorganisms, including bacteria and fungi, are capable of transforming energetic pollutants, which can be used as energy, carbon, and/or nitrogen sources reported by scholars. ${ }^{146,330,367,276}$ Whiterot fungi that secrete powerful peroxidases that mineralization of TNT. ${ }^{367} P$. chrysosporium is not a good candidate for bioremediation of TNT- contaminated sites containing a high concentration of explosives because of its high sensitivity to contaminants reported ${ }^{334}$ showed that the lignin peroxidase activity of $P$. chrysosporium is inhibited by the TNT intermediate hydroxylamino-dinitrotoluene. This is the prerequisite for the role of fungi consortium in xenobiotic bioremediation, Figure 3.

\section{Phytoremediation}

Transgenic plants ${ }^{305}$ exhibiting biodegradation capabilities of microorganisms bring the promise of an efficient and environmentally friendly technology for cleaning-up polluted soils. ${ }^{366}$ Phytoremediation of recalcitrant pollutants involve uptake, translocation, transformation and compartmentalization and sometimes mineralization. ${ }^{308}$ Plant roots secrete metabolites, which stimulate the growth of microorganisms in the rhizosphere, which in turn can degrade and mineralize the organic compounds. Plants lack xenobiotic degradative capabilities unlike bacteria of fungi. Therefore, introduction of genes for degradation of recalcitrant environmental pollutants from microorganisms or other eukaryotes will further enhance their ability to degrade/mineralize recalcitrant environmental pollutants. The $\mathrm{MnP}$ gene ${ }^{161}$ or the laccase gene from white-rot fungi has already been introduced into tobacco plants was reported (Figures 5-18). ${ }^{308}$ Hirai et al., ${ }^{151}$ reported that laccase cDNA $(s c L)$ from white-rot fungus Schizophyllum was used as a model ligninolytic enzyme, efficient expression of $s c L$ and removal of a recalcitrant compound in transgenic tobacco plant by decreasing the CpGdinucleotide motif content in order to develop phytoremediation with a ligninolytic enzyme-producing transgenic plant. Phytoremediation merit over other remediation options includes: low installation and maintenance costs; and zero impact on the environment with carbon sequestration and biofuel production, ${ }^{93}$ Figure 16.

Plants lack the catabolic enzymes necessary to achieve full mineralization of organic molecules, potentially resulting in the accumulation of toxic metabolites. ${ }^{98}$ Microbes and mammals are 
heterotrophic organisms that possess the enzymatic machinery necessary to achieve a complete mineralization of organic molecules, complementing the metabolic capabilities of plants..$^{98}$ The detection of oxidation and reduction metabolites, as well as large molecular weight products and non-extractable fractions $\mathrm{s}^{51,120}$ suggests that plants metabolize explosives according to the 'green liver' model. ${ }^{57,303}$ Like the liver of mammals, detoxification by plants typically involves three different phases: activation of the initial toxic compound (phase I), conjugation with a molecule of plant origin (phase II), and sequestration in plant organelles or structures (phase III). Plants via roots system have developed diverse detoxification mechanisms and have for long been recognized as capable of metabolizing organic compounds. ${ }^{74,303,320}$ Nitro-substituted explosives are efficiently taken up, Figure 13 and partially metabolized inside plant tissues. ${ }^{55,93,98}$

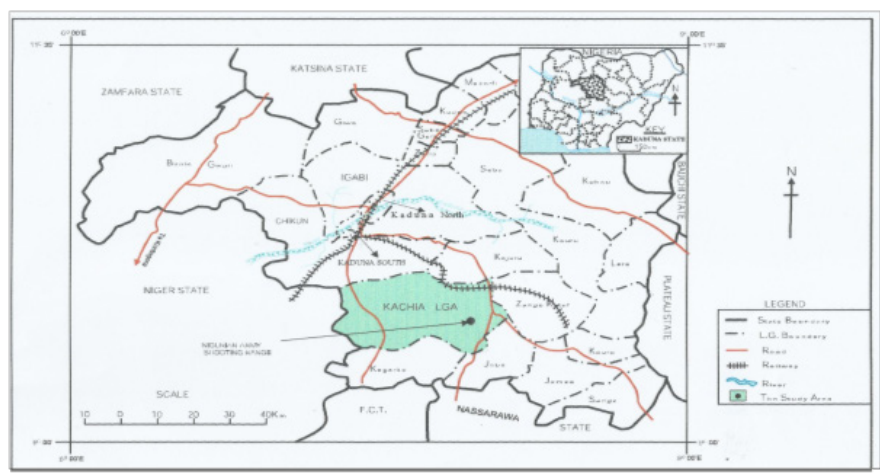

Figure 5 Map of Kachia within Kaduna state map, Nigeria showing study area (Nigerian Army Shooting Artillery, NASA Range).

Source: Geography Department NDA, Kaduna, Nigeria.

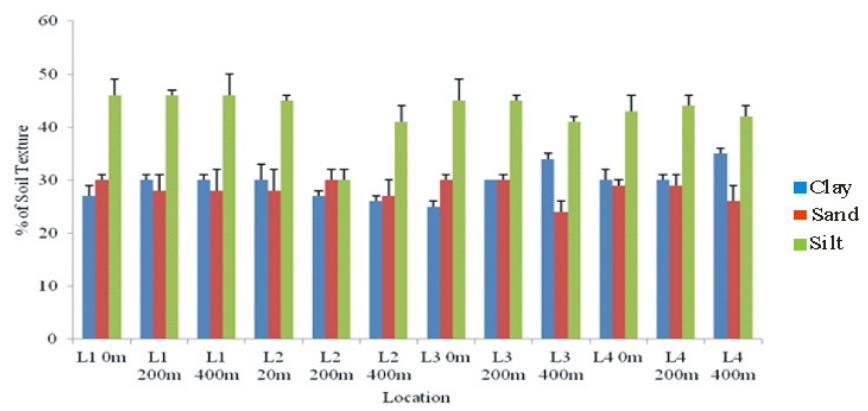

Figure 6 Percentage of Soil texture in various locations, Kachia, Nigeria. LI Om Location (I) - $\quad$ zero metre, LI 200m Location I 200 metre, Loc I, 400 Location I 400 metre, Loc 20m - locations (2). 0 metre, Loc 2- Location (2).

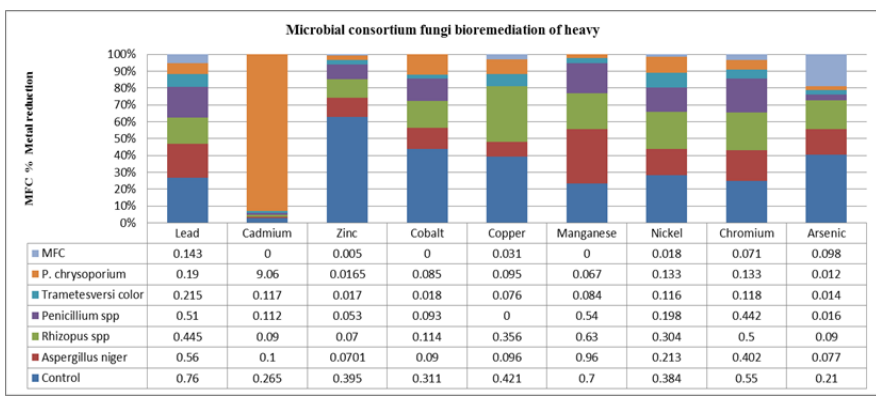

Figure 7 Microbial consortium fungi bioremediation of heavy metal.

\section{Restoration biofertilizer}

Molasses is a very effective carbon source that enhances the TNT degradation rate significantly over other carbon sources ${ }^{46}$ and compost. 396 Additionally, fungi can find application in phytoremediation if their potential genes of enzymes like peroxidases, laccases are expressed effectively in plants. ${ }^{328}$ Extensive reports on biofertilizer have revealed their capacity to provide nutrients to plants and consequently enhance crop yield. ${ }^{239,254,321}$ The goal of using such organic matter are twofold since it not only improves the quality and fertility of degraded soils but also simultaneously eliminates organic waste in a rational and environmentally friendly manner. ${ }^{148,390}$ Sustainable practices with the addition of biofertilizer ${ }^{255}$ (soil amendment) could be a useful tool for maintaining and even increasing the organic matter content for respiration in agricultural soils, thus preserving and improving soil fertility. ${ }^{310,311}$

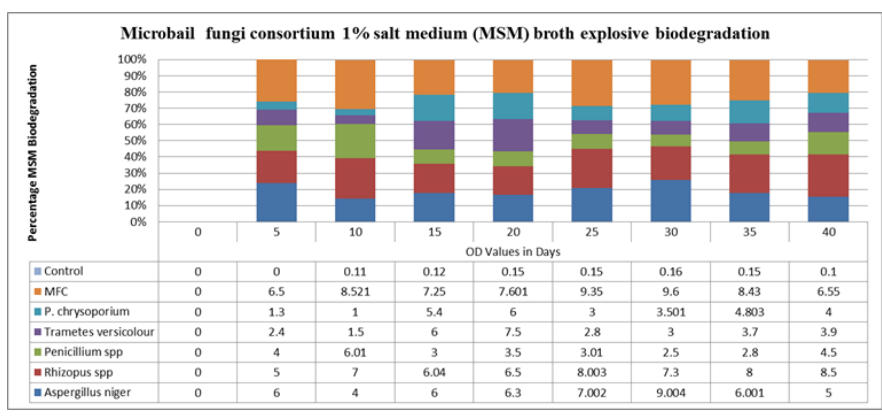

Figure 8 Growth Rate of (O.D Values) of Fungi in I\% Explosive Mineral Salt Medium broth.

* Means on the same column having different superscripts are significantly different $(P<0.05)$ according to Duncan Multiple Range Test.

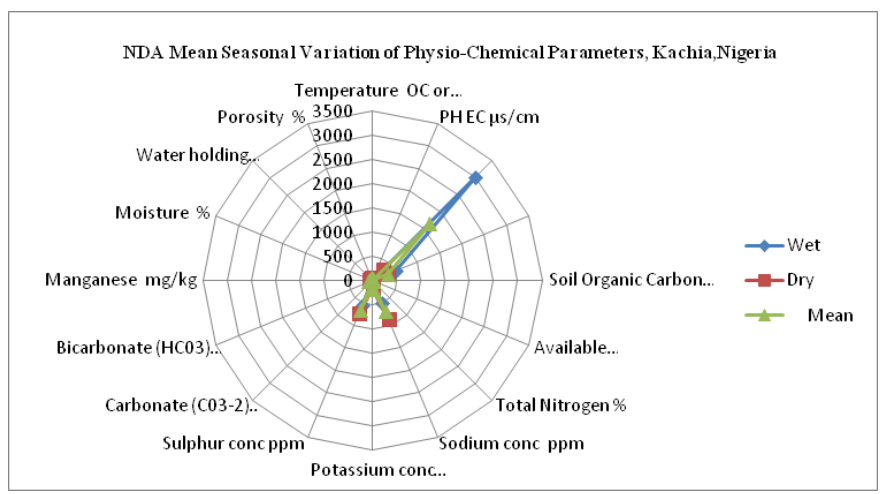

Figure 9 Mean seasonal variation of physcio-chemical parameters of composite samples of four shooting range locations.

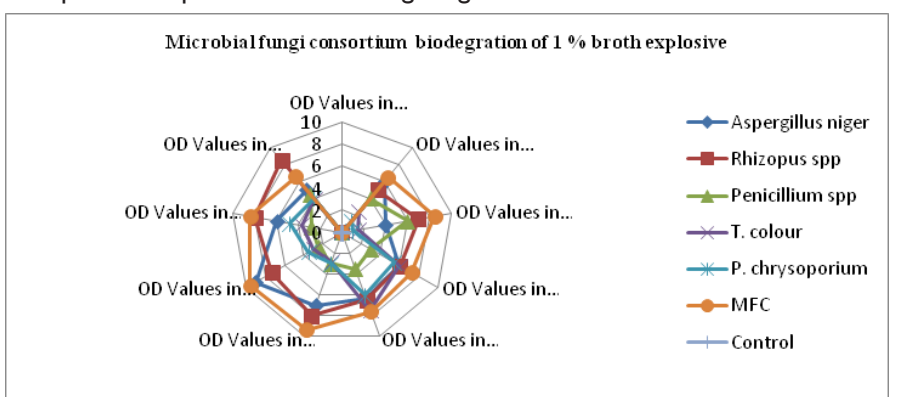

Figure I0 Shows the explosives fungal consortium isolates $>$ Aspergillus niger $>$ Trametes versicolor $>$ Rhizopus spp $>$ Phanorochate chrysoporium $>$ Penicillium spp. identified. Similarly to the Gunasekaran et al., ${ }^{135}$ reported that Rhizopus spp, Aspergillus niger, Trametes versicolor and Phanorochate chrysoporium as good mycoremediation potential for xenobiotic (Plate I).

Microbial communities contribute to fundamental processes that provide stability and productivity of agro-ecosystems. ${ }^{322}$ Soil biota 
affects ecosystem stability by regulating plant diversity, aboveground net primary production, and species asynchrony. ${ }^{401}$ The rhizosphere, which is the narrow zone of soil surrounding plant roots, can comprise up to 1011 microbial cells per gram of root $^{100}$ and above 30,000 prokaryotic species that in general, improve plant productivity. ${ }^{227}$ The collective genome of rhizosphere microbial community enveloping plant roots is larger compared to that of plants and is referred as microbiome ${ }^{54}$ whose interactions determine crop health in natural agro-ecosystem by providing numerous services to crop plants viz., organic matter decomposition, nutrient acquisition, water absorption, nutrient recycling, weed control and bio-control. ${ }^{227,255}$

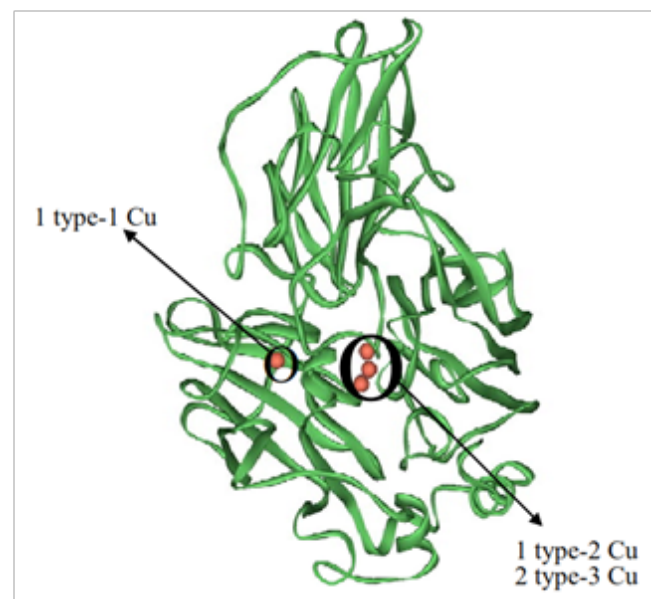

Figure II Ribbon representation of the X-Ray crystallographic structure of Trametes versicolor laccase adapted from Viswanath et al., ${ }^{378}$ and www.chem. ox.ac.uk/icl/faagroup/fuelcell.html.

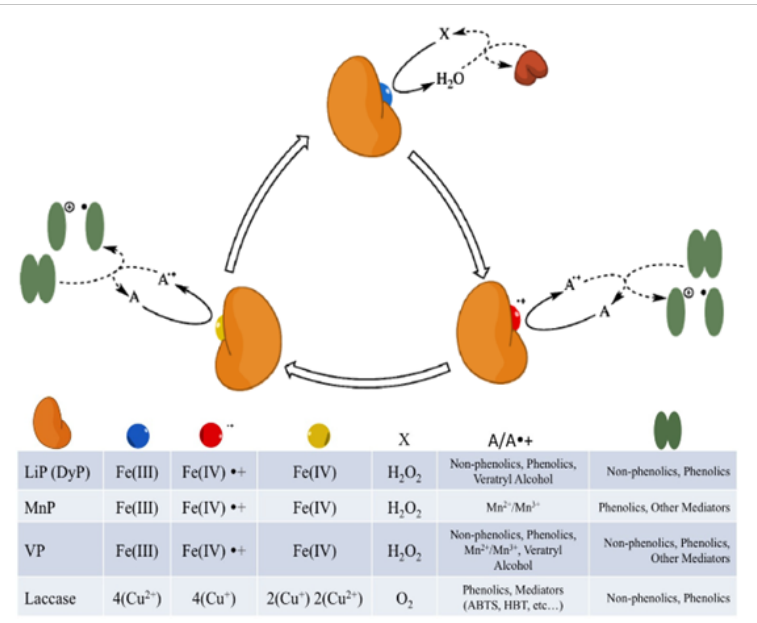

Figure 12 The catalytic cycle of ligninolytic peroxidases and laccases differ in their oxidizing substrate $(X)$, their target reducing substrates/mediators (A) and their electron accepting metal co-factors (coloured circles). The peroxidases (LiP, DyP, MnP and VP) react with hydrogen peroxide to form oxoferryl intermediates (red and yellow circles), while laccases contain a fourcopper active site that reduces oxygen to water to gain oxidative potential, adapted from Fisher et al."'I

\section{Reuse and mineralization}

However, unlike bacteria and mammals, plants are autotrophic organisms that lack the enzymatic machinery necessary for efficiently metabolizing organic compounds, often resulting in slow and incomplete remediation performance. ${ }^{98}$ This led to the idea to modify plants genetically by the introduction of bacterial or fungi for complete xenobiotic biodegradations and mineralization.

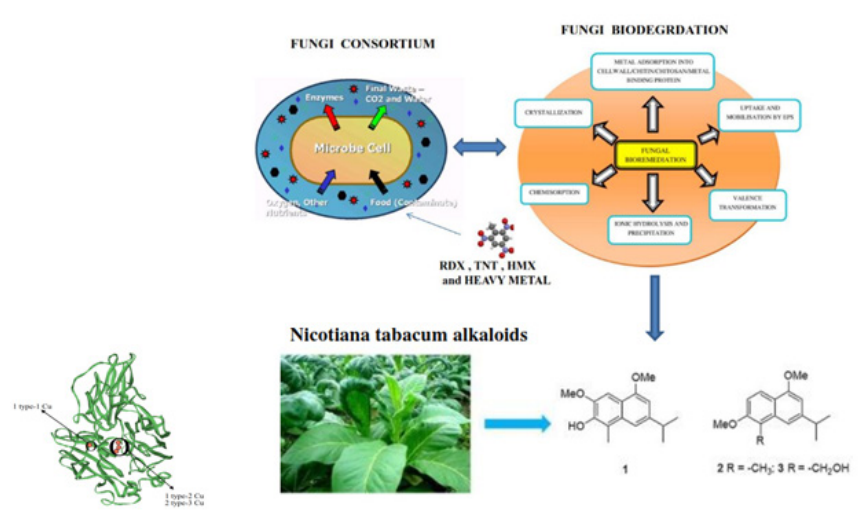

Figure 13 Illuminating the deconstruction of complex pollutants substrates requires many different types of enzymes and diverse chemical reactions within pollutants matrix simultaneously with resilience to environmental fluctuations by deploying microbial and phytoremediation combine techniques as affirmed by scholars. ${ }^{258,211}$

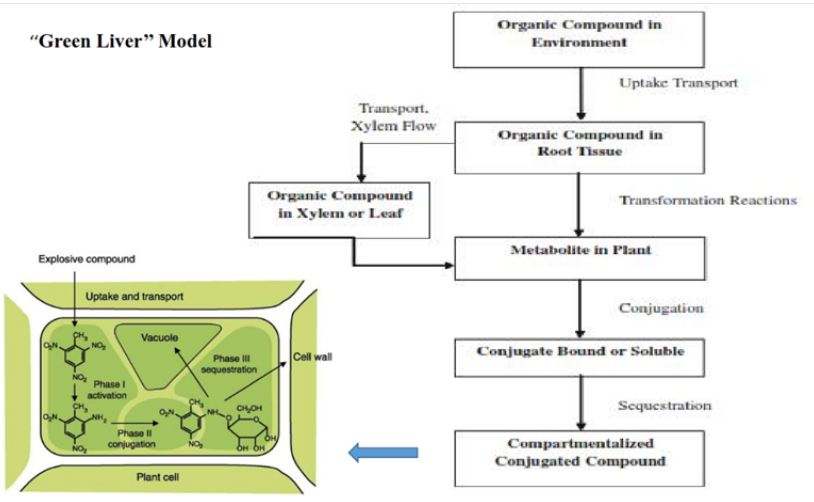

Figure I4 Green liver model for the metabolism of xenobiotic in plants and adapted from Burken et al. ${ }^{55}$

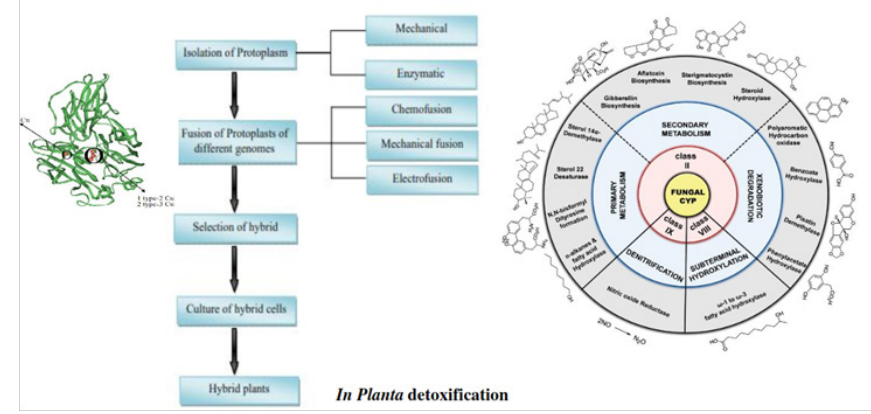

Figure 15 Schematic representation of production of hybrid plant via protoplast fusion. ${ }^{152}$ Representative scheme of functional diversification and classification of fungal CYP systems, adapted from Durairaj et al., ${ }^{95,152}$ reports. Categorization of the functional properties of Class II CYP systems based on the primary metabolism, secondary metabolism and xenobiotic detoxification was adapted ${ }^{80}$ and ribbon representation of the X-Ray crystallographic structure of Trametes versicolor laccase modified. www.chem.ox.ac.uk/icl/ faagroup/fuelcell.html

The detection of TNT metabolites, such as aminodinitrotoluene and amino -dinitrobenzoate, suggests that plants can carry out both reductive and oxidative transformation of nitroaromatic compounds. ${ }^{276}$ Identified RDX transformation products include reduction derivatives, such as hexahydro-1-nitroso-3,5-dinitro-1,3,5-triazine, 
and a range of breakdown products, such as 4-nitro-2,4-diaza-butanal, formaldehyde, and nitrous oxide. ${ }^{173,368}$ Another important barrier to field application of transgenic plants for bioremediation arises from the true or perceived risk of horizontal gene transfer to related wild or cultivated plants. Therefore, it is likely that the next generation of transgenic plants will involve systems preventing such a transfer, for instance by the introduction of transgenes into chloroplastic DNA or the use of conditional lethality genes. ${ }^{84}$

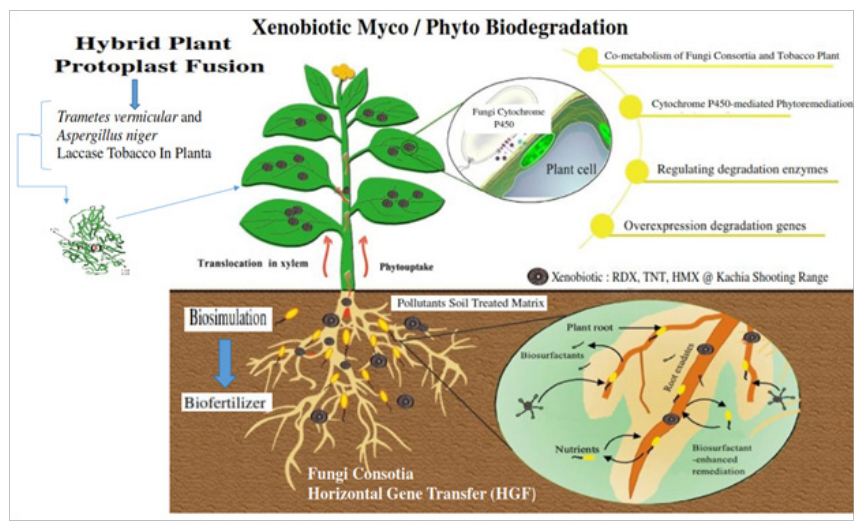

Figure 16 Potentially more cost-effective for in situ bioremediation, is the transfer of genes encoding microbial aerobic degradation pathways into transgenic plants tobacco (Nicotiana tabacum) will optimize the environmental risk to mineralization unidentified products during biodegradation, adapted Mo et al. ${ }^{238}$

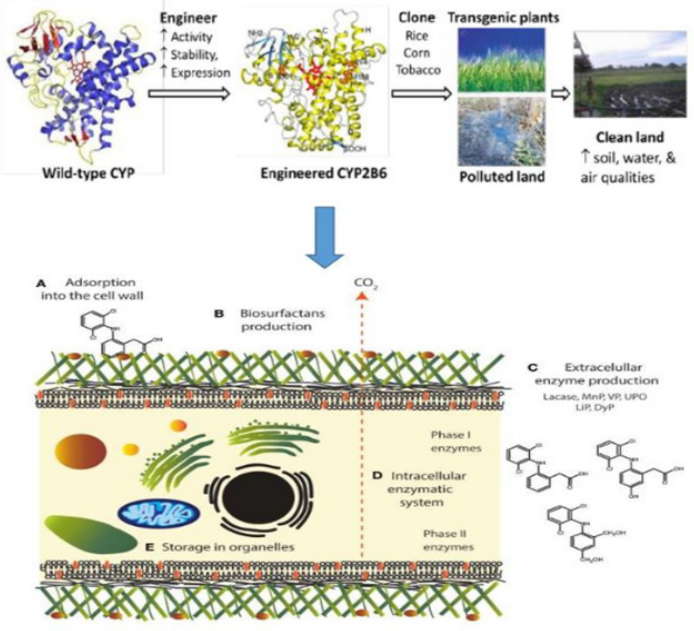

Figure 17 Using this genetic engineering, transgenic plants in which ligninolytic enzymes are expressed will be useful tool for phytoremediation of recalcitrant environmental pollutants adapted from Olicón-Hernández et al. ${ }^{249,305}$

French et al., ${ }^{116}$ designed the first transgenic plants specifically engineered for the phytoremediation of organic compounds by Doty ${ }^{94}$ tobacco plants (Nicotania tabacum) were modified by the introduction of a bacterial pentaerythritol tetranitrate (PETN) reductase, an enzyme involved in the degradation of nitrate esters and nitroaromatic explosives, and derived from an Enterobacter cloacae previously isolated from an explosive-contaminated soil. ${ }^{117}$ Meagher ${ }^{226}$ report the rmineralisation of TNT by native plants is inefficient and generally incomplete.

To engineer plant tolerance to TNT, two bacterial enzymes (PETN reductase and nitroreductase), able to reduce TNT into less harmful compounds, were over expressed in N. tabaccum cv. 'Xanthi'. The two genes, onr (encoding PETN reductase) and nfsl (encoding nitroreductase), under the control of a constitutive promotor provided the transgenic plants with increased tolerance to TNT at concentrations that severely affected the development of wild type plants. Research schalars ${ }^{116,142,143,182}$ reported that, N.tabacum is able to extract metals only from the upper part of the contaminated layer $(0.2 \mathrm{~m})$ unlike $Z$. mays (maize) and $S$. viminalis which could extract metals from depths up to $0.75 \mathrm{~m}$ ). Consequently, tobacco is suitable only for the phytoextraction of areas where the contaminated soil does not have a great depth. ${ }^{48}$

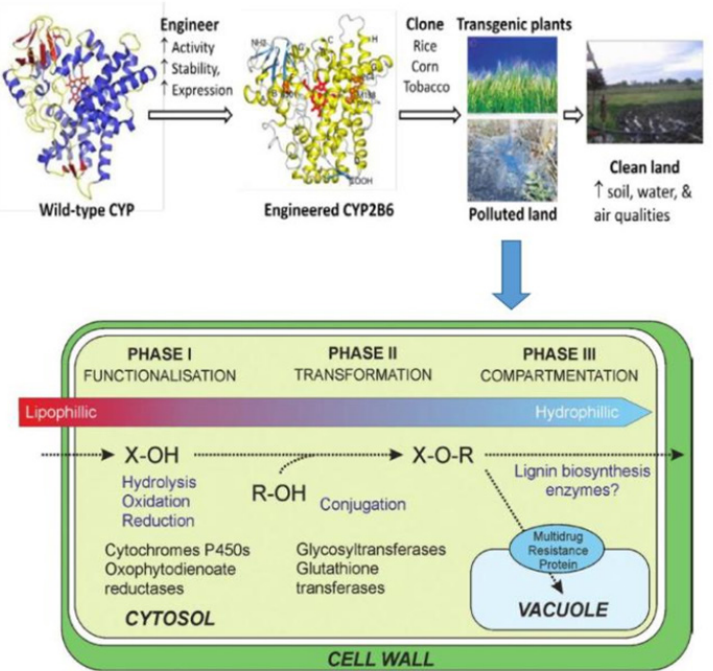

Figure 18 Classical pathway for xenobiotic detoxification in plants. In Phase I the foreign compound is functionalized, enabling Phase II, conjugation to sugars or glutathione, which facilitate Phase III, compartmentation to the vacuole or apoplast, adapted from Rylott et al. 296

\section{Rationale}

Jimenez et al., ${ }^{168}$ and Maruthamuthu et al., ${ }^{216}$ applied selected microbial consortia, over single strains, for such biotechnological purposes presents important advantages. One of them is that microbial consortia are able to perform complex tasks $^{181}$ that single strains. The reason is that the deconstruction of complex pollutants substrates requires many different types of enzymes and diverse chemical reactions, all at the same time or at short time intervals within pollutants matrix. Biodegradation is in phases, resilience to environmental fluctuations (resistance in variation substrate composition) and resistance to microbial invasion play major roles. ${ }^{211,258}$ White rot fungi can grow effectively under water stress conditions where no plant growth occurs. ${ }^{22}$ To optimize remediation approaches the development of genomes of specific white rot fungi like $P$. chrysosporium genome will result to the elucidation of specific cytochrome P450 monooxygenases, which may be differentially expressed in the presence of xenobiotic compounds. ${ }^{200}$ However, identification of specific interactions between microbes in a complex consortium is a difficult task, as it is highly likely that different interactions happen simultaneously. ${ }^{258}$ Application of synthetic microbial consortia could be a solution to this problem, as such consortia are usually composed of few wellidentified organisms ex situ inoculant. At times, those species do not co-inhabit the same environment, but their metabolic activities may be combined. ${ }^{163}$ Determination of nutrient utilization, metabolite production, exchange of metabolites, production of signal molecules, 
spatial distribution, genome sequence and population dynamics are fundamental to enhance our understanding of the interactions, (Figures 4\&16).

The knowledge could be applied to extend the stability of the microbial consortia and the process efficiency. ${ }^{126}$ The sheer scale of contamination of military shooting range in hectares ${ }^{297}$ means that while conventional remediation techniques may not be suitable, phytoremediation could be successfully applied to both remediate existing sites and to contain pollution from future use. ${ }^{297} \mathrm{RDX}$ is readily taken up by plant roots and trans located to the above-ground tissues, ${ }^{206,376,377}$ but the in planta, Figure 14 (construct) degradation of RDX is low ${ }^{16,31,32,391}$ with much of the RDX likely to be released back into the ground following leaf abscission. The detoxification of RDX by endogenous plant enzymes involves the reduction to hexahydro1-nitroso -3, 5-dinitro-1,3, 5-triazine and hexahydro-1,3-nitroso-5nitro-1,3, 5-triazine, ${ }^{368}$ with nitrous oxide and 4-nitro-2,4-diazabutanal also detectable Photolytic degradation has also been reported. ${ }^{173}$

The $\log$ Kow values are 0.90 for $\mathrm{RDX}^{235}$ and 1.86 for TNT and bioaccumulation has been reported for TNT transformation intermediates..$^{23,179,202}$ By transferring microbial genes relaying xenobiotic-catabolism into selected plant species, detoxification, or, ideally, mineralization of organic pollutants can be achieved. Both RDX and TNT are toxic, organic pollutants which are recalcitrant to degradation in the environment. ${ }^{298}$ Additionally, fungi can find application in phytoremediation if their potential genes of enzymes like peroxidases, laccases are expressed effectively in plants. ${ }^{332}$ However, in toxic metal removal applications, it is important to ensure that the growing cells can maintain a constant removal capacity after multiple bioaccumulation-desorption cycles, and a suitable method is required to optimize the essential operating conditions. The situation demands a multi-prong approach including strain isolation, cell development and process development in order to make the ultimate process technically and economically viable.

A. niger could remove significant quantities of $\mathrm{Cu}$ and $\mathrm{Pb}$ from growth media but was less resistant against $\mathrm{Cr} .{ }^{96}$ Multispecies consortia are considered more efficient over the monospecies culture due to greater resistance against environmental fluctuations and the metabolic relations among the member strains and the capabilities of such coaggregates. Five different enzymes, lignin peroxidase, manganese peroxidase, laccase, cellulose and hemicellulase, were believed to be the most important catalysts in biodegrading process, and they always worked synergistically. ${ }^{66}$ Instead of depending upon single species, a better approach could be towards designing a consortium of strains having high metal biosorption, bioaccumulation and bioprecipitation capacities. The positive interaction between constituent species may also facilitate the survival of sensitive strains. ${ }^{47}$

\section{Limitation of fungi biodegradation}

Most of the studies dealing with microbial metal remediation via growing cells describe the biphasic uptake of metals, that is, initial rapid phase of biosorption followed by slower, metabolism-dependent active uptake of metals. ${ }^{88,123}$ However, in toxic metal removal applications, it is important to ensure that the growing cells can maintain a constant removal capacity after multiple bioaccumulation -desorption cycles, and a suitable method is required to optimize the essential operating conditions. The situation demands a multi-prong approach including strain isolation, cell development and process development in order to make the ultimate process technically and economically viable, (Figures $3 \& 4$ ). A. niger could remove significant quantities of $\mathrm{Cu}$ and $\mathrm{Pb}$ from growth media but was less resistant against $\mathrm{Cr} .{ }^{96}$ However, until whole pollutant mineralisation, the use of different toxicity tests are needed to ensure the safety of the byproducts formed ${ }^{171}$ and the rationale for PC3R technology. Whole genome sequence analysis can reveal the capability of fungi for multiple metabolic adaptations owing to diversified enzyme functions such as cytochrome P450 monooxygenase. ${ }^{159}$ Phytochelatin synthase (PCS) is an enzyme catalyzing the biosynthesis of phytochelatin from glutathione which protects cells against the toxic effects of nonessential heavy metals. The genome analysis of fungi is helpful in tracing such genes like pes and studying their evolutionary aspects. ${ }^{316}$

A major limitation of the white-rot fungus is its sensitivity to biological process operations. The fungus does not grow well in a suspended cell system and enzyme induction is negatively affected by mixing actions and the ability of the fungus to effectively attach itself to a fixed medium is poor. ${ }^{77}$ The majority of the research on fungal performance has been conducted on autoclaved soil or on synthetic media. Although, the results show that the white rot fungus efficiently and successfully degrades highly toxic complex organic pollutants under these conditions, the results may not be as significant when they are grown under natural environmental conditions with variable native soil organisms, temperature, moisture and $\mathrm{pH} .{ }^{149,277}$ One problem with field application deals with the strict growth conditions required for most white rot fungi. For example, $P$. chrysosporium has a high temperature requirement $\left(30-37^{\circ} \mathrm{C}\right)$ for growth and ligninolytic enzyme production ${ }^{149}$ and like many white rot fungi, it has low competitive capabilities in the environment. Selection of fungal species with a competitive capability from nature and genetic engineering are needed for the future. The disadvantages of transforming filamentous fungi include changes in post-transcriptional treatment of recombinant proteins, resulting in low activity, defects in the morphology, low frequencies of transformation. ${ }^{381}$ Probably, the development of techniques of genome editing such as CRISPR-Cas9 (clustered regularly interspaced short palindromic repeats) in fungi could solve these problems in a near future to optimize bioremediation process.

\section{Material and method}

\section{Study site}

The study was conducted in the permanent military shooting/ training range located at $5 \mathrm{~km}$ east of Kachia town in Kaduna state, north central Nigeria. The range was established in 1965 and it covers an area of about 24.95 square kilometre that lies between longitudes 90 $55^{\prime} \mathrm{N}$ and $7058^{\prime} \mathrm{E}$, with an elevation of 732 meter above sea level and the topography is undulating and the vegetation is Guinea Savannah, Nigeria (Figure 5, Table 1). The area where the munitions /explosive are fired (the impact areas) is a valley consisting of about four large rocks, where the fired munitions/explosives land and explode during military training. Five military exercises involving the deployment of explosives are carried out annually by the Nigerian Defence Academy (NDA) Kaduna, Nigerian Air force (NAF) Kaduna, Nigerian Army School of Infantry (NASI) Jaji, Armed Forces Command.

\section{Sampling points}

Four sampling points selected for the study are locations 1, 2, 3 and 4, Table 1 , locations 1 and 2 are the twin smallest rocks closest to the road While locations 3 and 4 are much larger rocks heavily impacted by munitions/explosives between locations 1 and 2 is a flat ground where rain runoffs flow through to the stream in this site [map with global positioning system (GPS) coordinates, Figure 5. Locations 1 and 2 approximately 200 metres from the Plateau that is where the 
small arms are fired such as FN, Kalashinokov, Greenad, GPMG, SMG and Pistols. The soil in locations 1 and 2 is made of $50 \%$ silt and a flat ground with shrubs and drainage that flow through to the farm lands near the sites. Location 3 is approximately 9000 metres away from the Plateau lies between $9053^{\prime}$ and 44.71 ' $\mathrm{N}$ and 70 53' 17.87" E. The impact area of locations 3 and 4 are mainly largely

Table I Explosives sites analyses of wet and dry seasons, Kachia, Nigeria rocks containing high concentration of explosive due to the extensive use of bombardment by the artillery weapons, $155 \mathrm{~mm}$ nortwizer, and other heavy weapons while location 4 is ahead of location 3 is about 10,000 metres from the Plateau top where heavy weapons are fired too. The distance between locations 3 and 4 was covered with various shrubs and two major streams (Figure 5).

\begin{tabular}{llll}
\hline $\mathbf{N} / \mathbf{S}$ & Explosives & Wet Season $\boldsymbol{\mu g}_{\mathbf{~ k g}}{ }^{-1}$ & Dry Season $\boldsymbol{\mu g ~}_{\mathbf{~ g}}{ }^{-1}$ \\
\hline $\mathrm{I}$ & TNT & $0.12-26.6$ & $0.11-10.29$ \\
2 & HMX & $1.43-68.19$ & $0.39-35.67$ \\
3 & RDX & $0.38-15.33$ & $0.49-68.19$ \\
4 & PETN & $1.17-7.12$ & $0.39-4.38$ \\
\hline
\end{tabular}

\section{Sampling technique and soil treatment}

Soil sampling: Sampling collected both dry and wet season. Four locations located within NASA (Table 1) shooting/training range Kachia were earmarked as sampling sites for this study using soil iron auger. Where 10 grams of soil sample $(0-30 \mathrm{~cm}$ in depth) with diameter of $9 \mathrm{~cm}$ were collected from 3 different points within a location and harmonized to form a composite sample at various locations of the sites. All samples taken 2015 (June-August) and 2016 (FebruaryMarch) were sieved using a $63(106 \mathrm{~m})$ mesh size laboratory sieve and then stored in black labelled polythene bags until for analyses. Samples for microbial analyses were kept in a cool box (site sampling) refrigerated with ice pack to retain the original microbial activities.

\section{Soil sample pre-treatment}

Sampling points were treated in the laboratory before digestion as executed. 10 grams of the soil sample was weighed into a clean dried beaker and put into an oven at about $100^{\circ} \mathrm{C}$ for one hour. The soil sample was then ground in a porcelain mortar with pestle and sieved through $250 \mu \mathrm{g}$ mesh size to obtain a homogenous sample. The soil sample was stored in sterilized polythene bags, label and kept for next stage of pre-treatment. This procedure was repeated for all the collected soil samples. The ground soil samples were used for analysing heavy metal and explosives content for soil samples. ${ }^{165}$

\section{Fungi species characterization}

Preparation of media: Nutrient Agar - Nutrient agar (Antec /USA) by dissolving $28 \mathrm{~g}$ of the Agar in 1 litre of distilled water in a conical flask. The conical flaks with the media were autoclave at $121^{\circ} \mathrm{C}$ at 15 pressure per square Index (PSI) for 15 minutes and cooled to $40^{\circ} \mathrm{C}$ before pouring or dispensing if a sterile petri dishes. MacConkey MacConkey agar was prepared by dissolving $49.53 \mathrm{~g}$ of dehydrated medium in $1000 \mathrm{ml}$ distilled water in a conical flask. It was heated to dissolve the medium completely. The medium was sterilized by autoclaving at $15 \mathrm{lbs}$ pressure $\left(121^{\circ} \mathrm{C}\right)$ for 15 minutes and cooled to $45-50^{\circ} \mathrm{C}$, mixed well before pouring into sterile petri plates.

Potato dextrote agar (PDA) Thirty nine (39) g of dehydrated medium suspended in $1000 \mathrm{ml}$ distilled water was heated to dissolve the medium completely. It was then sterilized by autoclaving at $15 \mathrm{lbs}$ pressure $\left(121^{\circ} \mathrm{C}\right)$ for 16 minutes. Cooled ten percent $(10 \%)$ of tartanic acid was added and mixed well to achieve $\mathrm{pH} 3.5$ before dispensing into petri plates. The media were spread with the specimen soon after solidification of the media. Plates were incubated at $25-30^{\circ} \mathrm{C}$ in an inverted position (agar slide up) with increased humidity. Cultures were examined weekly for fungal growth and were held for 4-6 weeks.

\section{Serial dilution}

The sterile dilution blanks were marked in the following manner. $100 \mathrm{ml}$ dilution blank was $102 \mathrm{ml}$ and $9 \mathrm{ml}$ tubes sequentially were $103,104,10-6$ one gram of soil sample was weighed from each sample located and added to the 12-2 dilution blank and vigorously shaken for at least one minute with the cap securely tightened. All the 10-2 dilution was allowed to sit for a short period. The $1 \mathrm{ml}$ from this dilution was aseptically transferred to the 10-3 dilution was again transferred to the 10-4 dilution. The procedure was done to $10-5$ and 10-6. A flask of nutrient agar from the $45^{\circ} \mathrm{C}$ water bath was especially pounded into each petri plates for that set. $15 \mathrm{ml}$ was poured enough to cover the bottom of the plate and mixed with the one ml inoculum in the plate. Each set was gently swirled on the bench so that the inoculum gets thoroughly mixed with the ager. All the plates were allowed to stand without moving so that the agar solidified and set completely. The plates were inverted and stacked into pipette carnisters and placed in the incubator or at room temperature until after 48 hours the same procedures were applied for MacConkey agar and Potato Dextrote Agar (PDA).16S ribosomal RNA and Polymerase Chain Reaction (PCR) for Amplification of Catabolic Genes Sequencing of the $16 \mathrm{~S}$ ribosomal RNA (rRNA) gene and PCR based approaches. The concept of comparing gene sequences from microbial communities revolutionized microbial ecology.

Subsequently, a suite of molecular methods was developed that employ rRNA sequences ${ }^{10,128}$ referred to as rRNA. Medlin et al., ${ }^{228}$ first described amplification of 16S-like rRNA from algae, fungi, and protozoa, and reports using 16S rRNA of bacteria and other eukaryotes soon followed. ${ }^{99,123,389,395}$ Bacterial diversity can be distinguished with 16S rRNA gene which is a universal marker for bacteria. ${ }^{352}$ Today mycological researches are also very keen for Deoxyribose nucleic acid (DNA) barcoding of fungal species. Examples of marker genes are present in multiple copies and contain conserved coding (small subunit, SSU and large subunit, LSU) as well as variable non-coding parts (internal transcribed spacers, ITS). Thus, they are useful to distinguish taxa at many different levels ${ }^{278}$ can be introduced for fungus taxonomical studies. ${ }^{67}$

\section{Sequence-based classification and identification}

Principle: Under the International Code of Nomenclature of Prokaryotes (ICNP) ${ }^{259}$ 16S rRNA gene sequences are required for the description of new species, with a defined cut-off of $97 \%$ similarity between species..$^{335,352,384}$ The connection of this DNAbased observation to its source organisms was made when researchers obtained rRNA gene sequences from previously cultivated fungi that matched the environmental DNA clade. ${ }^{292}$ One of the first such efforts 
was the Ribosomal Database Project $(\mathrm{RDP})^{201,210}$ which initially consisted of nuclear small subunit (SSU) rRNA gene sequences from Archaea, Bacteria, and Eukarya. Recent additions to RDP include new databases for fungal ITS and large subunit (LSU) rRNA genes. ${ }^{72}$ The fungal LSU rRNA gene ${ }^{205}$ and ITS. ${ }^{270}$

The entirely on analyses of PCR-amplified nuclear rRNA genes, particularly the internal transcribed spacer (ITS) region, and they draw on incomplete taxonomic and functional databases. These are the so-called "dark taxa" ${ }^{260}$ that reside in the International Nucleotide Sequence Database Collaboration (INSDC), with its three partners: Gene Bank at the National Centre for Biotechnology Information (NCBI). This is incorporated in a broader effort to add type material identifiers to the NCBI Taxonomy database, which allows use of BLAST and other tools to search multiple databases for reliable entries that are specifically tied to type material. ${ }^{107} \mathrm{PCR}$ consist of an exponential amplification of DNA fragment and the principle is based on the mechanism of DNA replication in vivo, double stranded DNA is denatured to single stranded DNA, each single strand DNA is anneal by the forward and reverse primers of known sequence and elongated using tag DNA polymerase to produce copies of DNA template time for analysis as reported. ${ }^{190}$ The amplified 16S rRNA gene of each isolates were further characterized using gel electrophoresis. The amplified 16S rRNA gene of each microbial isolate was processed for sequencing and characterization.

The sequencing Kit (Applied Biosystems) with the Fungi Species Isolation of Genomic DNA. The genomic DNA of each fungus with observed remediation capabilities was isolated. $1 \mathrm{ml}$ of each fungal culture was pelleted by centrifuging at 12,000 rpm for 2 minutes; the pellet was treated with Iysis solution and proteinases $\mathrm{K}$ and incubated at $60^{\circ} \mathrm{C}$ for 30 minutes. DNA was extracted from each fungus precipitated with isopropanol by centrifuging at 10,000 rpm for 10 minutes, washed with $1 \mathrm{ml}$ of a $70 \%(\mathrm{v} / \mathrm{v})$ ethanol solution and dissolved in $0.1 \mathrm{ml}$ of a T.E buffer. The purity and quantity of (DNA) of each sample was examined using UV absorption spectrum and agarose gel (1\%) electrophoresis as described by scholars. ${ }^{174,347}$ Fungi species genes are present in multiple copies and contain conserved coding (small subunit, SSU and large subunit, LSU) as well as variable non-coding parts (internal transcribed spacers, ITS),
Plate 1. Thus, they are product was analysed with ABI prism DNA sequence $(\mathrm{ABI})$. The gene sequence of each isolates obtained in this study (Plate 1) were compared with known 16s rRNA gene sequences in the Gene Bank database as described by Jyothi et al. ${ }^{174}$

\section{Procedure}

Isolated explosive fungi DNA were amplified using catechol 2,3 dioxygenase gene primers. The genomic DNA, the primers and PCR master mix were added into a PCR tube. The tubes were spun to collect the droplets. The tubes were then inserted into the PCR machine while maintaining the regulation for initial denaturation (45 seconds at $\left.94^{\circ} \mathrm{C}\right)$, annealing $\left(1\right.$ minute at $\left.55^{\circ} \mathrm{C}\right)$ extension $(1$ minute at $72^{\circ} \mathrm{C}$ ) and final extension $\left(10\right.$ minutes at $\left.72^{\circ} \mathrm{C}\right)$. The amplified catabolic genes were resolved in $1.5 \%$ agarose gel electrophoresis stained with ethidium bromide and viewed under ultra-violet (UV light). The PCR reaction mixture containing $10 \mathrm{X}$ PCR buffer, $25 \mathrm{~mm}$, magnesium chloride, $25 \mathrm{~mm}$ dNTP's, $10 \mathrm{pm} / \mathrm{uL}$ primer concentrations and template DNA were used for the amplification of the 16S rRNA gene for each isolates. PCR conditions were optimized using lab net thermal cycler. The PCR program began with an initial 5-minuites denaturation step at $94^{\circ} \mathrm{C}$ and 35 cycles of $94^{\circ} \mathrm{C}$ for 45 seconds, annealing $\left(1\right.$ minute at $\left.55^{\circ} \mathrm{C}\right), 10$ minutes extension step at $72^{\circ} \mathrm{C}$.

Validated by comparison to ITS and LSU sequences within and among the same strains. ${ }^{349}$ As long-read sequencing technologies improve, ${ }^{191}$ it will become routine to obtain contiguous sequences containing ITS and its flanking LSU and SSU regions, which will facilitate integration of current datasets based on single markers. Fungal Genomes (1KFG) project, ${ }^{134}$ which is providing a platform for sharing protocols and for community networking and contributing to the transformation of fungal biology into a genomeenabled discipline. ${ }^{150}$ Genomic data from $1 \mathrm{KFG}$ and other projects may not have a major impact on species-level dentification, but they will be invaluable for predicting community function. Metagenomic binning makes it possible to assemble complete or near complete genomes from unculturable taxa while improved methods for isolating and growing previously uncultured microbes within their natural soil environments are opening possibilities to important new discoveries (Tables 2-4). ${ }^{203}$

Table 2 Fungi isolates implicated in biotransformation and mineralization. Kachia, Kaduna, Nigeria

\begin{tabular}{|c|c|c|c|}
\hline $\begin{array}{l}\text { Fungi isolates } \\
\text { species }\end{array}$ & Explosives & Conditions & References \\
\hline \multirow[t]{2}{*}{ Rhizopus spp } & TNT & TNT disappearance in malt extract broth & Otaiku\&Alhaji $i^{253}$ \\
\hline & & Electrophilic attack by microbial oxygenases & Rylott\&Bruce ${ }^{297}$ \\
\hline \multirow[t]{5}{*}{ P. chysosporium spp } & TNT & $\begin{array}{l}\text { Mineralization to } \mathrm{CO}_{2} \text { by mycelium and } 90 \% \text { removal of } \\
\text { TNT }\end{array}$ & Fernando et al.,.' ${ }^{19}$, Rh) et al.., ${ }^{280}$ Sublette et al. ${ }^{340}$ \\
\hline & & Mineralization to $\mathrm{CO}_{2}$ by spores & Spiker et al.., ${ }^{331}$ Donnelly et al. ${ }^{89}$ \\
\hline & & Mineralization to $\mathrm{CO}_{2}$ by mycelium & Michels and Gottschalk, ${ }^{230}$ Huang and Zhou ${ }^{155}$ \\
\hline & & $\begin{array}{l}\text { Mineralization correlated with appearance of peroxidase } \\
\text { activity }\end{array}$ & Sublette et al., ${ }^{340}$ Stahl\&A $t^{336,337}$ \\
\hline & & $\begin{array}{l}\text { Mineralization to } \mathrm{CO}_{2} \text { in soil-corn cob cultures and } \\
\text { stable }\end{array}$ & Fernando and Aust, ${ }^{119}$ Yinon and Zitrin ${ }^{403}$ \\
\hline \multirow[t]{2}{*}{ Compost microbes } & TNT & Biotransformation by Thermophile microorganisms & Kaplan and Kalpan, ${ }^{178}$ Isbister et al. ${ }^{160}$ \\
\hline & & $\begin{array}{l}\text { Transformed ring-[ } 14 C] \text {-labeled TNT,humification } \\
\text { reactions }\end{array}$ & Binks et al.., ${ }^{35}$ William et al.., ${ }^{396}$ \\
\hline P. chrysosporium spp & RDX & Biotransformation under nitrate-reducing & Freedman\&Sutherland ${ }^{114}$, Alc et al. ${ }^{8}$ \\
\hline
\end{tabular}


Table continued...

\begin{tabular}{|c|c|c|c|}
\hline $\begin{array}{l}\text { Fungi isolates } \\
\text { species }\end{array}$ & Explosives & Conditions & References \\
\hline & & Reduction by nitrogen-limiting conditions & Fernando et al., ${ }^{109}$ Fernando et $\mathrm{al}^{110}$ \\
\hline & & Reduction by sulfate-reducing condition & Boopathyet al.., ${ }^{43}$ McCormick et al. ${ }^{22 I-223}$ \\
\hline & & Methylenedinitramine formation under nerobic condition & Hawari et al., ${ }^{114}$ Kitts et al. ${ }^{187}$ \\
\hline & & Aerobic denitration of RDX and highly mobile in soil & Fournier et al., ${ }^{113}$; Clausen et al.., ${ }^{70}$ Alaviet al. ${ }^{4}$ \\
\hline & & Reduction under methanogenic conditions & Boopathyet al., ${ }^{44}$ Kaplan ${ }^{177}$ \\
\hline & & Reductions lead to destabilization, ring cleavage, & McCormick et al., ${ }^{223}$ Clausen ${ }^{69}$ \\
\hline & RDX & Final products may include methanol and hydrazines & Hawari et al., ${ }^{146}$; McCornkk et al ., ${ }^{222}$ \\
\hline \multirow[t]{4}{*}{ White rot fungus } & RDX & Coagulation in contaminated water by nitrate reductase & Sullivan et al ${ }^{343}$; Bhushan et al., ${ }^{34}$ \\
\hline & TNT & $\begin{array}{l}\text { Treated TNT in wastewater and achieved } 99 \% \text {. } \\
\text { degradation }\end{array}$ & Huang and $Z_{\text {hou }}{ }^{155} ;$ Bennett $^{25}$ \\
\hline & TNT & First step was degradation to OHADNT and ADNT, & Aken et al., ${ }^{3}$ Stahl\&Aust ${ }^{337}$ \\
\hline & & Second step was to DANT including HMX and RDX. & Axtel et al., ${ }^{14}$ Stahl\&Ast ${ }^{337}$ \\
\hline \multirow[t]{3}{*}{ Aspergillus niger spp } & $\mathrm{HMX}$ & Sequential denitration chemical substitution & Urbanski, ${ }^{361}$ Kaplan ${ }^{177}$ \\
\hline & & Low water solubilitlity in anaerobic conditions & Kaplan, ${ }^{176}$ McCormk et al., ${ }^{223}$ \\
\hline & PETN & $\begin{array}{l}\text { Mono-nitrated pentaerythritol to un-nitrated } \\
\text { pentaerythrito products }\end{array}$ & Williams and Bruce 395 \\
\hline Mineralization & PETN & Biodegraded by sequential denitration to pentaerythritol & Binks et al, ${ }^{35} ;$ Bait \& Aust ${ }^{21}$; de Boer et al., ${ }^{85}$ \\
\hline P. chrysosporium spP & PETN & $\begin{array}{l}\text { Nitroglycerin, or glycerol trinitrate, degraded co- } \\
\text { metabolism by sequential removal of nitro groups }\end{array}$ & Wendt, et al., ${ }^{386} ;$ Barr and Aust ${ }^{21} ;$ Stahl et al., ${ }^{338}$ \\
\hline \multirow{3}{*}{ White rot fungus } & \multirow{3}{*}{ Explosives } & & Angermaier et al., ${ }^{12} ;$ Angermaier and Simon ${ }^{13}$ \\
\hline & & Dissolution rates:TNT $>$ HMX $>$ RDX $>$ PETN & $\begin{array}{l}\text { Townsend and Myers, }{ }^{353} \text { Brannon and } \\
\text { Pennington }{ }^{49}\end{array}$ \\
\hline & & $\begin{array}{l}\text { Degraders glycerol trinitrate and isosorbide dinitrate : } \\
\text { nitrate esters }\end{array}$ & White \& Snape ${ }^{392}$ \\
\hline
\end{tabular}

\section{Results and discussion}

\section{Physio-chemical properties of the military firing ranges}

The temperatures of $22-34^{\circ} \mathrm{C}$ during the dry season and $27.16^{\circ} \mathrm{C}$ during the wet season were recorded respectively, Table 4 . The values obtained fell within the acceptable Federal Ministry of Environment (FMENV), Nigeria limit of $<40$. Similarly the $\mathrm{pH}$ of $6-8$ has been suggested to be appropriate for microbial bioremediation. ${ }^{357}$ In the current investigation, the soil $\mathrm{pH}$ range for all the soil samples falls well within the range suggested by US-EPA ${ }^{357}$ and range of $27-$ $35^{\circ} \mathrm{C}$ similar to the report of Jenkins et al., ${ }^{166}$ on characterization of explosives contamination at military firing ranges with soils characterization of silt, clay and loamy, (Table 3\&Figure 6)

The increased temperature obtained during the dry season can be attributed to the high concentration of explosives due to the frequent exercises by the personnel of Armed forces of Nigeria, Table 4 (Appendix 2). Compared with the wet season that the temperature is less as a result of rain washing away heavy metals and explosives drown the streams and soil porosity, Figure 6. The high value of electric conductivity (EC) recorded during the wet season is in agreement with the finding of Usman et al., ${ }^{258}$ on their physico-chemical of the soils samples within the Federal ministry of environment, Nigeria ( FMENV) and World Health Organization (WHO) permitted limits of $500 / \mu 5 / \mathrm{cm}$ and Penington et al. ${ }^{263}$ within the value of $2000 \mathrm{mg} / \mathrm{L}$ which was contrary to the finding values were within $2400-5900$ $\mathrm{mg} / \mathrm{L}$ and is in agreement with Usman et al. ${ }^{258}$ the high values of Total Dissolve Solid (TDS) would be due to the deposit of organic and inorganic matters necessitated by the military activities.

It was revealed that $\mathrm{RDX}$ had the highest concentration of $68.19 \mu \mathrm{gkg}^{-1}$ in dry season compared to wet season that was not very significant, Table 1 using the Anova test for total explosive contents shows a significant difference for all locations in both dry and wet seasons $(\mathrm{P}<0.05)$. In zero metre of the objective TNT, RDX and HMX were consistently found at the highest values of 49.39 $\mathrm{mg} / \mathrm{kg}, 68.19 \mathrm{mg} / \mathrm{kg}$ and $35.67 \mathrm{mg} / \mathrm{kg}$, respectively (location 4). An impact area and beyond within the hand grenade range, a $105 \mathrm{~mm}$ howitzer firing point and the heavy artillery and mortar range that had been analysed by GC-ECD. TNT concentrations ranged from 0.11 to $49.39 \mathrm{mg} / \mathrm{kg}$ in dry season and 0.12 to $26.6 \mathrm{mg} / \mathrm{kg}$ wet season. Among all the concentration of explosives both in dry and wet season RDX recorded the highest concentration of $68.19 \mathrm{mg} / \mathrm{kg}$ in Table 4 (Appendix 2) implied that Kachia shooting range consists of RDX and affirmed by Lachance et al., ${ }^{198}$ with potential for carcinogen and the toxicity impacts on the ecosystem, (Table 2).

\section{Myco-remediation of heavy metals: microbial fungi consortium (MFC)}

Fungi role as primary and secondary decomposers in these classic "cycles" of nature. $6,60,76,115$ and spent fungal biomass from industrial 
fermentations is an available resource for the concentration of heavy metal contamination. ${ }^{121,122,293}$ Fungi myco-remediation mechanism are:

(i) The target compound is used as a carbon source

(ii) The target compound is enzymatically attacked but is not used as a carbon source (co-metabolism)

(iii) The target compound is not metabolized at all but is taken up and concentrated within the organism (bioaccumulation).

Although fungi participate in all three strategies, they are often more proficient at co-metabolism and bioaccumulation than at using xenobiotic as sole carbon sources. "Co-metabolism refers to any oxidation of substances without utilization of the energy derived from the oxidation to support microbial growth. ${ }^{157}$ The phenomenon has also been called "co-oxidation" and or "gratuitous" "fortuitous" metabolism. Many biochemists dislike the term. ${ }^{127,158}$ Nevertheless, it has become well entrenched in the literature. A second meaning of co-metabolism is to describe the degradation of a given compound by the combined efforts of several organisms pooling their biochemical resources for mutual efforts, ${ }^{82}$ Figures 7. Fungal isolates showed very good activity in the reduction of heavy metals when observed. Lead concentration was reduced by Aspergillus niger to 20\%, Rhizopus to $31.5 \%$, Penicillium spp to $25 \%$, Trametes versicolor to $54.5 \%$, P. chrysporium to $57 \%$ and Microbial fungi consortium (MFC) to $61.7 \%$. Cadmium was reduced by $A$. niger to $16.5 \%$ Rhizopus spp to $17.5 \%$, Penicillum spp to $15.3 \%$, T.versicolor to $24.8 \%$, P. chrysoporium to $20.5 \%$ and MFC to $100 \%$. Zinc was reduced by $A$. niger to $32.49 \%$, Rhizopus spp, to $38.8 \%$, Penicillium spp to $34.2 \%$, T. versicolor to $32.8 \%$, P. chrysoporium to $37.85 \%$ and MFC to $39 \%$.

Cobalt was reduced A. niger to $100 \%$, Rhizopus spp to $19.7 \%$, Penicillum spp $21.8 \%$, T. versicolor to $100 \%$, P. chrysoporium to $100 \%$, and MFC to $100 \%$. Copper was reduced by to $22.1 \%$, Rhizopus spp to $6.5 \%$, Penicillium spp $23.19 \%$, T. versicolor to $34.5 \%, P$. chrysoporium to $32.8 \%$ and MFC to $39 \%$. Manganese was reduced by $A$. niger to $60.4 \%$, Rhizopus spp to $7 \%$, Penicillium spp to $16 \%, T$. versicolor to $61.6 \%, P$. chrysoporium to $63.3 \%$ and MFC to $68.2 \%$. Nickel was reduced by $A$. niger to $17.1 \%$, Rhizopus spp to $8 \%$,
Penicillium spp to $18.6 \%$, T. versicolor to $26.8 \%$, P. chrysoporium to $28.90 \%$ and MFC to $31.3 \%$. Chromium was reduced by $A$. niger to $14.8 \%$, Rhizopus spp to $5 \%$, Penicillium spp to $10.9 \%$, T. versicolor to $43.2 \%$, P. chrysoporium to $41.7 \%$ and MFC to $45.5 .2 \%$ while. Arsenic was reduced by $A$. niger to $13.3 \%$, Rhizopus spp to $14 \%$, Penicillium spp to $19.4 \%$, T. versicolor to $19.8 \%$, P. chrysoporium to $19.8 \%$ and MFC to $20.1 \%$.

The best fungal isolates for heavy metal reduction in increasing order were Aspergillus niger $>$ Phanorochate chrysoporium $>$ Trametes versicolor $>$ Rhizopus spp $>$ Penicillium spp while, in the overall, the mixed culture consortium are the highest percentage reduction of each heavy metal analysed in this study as a result of co-metabolism and bioaccumulation as reported by Dagley. ${ }^{82}$ Anova test for total explosive contents shows a significant difference for all locations in both dry and wet seasons $(\mathrm{P}<0.05)$, Appendix 1. Fungi pattern of growth and development is less predictable with fixed into developmental pathways and affirmed by the report of Robson et al. ${ }^{287}$ who reported that the life cycle of a fungus is unpredictable and flexible. The growth phases demonstrated by the fungi identified in this study show that the pattern of growth (Figure 8) displayed must have responded to the fixed nutrients of mineral salt medium supplemented with $1 \%$ munitions. The stages of growth are typically of any organism growing in a fixed quantity of nutrient. Every single isolate of fungus grew rapidly in the beginning that is, the exponential phase. This could be attributed to their previous association with munitions/explosives contaminated environment (Figure 10) and impacts of soil matrix on fungi physiology, Figure 11.

This is in conformity with Diaz \& Massol-Deya, ${ }^{92}$ discovered that most of the fungal species were able to grow efficiently and appear concurrently in the environment as novel growth and energy substrate. Therefore, these fungi have a potential to degrade xenobiotic compounds (Figure 9). The growth pattern of fungus had different maximum growth peaks. This could be as a result of exhaustion of nutrients and release of toxic materials into the medium (transformation of waters explosives) and there is a need for improved biodegradation techniques with zero pollutants footprint (Figure 4). The growth pattern of fungi in $1 \%$ munitions/explosives and minimal salt broth is represented Figure 8.

\section{Appendix I}

Table 3 Mean seasonal variation of physcio-chemical parameters of composite samples of four firing rae locations (I 2 different metres)

\begin{tabular}{lllll}
\hline Parameters & Unit & Wet & Diy & Mean \\
\hline Temperature & OC or OF & 27.16 & 22.71 & 24.94 \\
PH & $\mathrm{EC} \mu \mathrm{s} / \mathrm{cm}$ & 6.07 & 2.31 & 4.19 \\
Electric Conductivity (EC) & $\mathrm{EC} \mu \mathrm{s} / \mathrm{cm}$ & $301 \mathrm{I}$ & 312 & 1661.5 \\
Total Dissolved solutes (TDS) & $(\mathrm{mg} / \mathrm{L})$ & 513.1 & 347.7 & 347.7 \\
Soil Organic Carbon (SOC) & $\%$ & 5.11 & 5.76 & 5.44 \\
Available phosphorus & $(\mathrm{mg} / \mathrm{kg})$ & 4.7 & 4.9 & 4.8 \\
Total Nitrogen & $\%$ & 9.32 & 9.72 & 9.52 \\
Sodium conc & $\mathrm{PPm}$ & 498 & 863 & 680.5 \\
Potassium conc (Ppm) & $\mathrm{PPm}$ & 169 & 162 & 165.5 \\
Sulphur conc & $\mathrm{Ppm}$ & 560 & 724 & 642 \\
Carbonate (CO3-2) & $\mathrm{mg} / 100 \mathrm{~g}$ & 0.22 & 0.35 & 0.285 \\
Bicarbonate (ITCO3) & $\mathrm{mg} / 100 \mathrm{~g}$ & 1.11 & 1.68 & 1.4 \\
Manganese & $\mathrm{mg} / \mathrm{kg}$ & 75.01 & 75.01 & 79.1 \\
Moisture & $\%$ & 59.56 & 59.56 & 35.87 \\
Water holding capacity & $\%$ & 59.56 & 51.12 & 55.34 \\
Porosity & $\%$ & 56027 & 69.39 & 62.83 \\
\hline
\end{tabular}




\section{Appendix 2}

Table 4 Mean seasonal variation of total explosives concentration in various locations of NDA shooting range Kachia, Kaduna state $\mu \mathrm{g} / \mathrm{kg}$, Nigeria

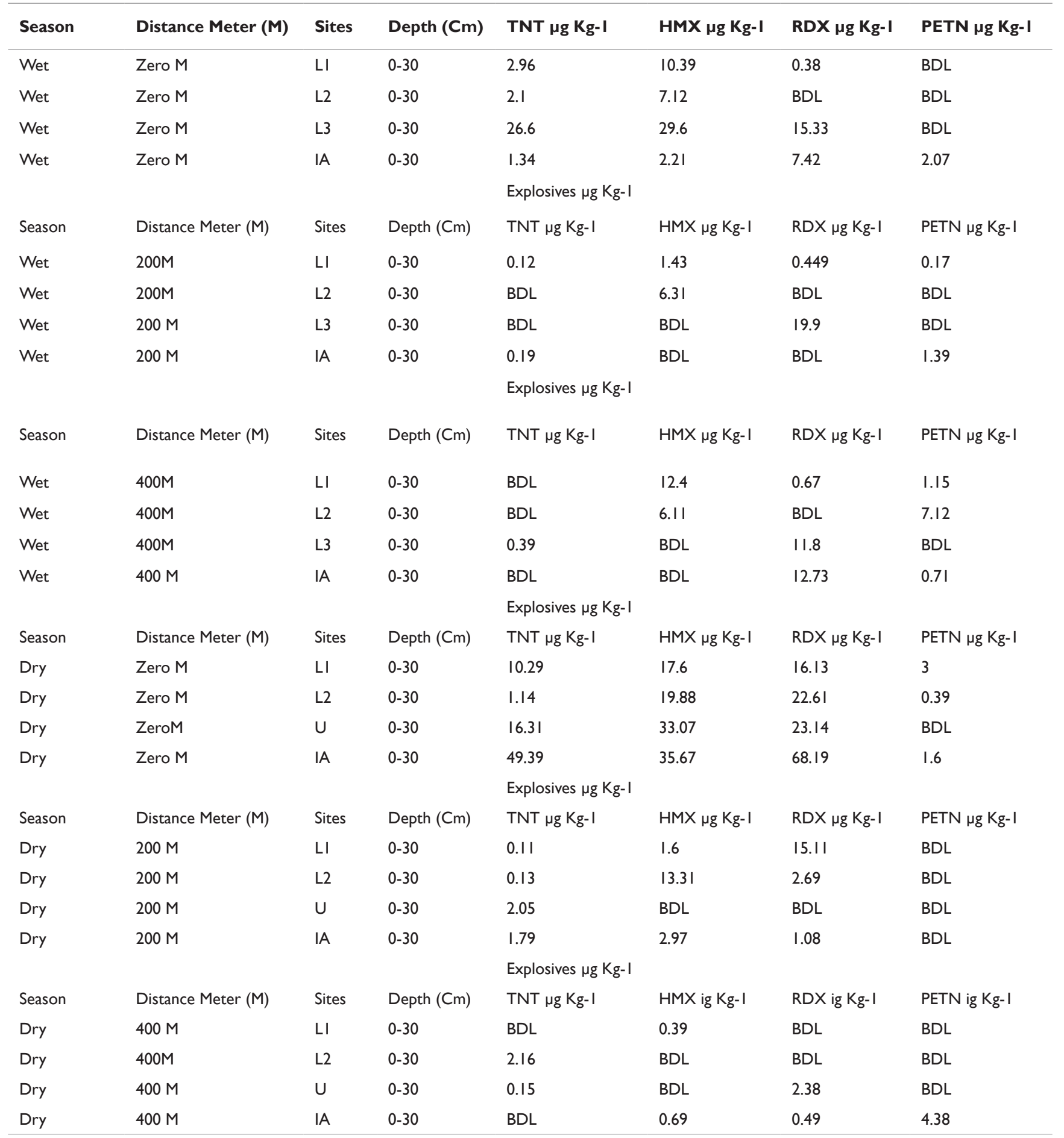

N.B: TNT, 2, 4, 6 - trinitrotohience; RDX, royal demolition explosive; - I,3,5 frinitro - I,3,5 - trazinanze; HMX, I, 3,5 tetranitor I,3,5 - tetrazocalne high melting explosion; BDL; below detectable level

Similarly, Gunasekaran et al., ${ }^{135}$ identified Rhizopus spp, Aspergillus niger, $T$. versicolor and $P$. chrysoporium as good mycoremediation potential for xenobiotic pollutants (Plate1). The fungal consortium performs better than the single culture isolates of the fungi species which may be as result of a synergistic interaction of the fungal isolates. Similarly, Okerentugba \& Ezeronye ${ }^{252}$ reported that a single microbe does not possess the enzymatic capability to degrade all or even most of the organic compounds in a polluted soil but mixed microbial communities possess powerful biodegradable potential because the genetic information of more than one organism is necessary to degrade the complex mixtures of organic compounds present in contaminated areas. 


\section{Fungi species (explosives by turbidometry) - the growth potential}

Fungal celluloses provide a good example of the contrasting faces of a single enzymatic capability, example in the non-specificity of the white rot fungi is ideally suited to treating low concentrations of mixed wastes in a nutrient deficient habitat, complete pathways of degradation are more likely to occur through the combined effects of many organisms biochemistry. These include fungal amylases, glucoamyases, lipases, pectinases, and proteases ${ }^{27,132}$ and secondary products like LiP and MnP. ${ }^{145}$ Penicillium janthinellum degrade high molecular weight polycyclic aromatic hydrocarbons more efficiently than does either microorganism alone. ${ }^{40}$ The Figures 8 and 10 shows the optical density reading of biodegrading activity of each fungal isolate on $1 \%$ explosive mineral salt medium (MSM) broth (Basal salt medium). It was revealed that Aspergillus niger had a maximum growth peak at 9.004 on the $30^{\text {th }}$ day as affirmed by similar work of Svecova et al., ${ }^{344}$ Rhizopus spp had maximum growth peak at optical density $8.000-8.500 \quad$ on the $25^{\text {th }}, 35^{\text {th }}$ and $40^{\text {th }}$ respectively, Penicillium spp had the lowest growth peak at optical density 2.500 on the $30^{\text {th }}$ day while the maximum was 6.010 on the $10^{\text {th }}$ day. The maximum growth peak of Trametes versicolor was at 7.800 on the $20^{\text {th }}$ day and the lowest growth peak was at 1.500 on the $10^{\text {th }}$ day (Plate 1).

Phanorochate chrysoporium had the maximum growth peak at 6.000 on the $20^{\text {th }}$ day while the lowest for P. chrysoponium was at 1.000 on the $10^{\text {th }}$ day as a results of the impacts of lignin peroxidases genes [lipA, lipB, lipC, lipD, lipE, lipF, lipG, lipH, lipI and lip J] as reported affirmed by scholar's reports. ${ }^{21,409}$ Aspergillus niger had the best ability to degrade explosive while Penicillium spp had the least ability. The analysis of variance result shows that there is a significant difference in the overall growth pattern of fungi in MSM broth supplemented with $1 \% \mathrm{v} / \mathrm{v}$ explosive $(\mathrm{P}>0.05)$. The overall result also indicates that the growth rate increased significantly from the zero hour to the $5^{\text {th }}$ day and beyond. Means on the same column having different superscripts are significantly different $(\mathrm{P}<0.05)$ according to Duncan multiple range test.

Furthermore, Fritsche et al., ${ }^{118}$ demonstrated that manganese peroxidase and lignin peroxidase from $P$. chrysoporium and $T$. versicolor have the ability to oxidize or reduce cyclic nitromines. This result is in agreement with Sheremata \& Hawari ${ }^{214}$ similar work revealed that $P$. chrysoporium, $T$. versicolor, or Aspergillus niger and Rhizopus spp, are capable of utilizing heavy metals (Figure 7) and TNT, RDX and HMX. Also, in this study, fungi pattern of growth and development is less predictable. Fungi were not fixed into developmental pathways. The life cycle of a fungus is unpredictable and flexible because the mechanism of action is co-metabolism and bioaccumulation as confirmed by Dagley. ${ }^{82}$ Complete transformation of TNT and $10-40 \%$ mineralization were discovered in Phanerochaete chrysosporium, a white rot fungi was reported. ${ }^{214,409} P$. chrysosporium, a white rot fungus, was used in the degradation of RDX. It removed RDX (62 $\mathrm{mg} / \mathrm{L}$ ) from liquid medium containing glycerol as the main carbon source. Approximately, $53 \%$ of the molecule was mineralized, and the major by product $(62 \%)$ of the degradation was $\mathrm{N}_{2} \mathrm{O}$. P. chrysosporium mineralized HMX under nitrogen-limiting conditions. After 25 days of incubation, $97 \%$ of HMX was removed via reduction with the accumulation of 4-nitro-2,4-diazabutanal. Zhao et al., ${ }^{409}$ reported that, the presence of glucose enhanced the degradation of HMX in marine sediment from a military UXO disposal and in which after 50 days, the HMX concentration in the aqueous phase $(1.2 \mathrm{mg} / \mathrm{L})$ was reduced by $50 \%$. The disappearance of HMX was accompanied by the formation of a mononitroso derivative.

\section{MFC biodegradation significance}

Fungal biodegradation mechanisms life cycle is unpredictable and flexible with intermediate bioremediation products which showed formation of MNX and ring cleavage and the subsequent formation of methylene dinitramine (MEDINA) by the white-rot fungus $P$. chrysosporium with $\mathrm{RDX}^{214}$ because the mechanism of action is cometabolism and bioaccumulation as confirmed by Dagley. ${ }^{82}$ Nutrient availability is one important factor that plays a significant role in the rate of explosives biodegradation. Compared to other common pollutants, explosives, particularly RDX and HMX, are characterized by a higher N/C ratio. Although they may theoretically serve as sources of both carbon and nitrogen, only nitrogen is used by some organisms, and hence, another carbon source must be added ${ }^{9}$ and see Figure 4. Since denitration is frequently carried out by strains that are capable of utilizing the explosive compound as a nitrogen source, a negative response is often observed in microcosm experiments when external nitrogen sources (either ammonium or nitrate) are added, as these nitrogen-containing compounds may compete with degradation of the explosives for nitrogen..$^{30,35,73,291,243}$

There is a need for the development of ex-situ bio-augmentation products for the biodegradation of xenobiotic to assist mineralization because the additional nitrogen supports microbial growth without competing with the explosive compounds for metabolism of RDX as reported by scholars ${ }^{291,329,379}$ and TNT ${ }^{41}$ nitrogen-bearing compounds are also potential inhibitors of enzyme expression, as presented by Nejidat et al., ${ }^{243}$ who showed that ammonium and nitrite repress fungi lignin peroxidase. The mechanism by which the fungi mineralize the explosive is not known, but preliminary information about the process has been reported ${ }^{230,231}$ and mineralization by microbial consortium affirmed in similar work by Young et al. ${ }^{404,405}$ employed a consortium from horse manure to successfully biodegrade RDX. Biodegradation rates are also influenced by the type of electron acceptors and electron donors. For example, the degradation of RDX, HMX and TNT was shown to be enhanced by additional hydrogen or hydrogen-producing electron donors under anaerobic conditions ${ }^{1,2}$ and the degradation of HMX was enhanced by adding mixed electron acceptors to anaerobic microbial consortia. ${ }^{45}$ Redox potential is another important factor that not only plays an important role in dictating the mechanism of degradation, but also influences the actual biotic degradation rate. Biodegradation is generally enhanced under reduced conditions, and in saturated soils. ${ }^{272,283,329}$

\section{Laccase reaction mechanism}

Laccases are of particular interest with regard to potential applications, because of their capabilities to oxidize a wide range of environmentally dangerous substrates. Greater attention on laccase, an eco-friendly enzyme and a green catalyst in recent past is generating information that appeared in a number of reviews. ${ }^{17,321,388}$ Some soil ascomycete species from the genera Aspergillus, Curvularia and Penicillium, ${ }^{19}$ Trametes versicolor, ${ }^{290,232}$ are some examples of basidiomycetes that produce laccases. ${ }^{378}$ Laccases from different sources displays a wide range of redox potentials. The $\mathrm{T} 1$ site of laccase of T. versicolor shows a high redox potential of $780-800 \mathrm{mV},{ }^{267}$ Figure 10 Expression of laccase in some fungi is regulated by nitrogenlimiting conditions ${ }^{102,186,262,268}$ while in others nitrogen sufficiency results in enhanced enzyme production. The effect of various nutrient nitrogen concentrations on expression of $l c c$ genes at molecular level in $T$. Versicolor was examined.$^{75}$ There was a direct correlation between concentration of nitrogen nutrient in growth medium and the level of $l c c$ expression by T. versicolor. Copper is also often a strong inducer of laccase gene transcription, and this has been suggested to 
be related to a defense mechanism against oxidative stress caused by free copper ions. ${ }^{75,86,108,119,204,257,327}$ In addition to copper, other metal ions such as $\mathrm{Mg}^{2+}, \mathrm{Cd}^{2+}$ or $\mathrm{Hg}^{2+}$ can stimulate laccase expression. ${ }^{119,306,327}$ Figure 9 shows the explosives $\quad$ f u n g a 1 consortium isolates impacts on biodegradation of munitions explosive because of laccase. The importance of adequate copper concentration for proper laccase folding was further corroborated by studies in which two genes related to copper-trafficking in $T$. versicolor were over-expressed in $S$. cerevisiae expressing $T$. versicolor lcc3 gene; the heterologous laccase production by $S$. cerevisiae was improved up to 20 -fold, ${ }^{361}$ Figure 11 . The effect was suggested to result from more efficient transport of copper to the Golgi compartment. ${ }^{36}$ Laccase biocatalyst protein engineering potentials in the development of robust, active and tailor made enzymes. In addition to substrate oxidation, laccase can also immobilize soil pollutants by oxidation, coupling to soil humic substances - a process analogous to humic acid synthesis in soils ${ }^{39}$ and an active biocatalyst for biofertilizer. ${ }^{255}$

Also, engineered to improve the efficiency of particular bioremediation processes like the T. versicolor in Aspergillus niger ${ }^{38}$ and mediators to attack non-phenolics. Laccases are multi-copper oxidases produced by fungi, bacteria, plants and even insects that catalyse the one-electron oxidation of four equivalents of reducing substrate, with the corresponding four-electron reduction of atmospheric oxygen to water, ${ }^{97,68,317}$ Figure 12. Fungal laccases are known to have higher redox potentials than bacterial laccases and are produced by a wide range of fungi. Biological role and significance of laccases in lignin degradation remains unclear like $P$. chrysosporium contains no laccase homologs in its genome, yet depolymerize $\operatorname{lignin}^{101,168,218}$ and see Figure 8. The application of selected microbial consortia, over single strains, for such biotechnological purposes presents advantages to perform complex tasks that single strains. The reason is that the deconstruction of complex substrates requires many different types of enzymes and diverse chemical reactions within pollutants matrix simultaneously with resilience to environmental fluctuations was reported ${ }^{258,211}$ and illustrated by Figure 12 (microbial and phytoremediation construct).

Application of synthetic microbial consortia could be a solution to this problem, as such consortia are usually composed of few wellidentified organisms. Sometimes, those species do not co-inhabit the same environment, but their activities may be combined, ${ }^{163}$ Figure 13.

\section{Phytoremediation with laccase gene}

Phytoremediation for removal of recalcitrant environmental pollutants involve uptake, translocation, transformation and compartmentalization and sometimes mineralization (Figure 16). ${ }^{308}$ Plant roots also secrete metabolites, which stimulate the growth of micro-organisms in the rhizosphere, which in turn can degrade and mineralize the organic compounds. Although plants have several advantages over Fungi as candidates for bioremediation, they lack xenobiotic degradative capabilities unlike fungi. Hence, introduction of genes for degradation of recalcitrant environmental pollutants from microorganisms or other eukaryotes will further enhance their ability to degrade/mineralize recalcitrant environmental pollutants.

Microorganisms' gene sequences are rich in $\mathrm{CpG}$ dinucleotides and have highly skewed codon usages, both of which are particularly unfavorable to efficient expression in plants. ${ }^{294}$ The $M n P$ gene ${ }^{161}$ or the laccase gene ${ }^{328}$ from white- rot fungi has already been introduced into tobacco plants. Hirai et al., ${ }^{151}$ reported laccase cDNA ( $s c L$ ) from white-rot fungus Schizophyllum commune was used as a model ligninolytic enzyme to obtain efficient expression of $\mathrm{scL}$ and removal of a recalcitrant compound in transgenic tobacco plant by decreasing the CpGdinucleotide motif content in order to develop phytoremediation with a ligninolytic enzymeproducing transgenic plant and a construct model in Figure 12. Findings

\section{Gene transfer into the fungi and myco-remediation}

HGT and adaptation to different environments: Horizontal gene transfer (HGT), or lateral gene transfer, describes the transmission of genetic material between organisms, specifically across species boundaries. ${ }^{11,91,180,251}$ The term species is of course a difficult concept to apply to asexual microbes. ${ }^{71,90,189}$ HGT represents an important factor in shaping the genomes of prokaryotes and has provided a key source of evolutionary innovations. ${ }^{164,251}$ Several routes for transfer have been identified including gene transfer agents, transduction, transformation and conjugation. ${ }^{200,350}$ Fungi theoretically lack the beta-glucuronidase GUS) gene and therefore the metabolic capacity to utilize glucuronides as a carbon source. Wenzl et al., ${ }^{385}$ screened for fungi in vertebrate urine using culture enrichment with selection for fungi with glucuronide metabolic capabilities. Using this approach they identified GUS genes in Penicillium canescens and Scopulariopsis spp. Subsequent, phylogenetic analysis demonstrated that these genes, along with GUS genes of Aspergillus and Gibberella, were derived by HGT from bacteria, ${ }^{350,385}$ again demonstrating cases of HGT which have expanded the metabolism of fungi and enabled them to adapt to new environments. The implication for the study Figure 10 shows the explosives fungal consortium isolates biodegradability in increasing order $>$ Aspergillus niger $>$ Trametes Versicolor $>$ Rhizopus spp >Phanorochate chrysoporium $>$ Penicillium spp. identified. Similarly to the Gunasekaran et al., ${ }^{135}$ reported that, Rhizopus spp, Aspergillus niger, Trametes versicolor and P. chrysoporium as good mycoremediation potential for xenobiotic (Plate 1). The fungi-tofungi transfers identified encompass five gene clusters representing a total of 53 individual gene phylogenies and seven gene cluster transfer events. ${ }^{184,261,324,325,326}$ Perhaps the most striking example of a gene cluster transfer was the transfer of a 23-gene cluster from the Aspergillus lineage to Podospora. ${ }^{326}$ The majority of gene transfers between fungi ( 53 of 66 genes) were located in gene clusters, providing direct support for the hypothesis that gene clustering has played a role in facilitating gene transfer in fungi. ${ }^{380}$ Functional annotation of the 323 HGTs demonstrates that transfer has played a role in reconfiguring the core nutrient metabolism of many fungi, added to osmotrophic capacity of fungi, and allowed fungi to colonize 'new' environments. Mechanisms for gene transfer in fungi remain unclear, but the patterns of transfer (originating from bacteria and fungi) provide circumstantial evidence that supports two previously hypothesized routes of transfer: inter-domain transformation and conjugation-like transfer (for genes of bacterial origin) and anastomosis of cells (for those of fungal) reported. ${ }^{281}$

\section{Surface sequestration}

The fungi hyphal surface that is in direct contact with the environment consists of a cell wall, a cell surface component that is composed typically of chitin, $1,3-\beta-$ and 1,6- $\beta$-glucan, and mannan along with different proteins and pigments (that is, melanin). Although, such interactions include physical adsorption, complexation, coordination, or chelation ${ }^{64,196}$ Figure 17, which do not depend on intracellular metabolism, their effects on the cellular metabolism remains unclear. ${ }^{111}$ The surface sequestration depends on three factors:

a) Intracell wall composition and the distribution of the metal binding groups, ${ }^{266}$ 
b) Several physicochemical factors that include primarily the environmental variables (temperature, $\mathrm{pH}$, ionic strength, etc.) and

c) The pollutants on centrations and their chemical behaviour in the environment. ${ }^{87}$

Biodegradation with extracellular enzymes with plethora of nonspecific extracellular enzymes are synthesized by fungi that can convert the complex extracellular growth substrates into simpler molecules, which can subsequently be absorbed into their cells as nutrients. ${ }^{378}$ The enzymes that are most beneficial Laccase gene transcription and biosynthesis, for example depends on a wide array of environmental cues, which include metals ions (e.g., copper (II) and iron (II)) and several aromatic compounds in the environment. ${ }^{111}$ In Figure 8, microbial fungi consortium (MFC) to $61.7 \%$ bioremediate heavy metal better than the isolated fungi species because the lateral gene transfer with where T. versicolor ${ }^{359}$ in Aspergillus niger are HGT mediators and similar to Bohlin et al. ${ }^{38}$ report.

\section{Intracellular degradation}

Fungal cells also possess the ability to catabolize internalized pollutants using their intracellular enzymes. One of the best studied enzyme systems used for this purpose comprises a set of mixed function oxidases called cytochrome P450s, which demonstrate the ability to catalyze a wide range of biodegradation reactions that involve epoxidation, hydroxylation, deamination, nitro reduction, dehalogenation, and desulfuration reactions. ${ }^{28,80,139,341}$ Example of mycoremediation involving cytochrome P450 systems include biodegradation of kerosene and pharmaceutical waste products, ${ }^{63,131,213}$ dye decolorization 63 pesticide remediation. ${ }^{342,398}$ Mycoremediation reports the oxidoreductases that function hand-in-hand by Harms et al., ${ }^{139}$ for pollutant degradation both within and outside of the cell (Figure 13). Most popular among these enzymes are the cytochrome P450 monooxygenase systems that are known to generate reactive oxygen species in eukaryotes ${ }^{274}$ and result in increased intracellular oxidative stress. Laccase is involved in the pigmentation process of fungal spores, the regeneration of tobacco protoplasts, as fungal virulence factors, and in lignification of cell walls and delignification during white rot of wood, ${ }^{220}$ Figure 15 is an illustration of a construct intracellular degradation.

\section{Kachia pollutants ecosystem restoration}

Vegetation is not only an aid to ecosystem restoration, it is a key indicator of munitions xenobiotic. ${ }^{288}$ Plant species that are present on a site, as well as their quantities and condition, describe a watershed's health and resilience. Kachia (Figure 19, Appendix 3) lies in the more southern Guinea savannah zone, Nigeria. ${ }^{140}$ Semi-arid zones of northern with soil fertility management strategies by smallholders that combine organic and inorganic inputs to sustain agricultural production. ${ }^{140}$ Adopting best-fit legume technologies in cropping systems will contribute to improved soil fertility through biological $\mathrm{N}_{2}$-fixation and thereby increasing productivity of agricultural fields. ${ }^{112}$ Legume crop residue provides high quality fodder to feed livestock. Groundnut and soybean (Glycine max) variety TGx 1448$2 \mathrm{E}$ are widely grown by farmers are the common legumes and cultivate ginger for income generation and yam for food as well as income and the application of biofertilizer will help bio-remediate the residual pollutants within the ecosystems. Therefore, the use of the less efficient wild type tobacco plants could be combined with profit making operations, such as bioenergy cultivated (Figure 18) using PGPRs Biosurfactants presents in OTAI $\mathrm{AG}^{\circledR}$ Inocula in the biofertilizer (https://www.youtube.com/ watch? v=Hi_OpgVcFeg biofertilizer) from bio-waste in anaerobic digester inoculated with beneficial microbes that exhibit differing metabolic capabilities. ${ }^{255}$

\section{Appendix 3}

Agro-ecological of Kachia, Kaduna state, Nigeria

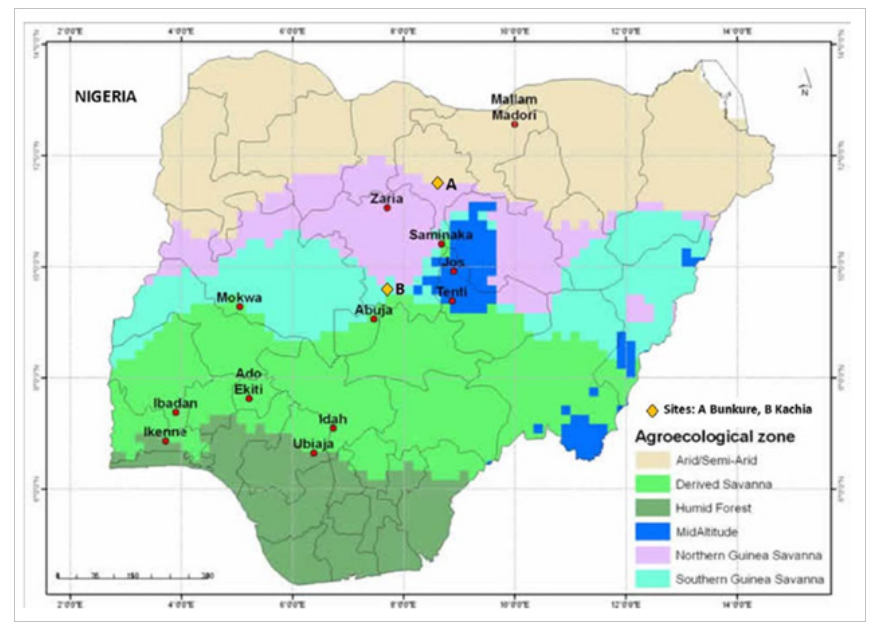

Figure 19 Agro-ecological of Kachia (B), Kaduna state, Nigeria.

Source: Foli, Samson (2012).

Kachia ecosystem restoration protocol is illuminated in Figure 15 where 'Green liver model' for the metabolism of xenobiotic in plants intracellular degradation role of fungi gene in planate and affirmed by scholar Burken et al., ${ }^{55}$ Phytoremediation with protoplast fusion from micro-organisms, Figures 13 and 14. Most of the microorganisms' enzyme activities could not be detected in microorganisms' gene-introducing transgenic plants, and most studies in these transgenic plants have used Western blot analysis to detect these target proteins. ${ }^{179,241,234}$ Protoplasts have a negative charge on the surface that helps to repulse surrounding protoplasts. They need to be in close contact prior to fusion, which can be achieved physically (by mechanical pressing with micropipette, by centrifugation) or chemically. Protoplast fusion consists of three steps: agglutination, the fusion of membranes in small localized places and forming of bridges among protoplasts, rounding of fused protoplasts. Protoplast fusion requires approaching, adhesion and joining of two different types of protoplasts. Approaching of the protoplasts is determined by many electrostatic forces arising from the potential on the cell surface. The result of the interaction is either fusion or complete failure. ${ }^{33,37}$

\section{Protoplast fusion}

Somatic hybridization is an important tool of plant breeding and crop improvement by the production of inter-specific and inter-generic hybrids. The technique involves the fusion of protoplasts of two different genomes followed by the selection of desired somatic hybrid cells and regeneration of hybrid plants. ${ }^{104}$ Protoplast fusion provides an efficient mean of 'gene transfer' with desired trait from one species to another and has an increasing impact on crop improvement. ${ }^{53}$ Somatic hybrids were produced by fusion of protoplasts from rice and ditch reed using electro-fusion treatment for salt tolerance. ${ }^{237}$ In vitro fusion of protoplast opens a way of developing unique hybrid plants by overcoming the barriers of sexual incompatibility. The technique has been applicable in horticultural industry to create new hybrids with increased fruit yield and better resistance to diseases. Kachia pollutants ecosystem restoration for biodiversity of the shooting ranges is illustrated with Figure 16 xenobiotic myco /phytoremediation. 


\section{Green liver model}

Phytoremediation is the term used to describe those methodologies that use living higher organisms, which include green vegetation, plants, aquatic plants, trees and grasses, to remove toxic compounds. This technology has the advantage of $i$ situ treatment of contaminated soils, sediments, groundwater, surface water and external atmosphere. $81,217,351$

To some extent, molecular biology approaches have already been used to evaluate phyto-remediation and reveal elimination of toxicity from contaminated sites. ${ }^{36,58,192,295}$ However, these sequences of microorganisms' gene, which might be introduced into plants, are rich in $C p G$ dinucleotides and have highly skewed codon usages, both of which are particularly unfavorable to efficient expression in plants. ${ }^{294}$ Practically, these $M n P$ gene - or laccase gene-introducing transgenic plants have produced very low amounts of these enzymes. ${ }^{166,328}$ The mechanisms of degradation of xenobiotic by plants (Figure 14). Prior to the introduction of xenobiotic to plant cells, they must be takenup through the roots. Research studies reports predictive relationships between the uptake rate of a compound and its physical-chemical properties. ${ }^{52,56}$ Enzymatic transformation of xenobiotic by plants follows the 'green-liver model' Figure 14 and involves three steps. First, the foreign compounds taken up by plants are transformed by enzymes such as cytochrome P450, carboxylesterases, and peroxidase. ${ }^{303}$ Secondly, the transformed xenobiotic are conjugated with D-glucose, glutathione, or amino acids ${ }^{188}$ by enzymes such as glutathione S-transferases, glucosyltransferases and malonyltransferases, resulting in either soluble or insoluble products. The third step is storage and compartmentation; the soluble compounds are stored in vacuoles or as cell-wall materials by further processing, and the insoluble compounds are generally assumed to be stored in the cell wall (Figure 14). ${ }^{209}$ The transformed products of TNT are further conjugated and sequestered in plant cells. Over $80 \%$ of the TNT label was associated with plant biomass, suggesting that the labelled carbon from TNT was sequestered in the plant tissues. ${ }^{138}$ The exemplar protocol for transformation and mineralization of TNT, ${ }^{156} \mathrm{RDX}^{299}$ and HMX, in Figures 15 and 16 the xenobiotic biodegradation schematic. RDX biotransformation occurs in a variety of environments from surface and subsurface soils cold marine sediments ${ }^{410}$ and several microorganisms have been shown to co-metabolize both RDX and HMX. ${ }^{411}$ RDX and HMX has generally been thought to be recalcitrant to aerobic biodegradation ${ }^{411}$ and requires alternative biodegradation method like the Figure 15 biodegradations protocol affirmed by similar research report by Wang et al., ${ }^{383}$ reported that, RDX is degraded via sequential reduction of the nitro functional groups followed by abioticringcleavage.

\section{Xenobiotic myco bio-augmentation/ phytoremediation/} biosimulation (xenobiotic Myco B-P-B) techniques The mechanisms by which TNT and its metabolites affect RDX and HMX degradation appear to lie in their cytotoxicity to most of the microorganisms present in the explosives - degrading culture reported. ${ }^{302}$ TNT and its degradation products are adsorbed to the upper soil layer, whereas RDX and HMX are not, being transported instead with the infiltrating water affirmed and reported ${ }^{302,402}$ that the potential for RDX biodegradation in the upper $4 \mathrm{~m}$ is extremely high. The Kachia biodegradation and restoration of the military shooting range will requires xenobiotic myco /phytoremediation construct, Figure 16. Mycoremediation is a type of bioremediation using fungi, including WRF, for that purpose and it refers to their possibilities as microorganisms of degrading a great number of recalcitrant pollutants and transforming industrial wastes into products (Figure 16). ${ }^{194}$
Some of the most widely investigated fungi species capable of synthesising LiP are P. anerochaete chrysosporium, Trametes versicolor, Trichoderma reesei, Aspergillus niger, Phlebia radiata, Pleurotus ostreatus, Pleurotus sajor-caju. ${ }^{105}$ Biotransformation involving enzymes does not cause accumulation of toxic by-products, and the enzymes are digested after the completion of the process by the microorganisms dwelling in contaminated environments. Secondly, increasing the bioavailability of contaminants is more easily achieved than in the case of using whole cells. ${ }^{5,212}$ Laccase (benzenediol, oxygen oxidoreductases, EC 1.10.3.2) is one of the few lignin-degrading enzymes that have been extensively studied since $18^{\text {th }}$ century. RDX degradation has also been examined in constructed wetlands. ${ }^{31,32}$ Both submerged and emergent plants were shown to take-up pollutants accumulated in sites of active growth. Biotransformation of RDX to unidentified products was also observed. Mineralization was very low (less than $5 \%$ ) and production of volatile organics negligible. The nature of the chloromethane cycle ${ }^{137}$ transformation products remains unclear by Figure 16 xenobiotic protocol will optimize the environmental risk. Recently, laccases were reported from eukaryotes e.g. fungi, plants and insects. ${ }^{313}$ This makes laccases highly interesting for a wide variety of processes, such as textile dye decolouration, pulp bleaching, effluent detoxification, biosensors and bioremediation. ${ }^{78}$ Laccase is involved in the pigmentation process of fungal spores, the regeneration of tobacco protoplasts (Figure 13), as fungal virulence factors, and in lignification of cell walls and delignification during white rot of wood. ${ }^{220}$ Trametes versicolor is one of the most efficient laccase-producing fungi. Laccases are also produced in conjunction with $L i P, M n P$, or both. Laccases from marine fungi effectively mineralized 14C-(ring)-labelled synthetic lignin to ${ }^{14} \mathrm{CO}_{2} \cdot{ }^{275}$ Laccase genes several strains of Trametes versicolor. ${ }^{169}$

Plants deal with organic explosives, such as RDX and TNT in three phases as depicted in Figure 14 and reported by scholars. ${ }^{207,270,297}$ Phase I (transformation). The contaminant is metabolized into a more soluble and less toxic intermediate products by several reactions, such as oxidation, reduction, or hydrolysis. The oxidative metabolism of explosive compounds is generally mediated by cytochrome P450 mono-oxygenase in plants. In plants, cytochrome P450 forms a largest group of plant protein which plays an important role in degradation of explosives. ${ }^{236}$ Phase II (conjugation)-In conjugation between organic contaminant and endogenous hydrophilic molecules, such as D-glucose, glutathione, or amino acids, soluble or insoluble substances are produced to be subsequently sequestered in different cellular compartments of the plant for storage. ${ }^{307,406}$ Conjugation also enhances metabolic activity which is further catalysed by glycosyl-, malonyl,and glutathione S-transferases. Phase III (compartmentation), (Figures 15\&18).

\section{Cytochrome P450-mediated phytoremediation}

Cytochrome CYP superfamily of enzymes exist in all biological domains and their presence predates the emergence of oxygenmetabolizing life form. ${ }^{393}$ Cytochrome P450 (CYP) monooxygenases, the ubiquitous enzymes with catalytic versatility, substrate diversity and atypical kinetics are one of the most fascinating targets for biocatalysis and play diverse roles in biotechnology, medicine and bioremediation..$^{51,120,195}$ Being a ubiquitous organism, fungi inhabitant's diverse ecological niches, adapts to various sources of carbon and nitrogen for their survival and metabolism. ${ }^{130}$ Comprehensive biochemical analysis of molecular mechanisms showed that fungal adaption are often facilitated by CYP monooxygenases. ${ }^{130}$ Fungal CYPs play an essential role in their adaptations to ecological niches 
due to their diverse roles in the production of metabolites critical for pathogenesis, detoxification of xenobiotic and exploitation of substrates (Figure 2). ${ }^{130,265}$ To date, a vast number of CYPs have been identified in $>2500$ fungal species, and these are classified into $\approx 400$ CYP families (namely CYP51-CYP69, CYP501-CYP699, and CYP5001-CYP6999). ${ }^{20,65}$

Under aerobic conditions, RDX is highly persistent in soil and groundwater; it is much less susceptible than TNT to biotransfonnation, is less strongly adsorbed to soil, and undergoes much less immobilization. ${ }^{321}$ Some notable examples of the fungal primary metabolism are housekeeping functions such as ergosterol biosynthesis, meiotic spore-wall biogenesis, and n-alkane hydroxylation, whereas fungal secondary metabolism deals with the biosynthesis of hormones, mycotoxins, and the like (Figure 15) reported by Črešnar and Petrič.$^{80}$ Fungal CYPs are also capable of detoxifying and degrading various xenobiotic compounds encountered in their environments, ${ }^{345,346}$ such as polycyclic aromatic hydrocarbons (PAHs), phenolic compounds, and other toxic environmental pollutants. ${ }^{80}$ Remarkably, the transcriptional regulation of CYPdependent metabolic pathways can be alternatively induced or upregulated by defined high or low nitrogen conditions, as observed in P. chrysosporium, C. versicolor, P. placenta, and A. oryzae (Figure 17). ${ }^{170,219,242}$

Considering the extraordinary potential of CYPs, several reviews have addressed their limitations and have focused on tackling these challenges to promote CYPs as robust (Figure 15) biocatalysts. ${ }^{29,195,224,250}$ Fungal CYPs also inherently possess the same limitations; and recent advancements has sought to overcome the major hurdles posed by fungal CYPs. ${ }^{29,61}$ Enzyme engineering through mutagenesis is one of the tools to modify fungal CYPs as sustainable catalysts by solving issues concerning low expression levels and poor activity. ${ }^{29,195,224,250}$ For example, the oxidizing activity of the $P$. chrysosprium PAH oxidase (CYP5136A3) was significantly improved by a rational designing approach through site-directed mutagenesis. ${ }^{224}$ Artificial CYP-CPR fusion constructs termed "Molecular lego" are a competent strategy for comparative analysis of differential redox partners to find the optimal redox system (Figure 16).$^{300,301}$ In addition, improved intracellular electron recycling can be obtained through cofactor regeneration ${ }^{369}$ by co-expressing CYPs along with glucose/ formate dehydrogenase or aldehyde reductase (Figure 15). ${ }^{206}$

\section{Biofertilizer-soil amendments}

The use of soil amendments such as compost, ${ }^{396}$ biochar, biofertilizer and molasses to 'kick-start' microbial degradation has been well studied for many xenobiotic reported by $\mathrm{Wu}$ et al. ${ }^{397}$ and Otaiku et al., ${ }^{255}$ But few studies have yet investigated the effect of amendments for phytoremediation on explosives. A laboratory study ${ }^{199}$ showed that the application of molasses to open burn/detonation areas enabled Guinea Grass (Panicum maximum) to remediate RDX, with plant and microbial communities' fully remediating soil contaminated with $1.3 \mathrm{mg} / \mathrm{kg}$ RDX within the 15 -week study. When biofertilizer applied as soil inoculants, they multiply and participate in nutrient cycling and benefit crop productivity. ${ }^{319}$

Depending on the family of N.tabacum $30-40 \%$ of the seed is in average oil ${ }^{129,360}$ and is composed of linoleic acid (71.63\%), oleic acid $(13.46 \%)$ and palmitic acid (8.72\%) . Although tobacco seed oil is a non- edible vegetable oil, it can be utilised for biodiesel production as a new renewable alternative diesel engine fuel. ${ }^{364,} 373$ For this purpose research has to focus on the amounts of inorganic and organic pollutants accumulated in the seeds during the phytoremediation process.
Tobacco is a plant, which fulfils all the characteristics for a suitable phytoremediation plant and combined with the production of bioenergy it could become one of the main plants used in the field of phytoremediation. Tobacco is a plant, which fulfils all the characteristics for a suitable phytoremediation plant and combined with the production of bioenergy. Niche fungi consortium research on diversity and distributions ${ }^{59,103,183,365,387}$ will enhance the re-construction ofthe Kachia biogeography spatial scale relevant to ecology and evolution. ${ }^{141}$ The convergence of biogeography and ecology is a relatively recent phenomenon ${ }^{282,285,286}$ species sorting and niche partitioning; local/regional saturation; and diversification of regional biotas $^{284}$ analyzes organism-environment relations through change over space and time, and often includes human-biota interactions (Figure 13).

\section{Site monitoring}

The significant cost factor of site remediation is monitoring of contaminant levels, and this is particularly difficult given the large scale, and inaccessibility of military sites. Novel studies have quantified the response to explosives of plant species native to military ranges in temperate regions. By measuring multiple variables representing morphological and physiological responses, such studies identified vegetation responses that could potentially be used to determine levels of TNT and RDX contamination. ${ }^{7,374,375}$ Hyper spectral imaging technologies are also being developed to remotely detect vegetation response using aerial drones as suitable carriers to record contamination levels on surface in accessible sites.

Myco B-P-B techniques-examplar Despite several studies, bioremediation of TNT is still considered challenging. Majority of studies have focused on discovering microorganisms that could be used to degrade pollutants was reported by Ayoub et al., ${ }^{15}$ and No lvak et al., ${ }^{247}$ research reported the effect of bioremediation methods and combinations (biostimulation, bioaugmentation, phytoremediation) on the degradation of TNT in soil. Biostimulation approaches add nutrients or electron acceptor/donors to the polluted environment to enhance the bioremediation of pollutants like TNT. ${ }^{125}$ Biostimulation can also be used in combination with bio-augmentation to improve the survival and catabolic activity of introduced microorganisms. ${ }^{209}$ Phytoremediation

Phytoremediation utilizes green plants to treat contaminated soil or water and has been successfully applied to remediation of different pollutants, including TNT. ${ }^{153,208}$ Plants release root exudates and enzymes that stimulate microbial activity and contaminant degradation in the rhizosphere, enabling the application of rhizoremediation, which is considered particularly effective for the treatment of contaminated soil (Figure 16). ${ }^{124,193,308}$ Using 16S rRNA gene full-length sequencing (BCCM/LMG, Belgium), the predominant bacterial strains in the inoculum were determined to be members of Pseudomonas and Stenotrophomonas genus. ${ }^{200}$

The research indicates that all treatments used resulted in decreased concentrations of TNT in soil. Similar to previous reports. ${ }^{34,355 \text {, }}$ 370 TNT and its aminoderivates 2ADNT and 4ADNT were the only compounds detectable by HPLC; all of these were reduced to a considerable degree of the initial concentrations. The isomeric aminoderivates (2ADNT and 4ADNT) are formed during microbial transformation of TNT; 395 these compounds exhibit less toxicity than TNT and bind more tightly to soil clay particles and organic matter, thereby reducing bioavailability as well as toxicity in soil. ${ }^{264,273} \mathrm{Of}$ the treatments used, the combined bioaugmentation - biostimulation approach coupled with plant (especially rye) cultivation was the most 
effective treatment resulting in the lowest final TNT concentrations. This corresponds well to other more recent results with similar TNT contamination rates. ${ }^{355}$

\section{Future work}

The Figures 14-16 xenobiotic myco /phytoremediation construct are an integrated approach to metabolic engineering has beentermed inverse metabolic engineering, where first a desired phenotype is formulated, then the necessary factors to create it are determined, finally these are assembled in the host (microbial/Phyto) as affirmed by Bailey et al., ${ }^{16}$ as a construct for xenobiotic biodegradation model called PC3R technology. Finally, incremental genetic changes in vivo and input the results of each change back into the model. The technological and methodological tools now exist to accomplish PC3R technology where Aspergillus as exemplar as gene mediator. Further work on PC3R technology with respect to xenobiotic biodegradation will require the solution mathematical modelling of metabolic pathway networks; the theory is well developed at present $^{244,389}$ and comprises several complementary approaches to metabolic modelling, e.g., stoichiometric and carbon flux models (metabolic flux analysis ${ }^{339,371}$ kinetic models (metabolic control analysis and morphologically structured models. ${ }^{233,245,323}$ The development of remediation approaches is the determination of the genomes of specific white rot fungi. For example, research into the $P$. chrysosporium genome has resulted in the elucidation of specific cytochrome P450 monooxygenases, which may be differentially expressed in the presence of xenobiotic compounds. ${ }^{400}$

In the future, efforts should be made to develop strategies to improve the tolerance, uptake, and yperaccumulation of heavy metals/ metalloids using genomic and metabolic engineering approaches. Pathways that control the uptake, detoxification, transport from root to shoot tissues and translocation and hyper-accumulation in the aboveground storage tissues can be engineered using gene-stacking approaches. Genome editing strategies can be designed using TALENs (transcription activator like effectors nucleases) technology or the powerful CRISPR- Cas9 (clustered regularly interspaced short palindromic repeats) system to produce microbes/plants for bio/ phytoremediation purposes (Figures 17\&18). Recently, efficient and successful CRISPR/Cas9- mediated targeted mutagenesis has been reported in Populus plants. ${ }^{106}$

\section{Conclusion}

There is a need for the development of ex-situ bio-augmentation products for the biodegradation of xenobiotic to assist mineralization because the additional nitrogen supports microbial growth without competing with the explosive compounds for metabolism of RDX as reported by scholars ${ }^{291,329,379}$ and $\mathrm{TNT}^{41}$ nitrogen-bearing compounds are also potential inhibitors of enzyme expression, as presented by Nejidat et al., ${ }^{243}$ who showed that ammonium and nitrite repress fungi lignin peroxidase. Extracellular oxidoreductases. A unique characteristic of fungi is their ability to attack organic compounds using a range of extracellular oxidoreductases with relatively nonspecific activities. These enzymes have probably evolved to support fungal growth on recalcitrant substrates of random structure such as lignocellulose substrates that are not accessible for most bacteria through the depolymerisation and removal of lignin and its humic substance derivatives. ${ }^{18,154,269}$ Hence, these enzymes give fungi an ecological advantage over bacteria in particular decomposition niches. ${ }^{18}$ Genetic engineering of peroxidases to improve their catalytic properties allows enhancement of the $\mathrm{H}_{2} \mathrm{O}_{2}$ resistance of the enzymes, or the structural modification of already commercially available enzymes to enable the oxidation of other compounds with high redox potentials. ${ }^{296}$ Radical reactions may also covalently bind metabolites (for example, of TNT) to soil organic matter. ${ }^{144,248}$ Cytochrome P450 monooxygenases ${ }^{95}$ also contribute to the catabolic versatility of fungi lacking extracellular oxidoreductases.

\section{Acknowledgments}

None.

\section{Conflicts of interest}

The authors declare that there was no conflict of interest.

\section{Funding}

Authors had no funding for this research.

\section{References}

1. Adrian NR, Arnett CM. Anaerobic biotransformation of explosives in aquifer slurries amended with ethanol and propylene glycol. Chemosphere. 2007;66:1849-1856.

2. Adrian NR, Arnett CM, Hickey RF. Stimulating the anaerobic biodegradation of explosives by the addition of hydrogen or electron donors that produce hydrogen. Water Res. 2003;37:3499-3507.

3. Aken BV, Hofrichter M, Scheibner K. Transformation and mineralization of 2,4,6 -trinitrotoluene (TNT) by manganese peroxidase from the whiterot basidiomycete Phlebia radiata. Biodegradation. 1999;10:83-91.

4. Alavi G, Chung M, Lichwa J, et al. The fate and transport of RDX, HMX, TNT and DNT in the volcanic soils of Hawaii: A laboratory and modelling study. J Hazard Mater. 2011;185(2-3):1600-1604.

5. Alcade M, Ferrer M, Plou FJ, et al. Environmental biocatalysis: from remediation with enzymes to novel green processes. Trend Biotechnol. 2006;24:281-287.

6. Alexander, M. Introduction to Soil Microbiology, 2nd ed. John Wiley \& Sons, Inc., New York, N.Y; 1977.

7. Ali A, Zinnert JC, Muthukumar B, et al. Physiological and transcriptional responses of Baccharis halimifolia to the explosive "composition B" (RDX/TNT) in amended soil. Environ Sci Pollut Res Int. 2014;1(13):8261-8270.

8. Alic M, L Akileswaran, MH Gold. Characterization of the gene encoding manganese peroxidase isoenzyme 3 from Phanerochaete chrysosporium. Biochim Biophys Acta. 1997;1338:1-7.

9. Allard AS, Neilson AH. Bioremediation of organic waste sites: a critical review of microbiological aspects. Intl Biodeter Biodegrad. 1997;39:253-285.

10. Amann RI, Ludwig W, Schleifer KH. Phylogenetic identification and in situ detection of individual microbial cells without cultivation. Microbiol Rev. 1995;59:143-169.

11. Andersson JO. Gene transfer and diversification of microbial eukaryotes. Anпu Rev Microbiol. 2009;63:177e193.

12. Angermaier L, Simon H. On the reduction of aliphatic and aromatic nitro compounds by Clostridia, the role of ferredoxin and its stabilization. Hoppe-Seyler's Z Physiol Chem. 1983;364:961-975.

13. Angermaier L, Hein F, Simon H. Investigations on the reduction of aliphatic and aromatic nitro compounds by Clostridium species and enzyme systems. Biology of inorganic nitrogen and Sulphur. In: $\mathrm{H}$ Bothe, editor. Springer, Berlin; 1981.

14. Axtell C, CG Johnston, JA Bumpus. Bioremediation of Soil Contaminated with Explosives at the Naval Weapons Station Yorkton. Soil and Sediment Contamination. 2000;9(6):537-548. 
15. Ayoub K, Van Hullebusch ED, Cassir M, et al. Application of advanced oxidation processes for TNT removal: a review. Journal of Hazardous Materials. 2010;178:10-28.

16. Bailey JE, Sburlati A, Inverse metabolic engineering: a strategy for directed genetic engineering of useful phenotypes. Biotechnol Bioeng. 2002;79(5):568.

17. Baldrian P, Snajdr J. Production of lignolytic enzymes by litterdecomposing fungi and their ability to decolourize synthetic dyes. Enzyme and Microbial Technology. 2006;39:1023-1029.

18. Baldrian P. Wood-inhabiting ligninolytic basidiomycetes in soils: ecology and constraints for applicability in bioremediation. Fungal Ecol. 2008;1:4-12.

19. Banerjee UC, Vohra RM. Production of laccase by Curvularia sp. Folia Microbiologica. 1991;36:343-346.

20. Bao LJ, Maruya KA, Snyder SA, et al. China's water pollution by persistent organic pollutants. Environ Pollut. 2010;163:100-108.

21. Barr DP, Aust SD. Pollutant degradation by white rot fungi. Rev Environ Contam Toxicol. 1994;138:49-72.

22. Bastos AC, Magan N. Trametes versicolor: potential for atrazine bioremediation in calcareous clay soil, under low water availability conditions. Int Biodeterior Biodegrad. 2009;63:389-394.

23. Belden JB, Ownby DR, Lotufo GR, et al. Accumulation of trinitrotoluene (TNT) in aquatic organisms: part 2-bioconcentration in aquatic invertebrates and potential for trophic transfer to channel catfish (Ictalurus punctatus). Chemosphere. 2005;8:1161-1168.

24. Beller HR, Tiemeyer $\mathrm{K}$. Use of liquid chromatography/tandem mass spectrometry to detect distinctive indicators of in situ RDX transformation in contaminated ground water. Environmental Science and Technology. 2002;36:2060-2066.

25. Bennett JW. Prospects for Fungal Bioremediation of TNT Munitions Waste. International Biodeterioration \& Biodegradation. 1994;21-34.

26. Berg Gabriele, Christin Zachow, Henry Müller, et al. Next-Generation Bio-Products Sowing the Seeds of Success for Sustainable Agriculture Agronomy. 2013;3:648-656.

27. Berka RM, N Dunn Coleman, M Ward. Industrial enzymes from Aspergillus species, p. 155-214. In]. W. Bennett and M. A. Klich (ed.), Aspergillus. Biology and Industrial Applications. ButterworthHeinemann, Boston, Mass; 1992.

28. Bernhardt R. Cytochromes $\mathrm{P} 450$ as versatile biocatalysts. J Biotechnol. 2006;124(1):128-145.

29. Bernhardt R, Urlacher VB. Cytochromes $\mathrm{P} 450$ as promising catalysts for biotechnological application: chances and limitations. Appl Microbiol Biotechnol. 2014;98:6185-6203.

30. Bernstein A, Adar E, Nejidat A, et al. Isolation and characterization of RDX- degrading Rhodococcus species from a contaminated aquifer. Biodegradation. 2011;22:997-1005.

31. Best EPH, Sprecher SL, Larson SL, et al. Environmental behaviour of explosives in groundwater from the Milan army ammunition plant in aquatic and wetland plant treatments: uptake and fate of TNT and RDX in plants. Chemosphere. 1999a;39:2057-2072.

32. Best EPH, Sprecher SL, Larson SL, et al. Environmental behaviour of explosives in groundwater from the Milan army ammunition plant in aquatic and wetland plant treatments: removal, mass balances and fate in ground- water of TNT and RDX. Chemosphere. 199b;38:3383-3396.

33. Bhojwani SS, Razdan MK. Plant Tissue Culture: Theory and Practice (Developments in Crop Science, Vol. 5) - Elsevier Sci. Publ., Amsterdam-Oxford, New York, Tokyo; 1983.

34. Bhushan B, Haasz A, Spain J, et al. Biotransformation of hexahydro- 1,3,5-trinitro-1,3,5-triazine catalyzed by a $\mathrm{NAD}(\mathrm{P}) \mathrm{H}$ : Nitrate oxidoreduxtase from Aspergillus niger. Environmental Science and Technology. 2002;36:3104-3108.

35. Binks PR, Nicklin S, Bruce NC. Degradation of hexahydro-1,3,5trinitro-1,3,5-triazine (RDX) by Stenotrophomonas maltophilia PB1. Appl Environ Microbiol. 1995;61:1318-1322.

36. Bizily S, CL Summers AO, Meagher RB. Phytoremediation of methylmercury pollution: Mer B expression in Arabidopsis thaliana confers resistance to organomercurials. Proc Natl Acad Sci USA. 1999;96:6808-6813.

37. Blackhall NW, A MM de Laat, MR Davey, et al. Genotype-independent transformation of lettuce using Agrobacterium tumefaciens. Journal of Experimental Botany. 1994;45(10):1441-1449.

38. Bohlin, C, Jönsson LJ, Roth R, et al. Heterologous expression of Trametes versicolor laccase in Pichia pastoris and Aspergillus niger. Applied Biochemistry and Biotechnology. 2006;129:195-214.

39. Bollag JM, Myers C. Detoxification of aquatic and terrestrial sites through binding pollutants to humic substances. Science of the Total Environment. 1992;118:357-356.

40. Boonchan S, ML Britz, GA Stanley. Degradation and mineralization of high-molecular-weight polycyclic aromatic hydrocarbons by defined fungal bacterial co-cultures. Appl Environ Microbial. 2000;66:10071019.

41. Boopathy R, Manning JF. Characterization of partial anaerobic pathway for 2,4,6-trinitrotoluene degradation by a sulphate-reducing bacterial consortium. Canadian Journal Microbiology. 1996;42:1203-1208.

42. Boopathy R, M Wilsona, CD Montemagnob, et al. Biological transformation of 2,4,6- trinitrotoluene (TNT) by soil bacteria isolated from TNT contaminated soil. Bioresource Technology. 1994;47(1):1924.

43. Boopathy R, Gurgas M, Ullian J, et al. Metabolism of explosive compounds by sulphate-reducing bacteria. Curr. 1998a;37:127-131.

44. Boopathy R, Kulpa CF, Manning J. Anaerobic biodegradation of explosives and related compounds by sulphate-reducing and methanogenic bacteria: A review. Bioresour Technol. 1998b;63:81-89.

45. Boopathy R, CF Kulpa. Trinitrotoluene (TNT) as a sole nitrogen source for a sulphate reducing bacterium Desulfovirio sp. (B strain) isolated from an anaerobic digester. Current Microbiology. 1992;25:235-241.

46. Boopathy RM, Wilson C, Montemagno J, et al. Biotransformation of 2,4,6-trinitrotoluene (TNT). By co- metabolism with various co-substrates: A Laboratory-Scale Study. Bioresource Technology. 1994;47:205-208.

47. Bradshaw DJ, Marsh PD, Watson GK, et al. Role of Fusobacterium nucleatum and coaggregation in anaerobe survival in planktonic and biofilm oral microbial communities during aeration. Infect Immun. 1998;66(10):4729-4732.

48. Brannon, James M, Tommy E. Review of Fate and Transport Processes of Explosives Technical Report IRRP-97-2, Installation Restoration Research Program Prepared for Headquarters, U.S. Army Corps of Engineers; 1997.

49. Brannon JM, Pennington JC. Environmental Fate and Transport Process Descriptors for Explosives. Strategic Environmental Research and Development Program Installation Restoration Research Program. Environmental Laboratory U.S. Army Engineer Research and Development Centre 3909 Halls Ferry Road Vicksburg, MS; 2002;39180-619.

50. Brannon MTE. Myers. Review of fate and transport processes of explosives. Technical Report IRRP-97-2. U.S. Army Corps of Engineers. 1997. p. 1-32. 
51. Brentner LB, Mukherji ST, Merchie KM, et al. Expression of glutathione S- transferases in poplar trees (Populus trichocarpa) exposed to 2,4, 6 trinitrotoluene (TNT). Chemosphere. 2008;73:657-662.

52. Geoffrey G Briggs, Richard H Bromilow, Avis A Evans. Relationships between lipophilicity and root uptake and translocation of non-ionised chemicals by barley. Pesticide Science. 1982;13:495-504.

53. Brown DCW, Thorpe TA. Crop improvement through tissue culture. World J Microbiol \& Biotechnol. 1995;11:409-415.

54. Bulgarelli, Davide, Klaus Schlaeppi, et al. Structure and functions of the bacterial microbiota of plants. Annual Review of Plant Biology. $2013 ; ; 64: 807-838$.

55. Burken JG, Shanks JV, Thompson PL. Phytoremediation and plant metabolism of explosives and nitroaromatic compounds. In: Spain J et al., editors. Biodegradation of nitroaromatic compounds and explosives. Lewis Publishers, Boca Raton, 2000. p. 239-275.

56. Burken JG, Schnoor JL. Predictive relationships for uptake of organic contaminants by hybrid poplar trees. Environmental Science and Technology. 1998;32:3379-3385.

57. Burken J. Uptake and metabolism of organic compounds: green-liver model. In Phytoremediation: Control and Transport of Contaminants. Edited by McCutcheon S, Schnoor J. John Wilez. 2003. p. 499-528.

58. Burken JG, Shanks JV, Thompson PL. Phytoremediation and plant metabolism of explosives and nitro- aromatic compounds. In: Biodegradation of Nitro-aromatic Compounds and Explosives. Edited by Spain J.C, Hughes, J.B, Knackmuss H-J. Lewis Publisher. 2000;239 276.

59. Cadotte MW, Davies TJ, Regetz J, et al. Phylogenetic diversity metrics for ecological communities: integrating species richness, abundance and evolutionary history. Ecol Lett. 2010;13:96-105.

60. Carroll GC, DT Wicklow. The Fungal Community. Its Organization and Role in the Ecosystem, $2^{\text {nd }}$ edn. Marcel Dekker, Inc., New York, N.Y. 1992

61. Caswell JM, O’Neill M, Taylor SJ, et al. Engineering and application of P450 monooxygenases in pharmaceutical and metabolite synthesis. Curr Opin Chem Biol. 2013;17:271-275.

62. Cerniglia CE, Sutherland JB. In: Handbook of Hydrocarbon and Lipid Microbiology. In: Timmis KN, editor. 2010. p. 2079-2110.

63. Cha CJ, Doerge DR, Cerniglia CE. Biotransformation of malachite green by the fungus Cunninghamella elegans. Appl Environ Microbiol. 2001;67:4358-4360.

64. Chakraborty S, Mukherjee A, Das TK. Biochemical characterization of a lead- tolerant strain of Aspergillus foetidus: an implication of bioremediation of lead from liquid media. Int Biodeterior Biodegradation. 2013;84:134-142.

65. Chakraborty P, Zhang G, Li J, et al. Selected organochlorine pesticides in the atmosphere of major Indian cities: levels, regional versus local variations, and sources. Environ Sci Technol. 2010;44:8038-8043.

66. Chen H, Wang L, Su CX, et al. Isolation and characterization of lipopeptide antibiotics produced by Bacillus subtilis. Letters in Applied Microbiology. 2008;47(3):180-186.

67. Cho YS, Lee BU, Oh KH. Simultaneous degradation of nitroaromatic compounds TNT, RDX, atrazine, and simazine by Pseudomonas putida HK-6 in bench-scale bioreactors. Journal of Chemical Technology and Biotechnology. 2008;83(9):1211-1217.

68. Claus H. Laccases: Structure, reactions, distribution. Micron. 2004;35(1-2):93-96.

69. Clausen JL. Range assessment lessons learned. Federal Facilities. Environment Journal. 2005;16:49-62.
70. Clausen JL, J Robb, D Curry, et al. A case study of contaminants on military ranges: Camp Edwards, Massachusetts, USA. Environmental Pollution. 2004;129(1):13-21.

71. Cohan FM. What are bacterial species? Annu Rev Microbiol. 2002;56:457-e487.

72. Cole JR, Wang Q, Fish JA, et al. Ribosomal Database Project: data and tools for high throughput rRNA analysis. Nucleic Acids Res. 2013;42:D633-D642.

73. Coleman NV, Nelson DR, Duxbury T. Aerobic biodegradation of hexahydro-1,3,5-trinitro- b1,3,5-triazine (RDX) as a nitrogen source by a Rhodococcus sp., strain DN22. Soil Biol Biochem. 1998;30:11591167.

74. Cole DJ. Oxidation of Xenobiotic in plants. Prog Pest Biochem Toxicol. 1983;3:199-253.

75. Collins PJ, Dobson ADW. Regulation of laccase gene transcription in Trametes versicolor. Applied and Environmental Microbiology. 1997;63:3444-3450.

76. Cooke RC, ADM Rayner. Ecology of Saprotrophic Fungi. Longman, London, United Kingdom; 1984.

77. Cookson, J.T. (1995). Bioremediation Engineering: Design and Application. New York: McGraw Hill.

78. Couto SR, Toca-Herrera JL. Laccase production at reactor scale by filamentous fungi. Biotechnology advances. 2007;25(6):558-569.

79. Craig HD Sisk, WE Nelson, MD Dana, et al. Bioremediation of explosives contaminated soils: a status review. In: Proceedings of the 10th Annual Conference on Hazardous Waste Research. Kansas State University, Manhattan, Kansas. 1995;164-179.

80. Črešnar B, Petrič Š. Cytochrome P450 enzymes in the fungal kingdom. Biochimica et Biophysica Acta (BBA) Proteins Proteom. 2011;1814:29_ 35 .

81. Cunningham SD, Berti WR, Hung JW. Phytoremediation of contaminated soils. Trends Biotechnol. 1995;13:393-397.

82. Dagley S. Lessons from biodegradation. Annu Rev Microbial. 1987;41:1-23.

83. Daar AS, Thorsteinsdottir H, Martin DK, et al. Top ten biotechnologies for improving health in developing countries. Nat Gen. 2002;32:229232

84. Davison J. Risk mitigation of genetically modified bacteria and plants designed for bioremediation. J Ind Microbiol Biotechnol. 2005;32:639650 .

85. De Boer HA, YZ Zhang, C Collins, et al. Analysis of two nucleotide sequences of two ligninase cDNAs from a white-rot filamentous fungus, Phanerochaete chrysosporium. Gene. 1987;60:93-102.

86. Dekker RF, Barbosa AM, Giese EC, et al. Influence of nutrients on enhancing laccase production by Botryosphaeria rhodina MAMB-05. International Microbiology. 2007;10:177-185.

87. Dhankhar R, Hooda A. Fungal biosorption-an alternative to meet the challenges of heavy metal pollution in aqueous solutions. Environ Technol. 2011;32(5-6):467-491.

88. Donmez G, Aksu Z. The effect of copper (II) ions on growth and bioaccumulation properties of some yeasts. Process Biochem. 1999;35:135-142.

89. Donnelly KC, Chen JC, Huebner HJ, et al. Utility of four strains of white-rot fungi for the detoxification of 2,4,6-trinitrotoluene in liquid culture. Environ Toxicol Chem. 1997;16:1105-1110.

90. Doolittle WF. Microbial evolution: stalking the wild bacterial species. Curr Biol. 2008;18(13):R565-R567. 
91. Doolittle WF, Boucher Y, Nesbo CL, et al. How big is the iceberg of which organellar genes in nuclear genomes are but the tip? Philos Trans R Soc Lond B Biol Sci. 2003;358(1423):39-57.

92. Diaz E, Massol-Deya A. Trace element composition in forage samples from a military target range, three agricultural areas and one natural area in Puertorico. Carribean Journal of science. 2003;39(2):215-220.

93. Dietz A, Schnoor J. Advances in phytoremediation. Health Perspect. 2001;109(Supple 1):163-168.

94. Doty SL. Enhancing phytoremediation through the use of transgenic and endophytes. New Phytol. 2008;179:318-333.

95. Durairaj, Pradeepraj, Jae-Seoun Hur, et al. Versatile biocatalysis of fungal cytochrome P450 monooxygenases. Microb Cell Fact. 2016;15:125.

96. Dursun AY, Ulsu G, Cuci Y, et al. Bioaccumulation of copper (II), lead (II) and chromium (VI) by growing Aspergillus niger. Process Biochem. 2003;38(10):1647-1651.

97. Dwivedi UN, Singh P, Pandey VP, et al. Structure-function relationship among bacterial, fungal and plant laccases. J Molec Catal B. 2011;68(2):117-128.

98. Eapen S, Singh S, D’Souza SF. Advances in development of transgenic plants for remediation of xenobiotic pollutants. Biotechnol Adv. 2007;25(5):442-451.

99. Edwards U, Rogall T, Bl“ocker $\mathrm{H}$, et al. Isolation and direct complete nucleotide determination of entire genes: characterization of a gene coding for 16S ribosomal RNA. Nucleic Acids Res. 1989;17(19):78437853 .

100. Egamberdieva D, Kamilova F, Validov S, et al. High incidence of plant growth stimulating bacteria associated with the rhizosphere of wheat grown on salinated soil in Uzbekistan. Environ Microbiol. 2008;10:1-9.

101. Eggert C, Temp U, Eriksson KL. Laccase is essential for lignin degradation by the white-rot fungus Pycnoporus cinnabarinus. FEBS Lett. 1997;407:89-92.

102. Eggert C, Temp U, Eriksson KE. The ligninolytic system of the white rot fungus Pycnoporus cinnabarinus: purification and characterization of the laccase. Applied and Environmental Microbiology. 1996;62:11511158 .

103. Emerson BC, Gillespie RG. Phylogenetic analysis of community assembly and structure over space and time. Trends Ecol Evol. 2008;23(11):619-630.

104. Evans DA, Bravo JE. Agricultural applications of protoplast fusion. In: Marby TI, editor. Plant Biotechnol. Austin. 1998. p. 51-91.

105. Falade AO, Nwodo UU, Iweriebor BC, et al. Lignin peroxidase functionalities and prospective applications. Microbiology Open. 2016;6 e00394.

106. Fan XD, Wang JQ, Yang N, et al. Gene expression profiling of soybean leaves and roots under salt, saline alkali and drought stress by highthroughput Illumina sequencing. Gene. 2013;512:392-402.

107. Federhen S. Type material in the NCBI taxonomy database. Nucleic Acids Res. 2015;D1086-D1098.

108. Fernandez-Larrea J, Stahl U. Isolation and characterization of a laccase gene from Podospora anserine. Molecular and General Genetics. 1996;252(5):539-551.

109. Fernando T, Bumpus JA, Aust SD. Biodegradation of TNT $(2,4,6-$ trinitrotoluene) by Phanerochaete chrysosporium. Appl Environ Microbiol. 1990;56:1666-16671.

110. Fernando. Fluorescence Spot Sensor. Sci. Rep. 6, 25015. 1990.

111. Fisher Adam B, Fong Stephen S. Lignin biodegradation and industrial implications. AIMS Bioengineering. 2014;1(2):92-112.
112. Foli Samson. Farm characterisations in the southern and northern Guinea savannah zones of Nigeria. MSc thesis Plant Production Systems, Wageningen University; 2012.

113. Fournier D. Determination of key metabolites during biodegradation of hexahydro-1,3,5-trinitro-1,3,5-triazine with Rhodococcus sp. strain DN22. Appl Environ Microbiol. 2002;68 (1):166-172.

114. Freedman DL, Sutherland KW. Biodegradation Of Hexahydr01,3,5-Trinitr0-1,3,5-Triazine (RDX) Under Nitrate-Reducing Conditions. Wat Sci Tech. 1998;38(7):33-40.

115. Frankland JC. Biomass and Nutrient Cycling by Decomposer Basidiomycetes. In: Decomposer Basidiomycetes. Frankland JC, Hedger JW, Swift MJ, editors. Cambridge University Press, Cambridge, UK; 1982. p. 241-261.

116. French CE, Rosser SJ, Davies GJ, et al. Biodegradation of explosives by transgenic plants expressing pentaerythritol tetranitrate reductase. Nat Biotechnol. 1999;17:491-494.

117. French CE, Nicklin S, Bruce NC. Aerobic degradation of 2,4,6trinitrotoluene by Enterobacter cloacae PB2 and by pentaerythritol tetranitrate reductase. Appl Environ Microbiol. 1998;64:2864-2868.

118. Fritsche. Fungi in bioremediation of hazardous chemicals. Nat Rev Microbiol. 2000;9(3):177-192.

119. Galhaup, C, Goller S, Peterbauer CK, et al. Characterization of the major laccase isoenzyme from Trametes pubescens and regulation of its synthesis by metal ions. Microbiology. 2002;148:2159-2169.

120. Gandia-Herrero F, Lorenz A, Larson T, et al. Detoxification of the explosive 2, 4, 6- trinitrotoluene in Arabidopsis: discovery of bifunctional O- and C-glucosyltransferases. Plant J. 2008;56:963-974.

121. Gadd GM. Fungal responses towards heavy metals, p. 83-110. In : RA Herbert \& G. A. Gadd, editors. Microbes in Extreme Environments. Academic Press, Ltd., London, United Kingdom; 1986.

122. Gadd GM. Microbial control of heavy metal pollution, p. 59-88. In JC Fry, GM Gadd, RA Herbert, et al. editors.Microbial Control of Pollution. CambridgeUniversity Press, Cambridge, United Kingdom; 1992

123. Gargas A, Taylor JW. Polymerase chain reaction (PCR) primers for amplifying and sequencing 6uclear $18 \mathrm{~S}$ rRNA from lichenized fungi. Mycologia. 1992;84:589-592.

124. Gerhardt KE, Huang X, D Glick, et al. Phytoremediation and rhizoremediation of organic soil contaminants: potential and challenges, Plant Science. 1992;176:20-30.

125. Gerth A, Hebner A. Risk assessment and remediation of military and ammunition sites, In: Marmiroli N, Samotokin B, Marmiroli M, editors. Advanced science and technology for biological decontamination of sites affected by chemical and radiological nuclear agents. NATO science series, vol 75, Springer, Heidelberg. 2007;45-57.

126. Ghosh S, Chowdhury R, Bhattacharya P. Mixed consortia in bioprocesses: Role of microbial interactions. Appl Microbiol Biotechnol. 2016;100:4283-4295.

127. Gibson DT. Biodegradation, biotransformation and the Belmont. Ind Microbial. 1991;12:1-12.

128. Giovannoni S. The polymerase chain reaction. In: Stackebrandt E, Good fellow M (Eds) Nucleic Acids Techniques in Bacterial Systematics, John Wiley \&Sons, Chichester; 1991. p.177-203.

129. Giannelos PN, Zannikos F, Stournas S, et al. Tobacco seed oil as an alternative diesel fuel: Physical and chemical properties. Industrial Crops and Products. 2002;16:1-9.

130. Girvan HM, Waltham TN, Neeli R, et al. Flavocytochrome P450 BM3 and the origin of CYP102 fusion species. Biochem Soc Trans. 2006;34:1173-1177. 
131. Golan-Rozen N, Chefetz B, Ben-Ari J, et al. Transformation of the recalcitrant pharmaceutical compound carbamazepine by Pleurotus ostreatus: role of cytochrome P450 monooxygenase and manganese peroxidase. Environ Sci Technol. 2011;45(16):6800-6805.

132. Green F, TH Highley.Mechanism of brown-rot decay: paradigm or paradox. Int Biodeterior Biodegrad. 1997;39:113-124.

133. Gusek JJ. Design challenges for large-scale sulphate reducing bioreactors. To be presented at the Annual International Conference on Soils, Sediments and Water. University of Massachusetts, Amherst; 2003. p. 20-23.

134. Grigoriev IV, Nikitin R, Haridas S, et al. MycoCosm portal: gearing up for 1000 fungal genomes. Nucleic Acids Res. 2014;42:D699-D704.

135. Gunasekaran K, Tsai C, Kumar S, et al. Extended disordered proteins, targeting function with fewer scaffolds. Trends Biochemical Sciences. 2003;28:81-85

136. Gupta R, Ahuja P, Khan Set al. Microbial biosorbents: meetingchallenges of heavy metal pollution in aqueous solution. Curr Sci India. 2000;78:967-973.

137. Harper DB. The global chloromethane cycle: biosynthesis, biodegradation and metabolic role. Nat Prod Rep. 2000;17:337-348.

138. Scott D Harvey, Robert J Fellows, Dominic A Cataldo, et al. Fate of the explosive hexahydro-1,3,5-trinitro-1,3,5- triazine (RDX) in soil and bioaccumulation in bush bean hydroponic plants. Environmental Toxicology and Chemistry. 1991;10:845-855.

139. Harms H, Dietmar Schlosser, Lukas Wick. Untapped potential: exploiting fungi in bioremediation of hazardous chemicals. Nature Reviews Microbiology. 2011;9:177.

140. Harris FMA. Farm-level assessment of the nutrient balance in northern Nigeria. Agriculture, Ecosystems \& Environment. 1998;(1-3):201-214.

141. J Hawari, S Beaudet, A Halasz, et al. Microbial degradation of explosives: biotransformation versus mineralization. Appl Microbiol Biotechnol. 2000;54:605-618.

142. Halley JM. Ecology, evolution and 1/f-noise. Trends Evol. 1996;11:3337.

143. Hannink N, Rosser SJ, French CE, et al. Phytodetoxification of TNT by transgenic plants expressing a bacterial nitroreductase. Nature Biotechnology. 2001;19:1168-1172.

144. Hannink NK, Rosser SJ, Bruce NC. Phytoremediation of explosives Critical Reviews in Plant Sciences. 2002;21:511-538.

145. Hawari J, Beaudet S, Halasz A, et al. Microbial degradation of explosives: biotransformation versus mineralization. Appl Microbiol Biotechnol. 2000;54:605-618.

146. Hawari J, Halasz A, Sheremata T, et al. Characterization of metabolites during biodegradation of hexahydro-1,3,5-trinitro-1,3,5-triazine (RDX) with municipal anaerobic sludge. Applied and Environmental Microbiology. 2000;66:2652-2657.

147. Hawari J, Beaudet S, Halasz A, et al. Microbial degradation of explosives: biotransformation versus mineralization. Appl Microbiol Biotechnol. 2000a;54:605-618.

148. Hernández MT, García E, García C. A strategy for marginal semiarid degraded soil restoration: A sole addition of compost at a high rate. A five-year field experiment. Soil Biol Biochem. 2015;89:61-71.

149. Hestbjerg H, Willumsen PA, Christensen M, et al. Bioaugmentation of tar-contaminated soils under field conditions using Pleurotus ostreatus refuse from commercial mushroom production. Environ Toxicol Chem. $2003 ; 22: 692-698$.

150. Hibbett DS, Taylor JW. Fungal systematics: is a new age of enlightenment at hand. Nat Rev Microbiol. 2013;11:129-e133.
151. Hirai Hirofumi, Yoshiyuki Kashima, Katsuma Hayashi, et al. Efficient expression of laccase gene from white-rot fungus Schizophyllum commune in a transgenic tobacco plant. FEMS Microbiol Lett. 2008;286:130-135.

152. Hussain Altaf, Iqbal Ahmed Qarshi, Hummera Nazir, et al Plant Tissue Culture: Current Status and Opportunities. Licensee In Tech. 2012.

153. Hughes JB, Shanks J, Vanderford, M, et al. Transformation of TNT by aquatic plants and plant tissue cultures. Environmental Science \& Technology. 1996;31:266-271.

154. Hofrichter M. Review: lignin conversion by manganese peroxidase (MnP). Enzyme Microb Technol. 2002;30:454-466.

155. Huang J, Zhou SF. Study on the biodegradation of TNT packing wastewater by white rot fungi. Envir Sci Technol. 1999;(3):17-19.

156. Honeycutt ME, Jarvis AS, McFarland VA. Cytotoxicity and mutagenicity of 2,4,6-trinitrotoluene and its metabolites. Ecotoxicol Environ Saf. 1996;35:282-287.

157. Horvath RS. Microbial co- metabolism and the degradation of organic compounds in nature. Bacteriol Rev. 1972;146-155.

158. Hulbert MH, Krawiec S. Co- metabolism: A Critique. In: Bioremediation of Petroleum Contaminated Sites. CRC Press, FL, U.S.A. 1977. p. 35 63.

159. Ichinosse H..Cytochrome P450 of wood-rotting basidiomycetes and biotechnological applications. Biotechnol Appl Biochem. 2013;60:7181.

160. Isbister JD, Anspach GL, Kitchens JF, et al. Composting for decontamination of soils containing explosives. Microbiologica. 1984; 7:47-73

161. Iimura Y, Ikeda S, Sonoki T, et al. Expression of a gene for Mnperoxidase from Coriolus versicolor in transgenic tobacco generates potential tools for phytoremediation. Appl Microbiol Biotechnol. 2002;59:246-251.

162. Jackson RG, Raylot E, Fournier D, et al. Exploring the biochemical properties and remediation applications of the unusual explosive degrading P450 system XplA/B. Proc Nati Acad Sci USA. 2007;104(13):1682-16827.

163. Jagmann N, Philipp B. Design of synthetic microbial communities for biotechnological production processes. J Biotechnol. 2014;184:209218.

164. Jain R, Rivera MC, Moore JE, et al. Horizontal gene transfer accelerates genome innovation and evolution. Mol Biol Evol. 2003;20:1598-e1602.

165. Jaiswal PC. Soil, plant and water analysis Kalyani publishers, India; 2011.

166. Jenkins TF, JC Pennington, TA Ranney, et al. Characterization of explosives contamination at military firing ranges. ERDC TR-01-05. Hanover, NH: U.S. Army Engineer Research and Development Centre. 2001.

167. Jigami Y, Omori T, Minoda Y, et al. creening of $n$ - alkylbenzene assimilating yeasts and dentification of oxidation products fron n-alkylbenzenes. Agric Biol Chem. 1974;38:401-408.

168. Jimenez DJ, Brossi de Lima MJ, Schuckel J, et al. Characterization of three plant biomass-degrading microbial consortia by metagenomicsand metasecretomics-based approaches. Appl Microbiol Biotechnol. 2016; 100:10463-10477.

169. Jonsson L, H Saloheimo, M Penttila. Laccase from the white-rot fungus Trametes versicolor: cDNA cloning of lcc1 and expression in Pichia pastoris. Curr Genet. 1997;32:425-430.

170. Jung ST, Lauchli R, Arnold FH. Cytochrome P450: taming a wild type enzyme. Curr Opin Biotechnol. 2011;22:809-817. 
171. Jurado M, Martínez AT, Martínez MJ, et al. Application of white-rot fungi in transformation, detoxification, or revalorization of agriculture wastes: Role of laccase in the processes. Comprehensive Biotechnology. 2011;6:595-603.

172. Juhasz A, R Naidu. Explosives: fate, dynamics, and ecological impact in terrestrial and marine environments. Reviews of Environmental Contamination and Toxicology. 2007;191:163-215.

173. Just CL, Schnoor JL. Phytophotolysis of hexahydro-1,3,5- trinitro-1,3,5triazine (RDX) in leaves of reed canary grass. Environ Sci Technol. 2004;38(1):290-295.

174. Jyothi K, Surendra KB, Nancy CK, et al. Identification and isolation of Hydrocarbon Explosives Degrading Bacteria by Molecular Characterization. Helix. 2012;2:105-111.

175. Kalderis D, Juhasz A, R Boopathy, et al. Soils contaminated with explosives: environmental fate and evaluation of state-of-the-art remediation processes (IUPAC technical report). Pure and Applied Chemistry. 2011;83(7):1407-1484.

176. Kaplan R. The role of nature in the context of the workplace. Landscape and Urban Planning. 1993;26:193-201.

177. Kaplan DL. Biotechnology and bioremediation for organic energetic compounds," in Organic Energetic Compounds, P. Marikas, editor. pp. 373-395, Nova Science Publishers, New York, NY, USA; 1996.

178. Kaplan DL, Kaplan AM. Thermophilic biotransformations of 2,4,6trinitrotoluene under simulated composting conditions. App Environ Microbial. 1982;44:757-760.

179. Karavangeli M, Labrou NE, Clonis YD, et al. Development of transgenic tobacco plants overexpressing maize glutathione-Stransferase I for chloroacetanilide herbicides phytoremediation. Biomol Eng. 2005;22:121-128.

180. Keeling PJ, Inagaki Y. A class of eukaryotic GTPase with a punctate distribution suggesting multiple functional replacements of translation elongation factor 1alpha. Proc Natl Acad Sci USA. 2004;101:15380e15385.

181. Keith LH, Telliard W. Priority pollutants 1-A perspective view. Environ Sci Technol. 1979;13:416-423.

182. Keller C, Hammer D, Kayser A, et al. Root development and heavy metal phytoextraction efficiency: comparison of different plant species in the field. Plant and Soil. 2003;249:67-81.

183. Kembel SW. Disentangling niche and neutral influences on community assembly: assessing the performance of community phylogenetic structure tests. Ecol Lett. 2009;12:949-960.

184. Khaldi N, Wolfe KH, Elusive origins of the extra genes in Aspergillus oryzae. PLoS ONE. 2008;3:e3036.

185. Kim HJ, Song HG. Purification and characterization of NAD (P) $\mathrm{H}$ dependent nitroreductase I from Klebsiella sp. $\mathrm{C} 1$ and enzymatic transformation of 2,4,6-trinitrotoluene. Appl Microbiol Biotechnol. 2005;68:766-773.

186. Kirk TK, Farrell RL. Enzymatic "combustion": the microbial degradation of lignin. Annu Rev Microbiol. 1987;41:465-505.

187. Kitts CL, DP Cunningham, PJ Unkefer. Isolation of Three Hexahydro-1,3,5- Trinitro- 1,3,5-Triazine- Degrading Species of the Family Enterobacteriacea from Nitramine Explosive ContaminatedSoil. Applied and Environmental Microbiology. 1994;60(12):4608-4711.

188. Komoba D. Metabolic process for organic chemicals in plants. In: Plant Contamination: modelling and Simulation of Organic Chemical Processes.Trapp S, McFarlane JC, editors. Boca Raton: CRC Press Inc., 1995. p 69-103.

189. Konstantinidis KT, Tiedje JM. Genomic insights that advance the species definition for prokaryotes. Proc Natl Acad Sci USA. 2005;102:2567e2572.
190. Kloss K, Munch JC, Schoolmates M. A new method for the detection of Alkane Homologens genes (ALKB) in soil based on PCR Hybridization. Journal of Microbiology Method. 2006;66:486-496.

191. Koren S, Harhay GP, Smith TP, et al. Reducing assembly complexity of microbial genomes with single- molecule sequencing. Genome Biol. 2013;14:1.

192. Kr"amer U, Chardonnens AN. The use of transgenic plants in the bioremediation of soils contaminated with trace elements. Appl Microbiol Biotechnol. 2001;55: 661-672.

193. Kuiper I, Lagendijk E, L Bloemberg, et al. Rhizoremediation: a beneficial plant- microbe interaction. Molecular Plant- Microbe Interactions. 2004;17(1):6-15.

194. Kulshreshtha S, Mathur N, Bhatnagar P, et al. Cultivation of Pleurotus citrinopileatus on handmade paper and cardboard industrial wastes. Ind Crops Prod. 3013;41:340-346.

195. Kumar S. Engineering cytochrome P450 biocatalysts for biotechnology, medicine and bioremediation. Expert Opin Drug Metabol Toxicol. 2010;6:115-31.

196. Kuyucak N, Volesky B. The mechanism of cobalt biosorption. Biotechnol Bioeng. 1989;33(7):823-831.

197. Lachance B, Renoux AY, Sarrazin M, et al. Toxicity and bioaccumulation of reduced TNT metabolites in the earthworm Eisenia andrei exposed to amended forest soil. Chemosphere. 2004;55:1339-1348.

198. Lachance B, Robidoux PY, Hawari J, et al. Cytotoxic and genotoxic effects of energetic compounds on bacterial and mammalian cells in vitro. Mutat Res. 1999;444:25-39.

199. Lamichhane KM, Babcock RW, Turnbull SJ, et al. Molasses enhanced phyto and bioremediation treatability study of explosives contaminated Hawaiian soils. J Hazard Mater. 2012;243:334-339.

200. Lang AS, Beatty JT. Importance of widespread gene transfer agent genes in alpha-proteobacteria. Trends Microbiol. 2007;15:54e62.

201. Larsen N, Olsen GJ, Maidak BL, et al. The ribosomal database project. Nucleic Acids Res. 1993;21:3021-3023.

202. Leffler P, Brannas E, Ragnvaldsson D, et al. Toxicity and accumulation of trinitrotoluene (TNT) and its metabolites in Atlantic salmon alevins exposed to an industrially polluted water. Journal of Toxicology and Environmental Health A. 2014;77:1183-1191.

203. Ling LL, Schneider T, Peoples AJ, et al. A new antibiotic kills pathogens without detectable resistance. Nature. 2015;517:455-459.

204. Litvintseva AP, Henson JM. Cloning, characterization, and transcription of three laccase genes from Gaeumannomyces graminis var tritici, the take- all fungus. Applied Microbiology and Biotechnology. 2002;68:1305-1311.

205. Liu KL, Porras-Alfaro, A Kuske, et al. Accurate, rapid taxonomic classification of fungal largesubunit rRNA genes. Appl Environ Microbiol. 2012;78:1523-1533.

206. Lu Y, Mei L. Co-expression of P450 BM3 and glucose dehydrogenase by recombinant Escherichia coli and its application in an NADPHdependent indigo production system. J Ind Microbiol Biotechnol. 2007;34:247-253.

207. Macek T, Mackova, Kas J. Exploitation of plants for the removal of organics in environmental remediation. Biotechnol Adv. 2000;18:23-34.

208. Makris KC, Shakya KM, Datta R, et al. et al. Chemically catalyzed uptake of 2,4,6- trinitrotoluene by Vetiveria zizanioides, Environmental Pollution. 2007; 148:101-106.

209. Malik A. Metal bioremediation through growing cells. Enkviron Int. 2004;30(2):261-278. 
210. Maidak BL, Larsen N, McCaughey MJ, et al. The ribosomal database project. Nucleic Acids Res. 1994;22:3485-3487.

211. Mallo CnA, van Elsas JD, Salles JF. Microbial Invasions: The Process, Patterns, and Mechanisms. 342 Trends Microbiol. 2015;23:719-729.

212. Marchut-Mikolajczyk O, Kwapisz E, Wieczorek D, et al. Biodegradation of diesel oil hydrocarbons enhanced with Mucor circinelloides enzyme preparation. Int Biodeter Biodegr. 2015;104:142-148.

213. Marco-Urrea E, Pe'rez-Trujillo M, Bla'nquez P, et al. Biodegradation of the analgesic naproxen by Trametes versicolor and identification of intermediates using HPLC- DAD-MS and NMR. Biores Technol. 2010a;101:2159-2166.

214. Margesin R, Schinner F. Biodegradation and bioremediation of hydrocarbons in extreme environments. Appl Microbiol Biotechnol. 2001;56:650-663.

215. Martel RM, Mailloux U Gabriel, R Lefebvre, et al. S. Behaviour of energetic materials in ground water at an anti-tank range. Journal of Environmental Quality. 2009;38(1):75-92.

216. Martel R, J Robertson, DM Quan, et al. 2,4,6-Trinitrotoluene in soil and groundwater under a waste lagoon at the former Explosives Factory Maribyrnong (EFM), Victoria, Australia. Environmental Geology. 2008;53(6):1249-1259.

217. Macek T, Mackova M, Kas J. Exploitation of plants for the removal of organics in environmental remediation. Biotechnol Adv. 2000;18:23-34.

218. Maruthamuthu M, Jiménez DJ, Stevens P, et al. A multi- substrate approach for functional metagenomics-based screening for (hemi) cellulases in two wheat straw- degrading microbial consortia unveils novel thermoalkaliphilic enzymes. BMC Genomics. 2016;17:86.

219. Matsuzaki F, Wariishi H. Functional diversity of cytochrome P450s of the white- rot fungus Phanerochaete chrysosporium. Biochem Biophys Res Commun. 2004;324:387-93.

220. Mayer AM, Staples RC. Laccase: new functions for an old enzyme Phytochemistry. 2002;60(6):551-565.

221. McCormick NG, Cornell JH, Kaplan AM. Biodegradation of hexahydro-1,3,5- trinitro-1,3,5-triazine. Appl Environ Microbiol. $1981 ; 42: 817-823$

222. McCormick NG, Feeherry FE, Levinson HS, et al. Microbial transformation of 2,4,6-TNT and other nitroaromatic compounds. Appl Environ Microbiol. 1976;31:949-958.

223. McCormick NG, Cornell JH, Kaplan AM. The fate of hexahydro-1,3,5trinitro - 1,3,5-triazine (RDX) and related compounds in anaerobic denitrifying continuous culture systems using simulated waste water." Technical Report NaticwTR-85/008, ADA149462. US Army Natick Research and Development centre, MA. 1984

224. McIntosh JA, Farwell CC, Arnold FH. Expanding P450 catalytic reaction space through evolution and engineering. Curr Opin Chem Biol. 2014;19:126-34.

225. McLellan WL, Hartley WR. Brower ME. Health advisory for octahydro1,3,5,7-tetranitro-1,3,5,7- tetrazocine (HMX)." PB90-273525, US Army Medical Research and Development Command, Fort Detrick, MD; $1988 b$

226. Meagher RB. Plants tackle explosive contamination. Nature Biotechnology. 2006;24:161-163.

227. Mendes R, Garbeva P, Raaijmakers JM. The rhizosphere microbiome: significance of plant beneficial, plant pathogenic, and human pathogenic microorganisms. FEMS Microbiol Rev. 2013;37:634-663.

228. Medlin L, Elwood HJ, Stickel S, et al. The characterization of enzymatically amplified eukaryotic 16S- like rRNA-coding regions. Gene 1988;71(2):491-499.
229. Middelhoven WJ, Scorzetti G, Fell JW. Trichosporon veenhuisii sp. nov., an alkaneassimilating anamorphic basidiomycetous yeast. Int $J$ Syst Evol Microbiol. 2000;50:381-387.

230. Michels J, Gottschalk G. Inhibition of the lignin peroxidase of Phanerochaete chrysosporium by hydroxylamino-dinitrotoluene, an early intermediate in the degradation of 2,4,6- trinitrotoluene. App Environ Microbial. 1994;60:187-94.

231. Michels J, G Gottschalk. Pathway of 2,4,6-trinitrotoluene (TNT) degradation by Phanerochaete chrysosporium,p.135-149. In: JC Spain, editor. Biodegradation of nitroaromatic compounds. Plenum Press, New York, N.Y; 1995.

232. Minussi RC, Miranda MA, Silva JA, et al. Purification, characterization and application of laccase from Trametes versicolor for colour and phenolic removal of olive mill wastewater in the presence of 1hydroxybenzo - triazole. African Journal of Biotechnology. 2007;6:1248-1254.

233. Misiek M, Hoffmeister D. Fungal genetics, genomics, and secondary metabolites in pharmaceutical sciences. Planta Med. 2007;73(2):103115 .

234. Mohammadi M, Chalavi V, Novakova-Sura M, et al. Expression of bacterial biphenyl chlorobiphenyl dioxygenase genes in tobacco plants. Biotechnol Bioeng. 2007;97:496-505.

235. Monteil-Rivera F, L Paquet, S Deschamps, et al. Physico-chemica measurements of CL-20 for environmental applications: comparison with RDX and HMX. Journal of Chromatography. 2004;1025:125-132.

236. Morant M, Bak S, Moller BL, et al. Plant chromosomes P450: tools for pharmacology, plant protection and phytoremediation. Curr Opin Biotechnol. 2003;14:151-162.

237. Mostageer A, Elshihy OM. Establishment of salt tolerant somatic hybrid through protoplast fusion between rice and ditch reed. Arab J Biotech. 2003;6(1):01-12.

238. Mo Ce-Hui, Nai-Xian Feng, Jiao Yua, et al. Efficient phytoremediation of organic contaminants in soils using plant- endophyte partnerships. Science of The Total Environment. 2007;583:352-368.

239. Mukhtar S, Shahid I, Mehnaz S, et al. Assessment of two carrier materials for phosphate solubilizing biofertilizers and their effect on growth of wheat (Triticum aestivum L.). Microbiol Res. 2017;20:107-117.

240. Murphy G, Perry J. Assimilation of chlorinated alkanes by hydrocarbonutilizing fungi. J Bacteriol. 1984;160:1171-1174.

241. Nagata T, Kiyono M, Pan-Hou H. Engineering expression of bacterial polyphosphate kinase in tobacco for mercury remediation. Appl Microbiol Biotechnol. 2006;72:777-782.

242. Nazir KNH, Ichinose, H, Wariishi H. Molecular characterization and isolation of cytochrome P450 genes from the filamentous fungus Aspergillus oryzae. Arch Microbiol. 2010;192:395-408.

243. Nejidat A, Kafka L, Tekoah Y, et al. Effect of organic and inorganic nitrogenous compounds on RDX degradation and cytochrome P-450 expression in Rhodococcus strain YH1. Biodegradation. 2008;19:313320

244. Nielsen J. Metabolic engineering: techniques for analysis of targets for genetic manipulations. Biotechnol Bioeng. 1998;58(2-3):125-132.

245. Nielsen J. A simple morphologically structured model describing the growth of filamentous microorganisms. Biotechnol Bioeng. 1993;41(7):715-727.

246. Nie M, Pendall E, Bell C, et al. Positive climate feedbacks of soil microbial communities in a semi-arid grassland. Ecol Lett. 2013;16(2):234-241.

247. No lvak Hiie, Jaak Truu, Baiba Limane, et al. Microbial community changes in TNT spiked soil bioremediation Trial using biostimulation, phytoremediation and Bioaugmentation. Journal of environmental engineering and landscape management. 2013;21(3):153-162. 
248. Nyanhongo GS, Rodríguez Couto S, Gübitz GM. Coupling of 2,4,6-trinitrotoluene (TNT) metabolites onto humic monomers by a new laccase from Trametes modesta. Chemosphere. 2006;64(3):359-370.

249. Olicón-Hernández DR, González-López J, Aranda E. Overview on the Biochemical Potential of Filamentous Fungi to Degrade Pharmaceutical Compounds. Front Microbiol. 2017;8:1792.

250. O’Reilly, E Köhler V, Flitsch SL, et al. Cytochromes P450 as useful biocatalysts: addressing the limitations. Chem Commun. 2011;47:2490 501.

251. Ochman H, Lawrence JG, Groisman EA. Lateral gene transfer and the nature of bacterial innovation. Nature. 2000;405:299e304.

252. Okerentugba PO, Ezeronye OU. Petroleum degrading potentials of single and mixes microbial cultures isolated from rivers and refinery effluent in Nigeria. African Journal of biotechnology. 2003;2;288-292.

253. Otaiku AA, Alhaji IA. Kachia Military Shooting Range In Situ Fungi Species Biodegradation of Explosives, Kaduna, Nigeria. J Adv Res Biotech. 2019;4(2):1-26..

254. Otaiku AA, Mmom PC, Ano AO. Biofertilizer Impacts on Cassava (Manihot Esculenta Crantz) Cultivation: Improved Soil Health and Quality, Igbariam, Nigeria. World J Agri \& Soil Sci. 2020a;4(1):WJASS. MS.ID.000578.

255. Otaiku AA, Mmom PC, Ano AO. Biofertilizer Impacts on Cassava (Manihot Esculenta Crantz) Rhizosphere: Soil Microbiome Engineering, Genetic and Sustainable Agroecosystems, Igbariam, Nigeria. World J Agri \& Soil Sci. 2020b;6(1).

256. Otaiku AA, Alhaji A. Characterization of microbial species in the biodegradation of explosives, military shooting range, Kaduna, Nigeria. J Appl Biotechnol Bioeng. 2020c;7(3):128-147.

257. Palmieri G, Giardina P, Bianco C, et al. Copper induction of laccase isoenzymes in the lignolytic fungus Pleurotus ostreatus. Applied Microbiology and Biotechnology. 2000;66:920-924.

258. Pandhal J, Noirel J. Synthetic microbial ecosystems for biotechnology. Biotechnol Lett. 2014;36:1141-1151.

259. Parker CT, Tindall BJ, Garrity. International Code of Nomenclature of Prokaryotes. Int J Syst Evol Microbiol. 2015.

260. Parr CS, Guralnick R, Cellinese N, et al. Evolutionary informatics: unifying knowledge about the diversity of life. Trends Ecol Evol. 2012;27:94-103.

261. Patron NJ, Waller RF, Cozijnsen AJ, et al. Origin and distribution of epipolythiodioxopiperazine (ETP) gene clusters in filamentous ascomycetes. BMC Evol Biol. 2007;7:174.

262. Perie FH, Gold MH. Manganese regulation of manganese peroxidase expression and lignin degradation by white- rot fungus Dichomitus squalens. Applied and Environmental Microbiology. 1991;57:22402245 .

263. Penington JC, Brannon JM. Environmental Fate of Explosives. Thermochimica Acta. 2002;384:163-172.

264. Pennington JC, Hayes CA, Myers KF, et al. Fate of 2,4,6- trinitrotoluene in a simulated compost system. Chemosphere. 1995;30:429-438.

265. Pesce S, Bouchez A, Montuelle B. Effects of organic herbicides on phototrophic microbial communities in freshwater ecosystems. Rev Environ Contam Toxicol. 2011;214:87-124.

266. Plaza G, Lukasik W, Ulfig K. Sorption of cadmium by filamentous soil fungi. Acta Microbiol Pol. 1996;45(2):193-201.

267. Piontek K, Antorini M, Choinowski T. Crystal structure of a laccase from the fungus Trametes versicolor at 190- resolution containing a full complementof coppers. The Journal of Biological Chemistry. 2002;277:37663-37669.
268. Pointing SB, Jones EBG, Vrijmoed LLP. Optimization of laccase production by Pycnoporus sanguineus in submerged liquid culture. Mycologia. 2000;92:139-144.

269. Pointing SB. Feasibility of bioremediation by white rot fungi. Appl Microbiol Biotechnol. 2001;57:20-33.

270. Porras-Alfaro A, Liu K-L, Kuske CR, et al. From genus to phylum: large- subunit and internal transcribed spacer rRNA operon regions show similar classification accuracies influenced by database composition. Appl Environ Microbiol. 2014;80:829-840.

271. Prenafeta-Boldú FX, Summerbell R, Sybren de Hoog G. Fungi growing on aromatic hydrocarbons: biotechnology's unexpected encounter with biohazard? FEMS Microbiol Rev. 2006;30:109-130.

272. Price CB, Brannon JM, Yost SL, et al. Relationship between redox potential and $\mathrm{pH}$ on RDX transformation in soil-water slurries. $J$ Environ Eng. 2001;127:26-31.

273. Price CB, Brannon JM, Hayes CA. Effect of redox potential and $\mathrm{pH}$ on TNT transformation in soil water slurries. Journal of Environmental Engineering. 1997;123(10):988-992.

274. Puntarulo S, Cederbaum AI. Production of reactive oxygen species by microsomes enriched in specific human cytochrome P450 enzymes. Free Radical Biol Med. 1998;24(7-8):1324-30.

275. Raghukumar C, D Chandramohan, FC Michel, et al. Degradation of lignin and decolorization of paper mill bleach plant effluent (BPE) by marine fungi. Biotechnol Lett. 1996;18:105-106.

276. Ramos JL, Gonz'alez-P'erez MM, Caballero A, et al. Bioremediation of polynitrated aromatic compounds: plants and microbes put up a fight. Curr Opin Biotechnol. 2005;16:275-281.

277. Reddy CA, Mathew Z. Bioremediation potential of white rot fungi. In: G.M. Gadd, Ed., Fungi in Bioremediation. Cambridge, UK: Cambridge University Press; 2001.

278. Redecker D, Kodner R, Graham LE. Glomalean fungi from the Ordovician. Science. 2000;289:1920-1921.

279. Riccardi CM, Mansi A, Ciervo A, et al. Characterization of bacterial population coming from a soil contaminated by polycyclic aromatic hydrocarbons (PAHs) able to degrade pyrene in slurry phase. Aon Microbial. 2005;55(2):85-90.

280. Rho D, Hodgson J, Thiboutot S, et al. Transformation of 2,4,6trinitrotoluene (TNT) by immobilized Phanerochaete chrysosporium under fed-batch and continuous TNT feeding conditions. Biotech Bioeng. 2001;73:271-281.

281. Richards Thomas A, Leonard Guy, Soanes Darren M, et al. Gene transfer into the fungi. Fungi Biology Review. 2011;25.

282. Ricklefs RE. Disintegration of the ecological community. Am Nat. 2008; 172:741-750.

283. Ringelberg DB, Reynolds CM, Walsh ME, et al. RDX loss in a surface soil under saturated and well drained conditions. J Environ Qual. 2003;32:1244-1249.

284. Ricklefs RE, Jenkins DG. Biogeography and ecology: towards the integration of two disciplines. Phil Trans R Soc B. 2011;366:2438-2448.

285. Ricklefs RE, Schluter D. Species diversity in ecological communities. Chicago, IL: University of Chicago Press; 1993.

286. Ricklefs RE. Community diversity: relative roles of local and regional processes. Science. 1987;235:167-171.

287. Ricklefs RE. Disintegration of the ecological community. Am Nat. 2008; 172:741-750.

288. Robson TM, Lavorel S, Clement JC, et al. Neglect of mowing and manuring leads to slower nitrogen cycling in subalpine grasslands. Soil Biology \& Biochemistry. 2007;39:930-941. 
289. Robidoux PY, Bardai G, Paquet L, et al. Phytotoxicity of 2,4,6-trinitrotoluene (TNT) and octahydro- 1,3,5,7-tetranitro-1,3,5,7tetrazocine (HMX) in spiked artificial and natural forest soils. Arch Environ Contamin Toxicol. 2003;44:198-209.

290. Rocheleau S, Cimpoia R, Paquet L, et al. Ecotoxicological evaluation of a bioslurry process treating TNT and RDX contaminated soil. Bioremediation Journal. 1999;3:233-245.

291. Rogalski J, Lundell T, Leonowicz A, et al. Production of laccase, lignin peroxidase and manganese-dependent peroxidase by various strains of Trametes versicolor depending on culture conditions. Acta Microbiologica Polonica. 1991;40:221-234.

292. Ronen Z, Yanovich Y, Goldin R, et al. Metabolism of the explosive hexahydro-1,3,5-trinitro-1,3,5-triazine (RDX) in a contaminated vadose zone. Chemosphere. 2008;73:1492-1498.

293. Rosling A, Cox F, Cruz-Martinez K, et al. Archaeorhizomycetes: unearthing an ancient class of ubiquitous soil fungi. Science. 2011;333:876-879.

294. Ross IS. Some effects of heavy metals on fungal cells. Br Mycol Soc. 1975;64:175-193.

295. Rugh CL, Wilde HD, Stack NM, et al. Mercuric ion reduction and resistance in transgenic Arabidopsis thaliana plants expressing a modified bacterial merA gene. Proc Natl Acad Sci USA. 1996;93:31823187.

296. Rugh CL, Senecoff JF, Meagher RB, et al. Development of transgenic yellow poplar for mercury phytoremediation. Nat Biotechnol. 1998;16:925-928.

297. Rylott EL, Emily J Johnston, Neil C Bruce. Harnessing microbia gene pools to remediate persistent organic pollutants using genetically modified plants - a viable technology? Journal of Experimental Botany. 2015;66(21):6519-6533.

298. Rylott EL, NC Bruce. Plants disarm soil: engineering plants for the phytoremediation of explosives. Trends in Biotechnology. 2009;27 (2):73-81.

299. Rylott EL, Lorenz A, Bruce NC. Biodegradation and biotransformation of explosives. Current Opinion in Biotechnology. 2011c;22:434-440.

300. Rylott Elizabeth L, Maria V Budarina, Ann Barker, et al. Engineering plants for the phytoremediation of RDX in the presence of the cocontaminating explosive TNT. New Phytologist. 2011;192:405-413.

301. Sadeghi SJ, Fantuzzi A, Gilardi G. Breakthrough in P450 bioelectrochemistry and future perspectives. Biochimica et Biophysica Acta (BBA) Proteins Proteom. 2011;1814:237-248.

302. Sadeghi SJ, Gilardi G. Chimeric P450 enzymes: activity of artificial redox fusions driven by different reductases for biotechnological applications. Biotechnol Appl Biochem. 2013;60:102-110.

303. Sagi-Ben S, Moshe Z, Ronen BO, et al. Sequential biodegradation of TNT, RDX and HMX in a mixture. Environmental Pollution. 2009; 157:2231-2238

304. Sandermann H. Higher plant metabolism of Xenobiotics: the 'green liver' concept. Pharmacogenetics. 1994;4:225-241.

305. Salt D, Smith R, Raskin I. Phytoremediation. Annu Rev Plant Physiol Plant Mol Biol. 1998;49:643-668.

306. Santosh Kumar, Jin M, Weemhoff JL. Cytochrome P450-Mediated Phytoremediation using Transgenic Plants: A Need for Engineered Cytochrome P450 Enzymes. J. Pet Environ Biotechnol. 2012;3:127.

307. Scheel T, Höfer M, Ludwig S, et al. Differential expression of manganese peroxidase and laccase in white-rot fungi in the presence of manganese or aromatic compounds. Applied Microbiology and Biotechnology. 2000;54:686-691.
308. Schnoor JL, Van Aken B, Brentner LB, et al. Identification of metabolic routes and catabolic enzymes involved in phytoremediation of the nitrosubstituted explosives TNT, RDX, and HMX Final Technical Report. SERDP Project Number. 2006;CU1317.

309. Schnoor J, Licht L, McCutcheton S, et al. Phytoremediation of organic and nutrient contaminants. Environ Sci Technol. 199529:318A-323A.

310. Schroder P, Collins C. Conjugating enzymes involved in xenobiotic metabolism of organic xenobiotic in plants. International Journal of Phytoremediation. 2002;4:247-265.

311. Scotti R, Bonanomi G, Scelza R, et al. Organic amendments as sustainable tool to recovery fertility in intensive agricultural systems. $J$ Soil Sci Plant Nutr. 2015;5:333-352.

312. Scotti R, Pane C, Spaccini R, et al. On-farm compost: a useful tool to improve soil quality under intensive farming systems. Appl Soil Ecol. 2016;107:13-23.

313. Sevilla-Perea A, Mingorance MD. Field approach to mining-dump revegetation by application of sewage sludge co-compost and a commercial biofertilizer. J Environ Manag. 2015;158:95-102.

314. Sharma KK, Kuhad RC. Laccase: enzyme revisited and function redefined. Indian journal of microbiology. 2008;48(3):309-316.

315. Sheremata TW, Hawari J. Mineralization of RDX by the white rot fungus Phanerochaete chrysosporium to carbon dioxide and nitrous oxide. Environmental Science and Technology. 2000;34(16):3384-3388.

316. Shimp JF, Tracy JC, Davis LC, Lee E, et al. Beneficial effects of plants in the remediation of soil and groundwater contaminated with organic materials. Crit Rev Environ Sci Technol. 1993;23:41-77.

317. Shine AM, Shakya VP, Idnurm A. Phytochelatin synthase is required for tolerating metal toxicity in a basidiomycete yeast and is a conserved factor involved in metal homeostasis in fungi. Fungal Biol Biotechnol. $2015 ; 2: 1-13$.

318. Shleev S, Persson P, Shumakovich G, et al. Interaction of fungal laccases and laccase-mediator systems with lignin. Enzyme Microb Technol. 2006;39(4):841-847

319. Singh R, Paul D, Jain R. Biofilms: implications in bioremediation. Trends Microbiol. 2006;14(9):389-397.

320. Singh JS, Pandey VC, Singh DP. Efficient soil microorganisms: a new dimension for sustainable agriculture and environmental development. Agric Ecosyst Environ. 2011;140(3-4):339-353.

321. Singer A. The chemical ecology of pollutants biodegradation. In Phytoremediation and Rhizoremediation: Theoretical Background. Mackova M, Dowling D, Macek T, editors. Springer; 2006. p. 5-21.

322. Singh, D, Chen S. The white rot fungus Phaenerochaete chrysosporium: conditions for the production of lignin- degrading enzymes. Applied Microbiology and Biotechnology. 2008;81:399-417.

323. Singh JS. Plant-Microbe Interactions: A Viable Tool for Agricultura Sustainability Plant Microbes Symbiosis: Applied Facets; Arora, N.K., Ed.; Springer: New Delhi, India; Heidelberg, Germany; New York, NY USA; Dordrecht, The Netherlands; London, UK; 2015. 384 p.

324. Sims AH, Gent ME, Geoffrey D Robson, et al. Combining transcriptome data with genomic and cDNA sequence alignments to make confident functional assignments for Aspergillus nidulans genes. Mycol Res. 2004a;108:853-857.

325. Slot JC, Hibbett DS. Horizontal transfer of a nitrate assimilation gene cluster and ecological transitions in fungi: a phylogenetic study. PLoS ONE. 2007;2:e1097.

326. Slot JC, Rokas A. Multiple GAL pathway gene clusters evolved independently and by different mechanisms in fungi. Proc Natl Acad Sci USA. 2010;107:10136e10141. 
327. Slot JC, Rokas A. Horizontal transfer of a large and highly toxic secondary metabolic gene cluster between fungi. Curr Biol. 2011;21:134-e139.

328. Soden DM, Dobson ADW. Differential regulation of laccase gene expression in Pleurotus sajorcaju. Microbiology. 2001;147:1755-1763.

329. Sonoki T, Kajita S, Ikeda S, et al. Transgenic tobacco expressing fungal laccase promotes the detoxification of environmental pollutants. Applied Microbiology and Biotechnology. 2004.

330. Speitel G, Engels T, McKinney D. Biodegradation of RDX in unsaturated soil. Bioremediation J. 2001;5:1-11.

331. Spain JC. Biodegradation of nitroaromatic compounds. Annu Rev Microbiol. 1995;49:523-555.

332. Spiker JK, Crawford DL, Crawford RL. Influence of 2,4,6trinitrotoluene (TNT) concentration on the degradation of TNT in explosive- contaminated soils by the white rot fungus Phanerochaete chrysosporium. Appl Environ Microbial. 1992;58:3199-202.

333. Sonoki T, Kajita S, Iimura Y. Phytoremediation of bisphenol A via secretory fungal peroxidases produced by transgenic plants. Intech Open Access Publisher; 2012.

334. Spalding RF, JW Fulton. Groundwater munitions residues and nitrate near Grand Island, Nebraska, U.S.A. Journal of Contaminant Hydrology. 1988;2(2):139-153.

335. Scheibner K, Hofrichter M, A Herre, et al. Screening for fungi intensively mineralizing 2,4,6-trinitrotoluene. Appl Microbiol Biotechnol. 1997;47:452.

336. Stackebrandt E, Frederiksen W, Garrity GM, et al. Report of the ad hoc committee for the re-evaluation of the species definition in bacteriology. Int J Syst Evol Micr. 2002;52:1043-1047.

337. Stahl JD, Aust SD. Plasma membrane dependent reduction of 2,4,6trinitrotoluene by Phanerochaete chrysosporium. Biochem Biophys Res Commun. 1993a;192:471-476.

338. Stahl JD, Aust SD. Metabolism and detoxification of TNT by Phanerochaete chrysosporium. Biochem Biophys Res Commun. 1993b;192:477-482.

339. Stahl JD, Van Aken B, Cameron MD, et al. Hexahydro-1,3,5- trinitro1,3,5-triazine (RDX) biodegradation in liquid and solid-state matrices by Phanerochaete chrysosporium. Bioremed J. 2001;5:13-25.

340. Stephanopoulos G, Vallino JJ. Network rigidity and metabolic engineering in metabolite overproduction. Science. 1991;252:(5013):1675-1681.

341. Sublette KL, Ganapathy EV, Schwartz S. Degradation of munitions wastes by Phanerochaete chrysosporium. App Biochem Biotech. 1992;34/35:709-723.

342. Subramanian V, Yadav JS. Regulation and Heterologous Expression of P450 Enzyme System Components of the White Rot Fungus Phanerochaete Chrysosporium. Enzym Microb Technol. 2008;43(2):205213.

343. Suhara H, Adachi A, Kamei I, et al. Degradation of chlorinated pesticide DDT by litter-decomposing basidiomycetes. Biodegradation. 2011;22(6):1075-1086.

344. Sullivan JH, HD Puttman, HD MA. et al. A Summary and Evaluation of Aquatic Environmental Data in Relation to Establishing Water Quality Criteria for Munitions Unique Compounds: Part 2. Nitroglycerin, Water and Air Research, US Army Medical Research and Development Command, Gainesville, Fla, USA; 1979.

345. Svecova L, Spanelova M, Kubal M, et al. Cadmium, lead and mercury biosorption on waste fungal biomass issued from fermentation industry. I. Equilibrium studies. Separation and Purification Technology. 2006;52(1):142-153.

346. Syed K, Porollo A, Miller D, et al. Rational engineering of the fungal
P450 monooxygenase CYP5136A3 to improve its oxidizing activity toward polycyclic aromatic hydrocarbons. Protein Eng Design Select. 2013;gzt036.

347. Syed K, Shale K, Nazir KNH, et al. Genome-wide identification, annotation and characterization of novel thermostable cytochrome P450 monooxygenases from the thermophilic biomass-degrading fungi Thielavia terrestris and Myceliophthora thermophila. Genes Genom. 2014;36:321-333.

348. Thenmozhil R, Arumugan K, Nagasathya A, et al. Studies on mycroremediation of used engine oil contaminated Soil Samples. Advances in Applied Science Research. 2013;4(2):110-118.

349. Talmage SS, Opresko DM, Maxwel CJ, et al. Nitroaromatic munitions compounds: environmental effects and screening values. Reviews in environmental contamination toxicology. 1999;161:1-156.

350. Thiéry O, Vasar M, Jairus $\mathrm{T}$, et al. Sequence variation in nuclear ribosomal small subunit, internal transcribed spacer and large subunit regions of Rhizophagus irregularis and Gigaspora margarita is high and isolate-dependent. Mol Ecol. 2016;25:2816-2832.

351. Thomas CM, Nielsen KM. Mechanisms of, and barriers to, horizontal gene transfer between bacteria. Nat Rev Microbiol. 2005;3:711e721.

352. Thurston CF. The structure and function of fungal laccases. Microbiology. 1994;40:19-26.

353. Tindall BJ, Rossello'Mra, R Busse, et al. Notes on the characterization of prokaryote strains for taxonomic purposes. Int J Syst Evol Microbiol. 2010;60:249-266.

354. Townsend DM, Myers TE. Recent developments in formulating model descriptors for subsurface transformation and sorption of TNT, RDX, and HMX," Technical Report IRRP-96-1, U.S. Army Engineer Waterways Experiment Station Vicksburg, M.S; 1996.

355. Travis ER, Bruce NC, Rosser SJ. Microbial and plant ecology of a longterm TNT-contaminated site, Environmental Pollution. 2008a;153:119_ 126.

356. Travis ER, Bruce NC, Rosser SJ. Short term exposure to elevated trinitrotoluene concentrations induced structural and functional changes in the soil bacterial community. Environmental Pollution. 2008b;153:432-439.

357. Tyagi M, da Fonseca MM R, de Carvalho CC. Bio-augmentation and bio-stimulation strategies to improve the effectiveness of bioremediation processes. Biodegradation. 2011;22(2):231-241.

358. USEPA . United States Environmental Protection Agency Quality Assurance Management staff. 2006.

359. Usman DH, Ibrahim AM, Abdullahi S. Potentials of Bacterial isolates in Bioremediation of Petroleum Refinery Wastewater. Journal of Applied phyto technology in Environmental Sanitation. 2012;1(3):131-138.

360. Uldschmid A, Dombi R, Marbach K. Identification and functional expression of ctaA, a P-type ATPase gene involved in copper trafficking in Trametes versicolor. Microbiology. 2003;149:2039-2048.

361. Umarov AU, Khasanov M, Teshabaeva T. An investigation of the oil of Nicotiana tabacum seeds. Chemistry of Natural Compounds. 1991;26:706-707.

362. Urbanski T. Chemistry and technology of explosives. In: Laverton S, editor. Pergamon Press, 0xford; 1967. p 17-77.

363. Urlacher VB, Eiben S. Cytochrome P450 monooxygenases: perspectives for synthetic application. Trends Biotechnol. 2006;24:324-330.

364. Urlacher VB, Girhard M. Cytochrome P450 monooxygenases: an update on perspectives for synthetic application. Trends Biotechnol. 2012;30:26-36. 
365. Usta N. An experimental study on performance and exhaust emissions of a diesel engine fuelled with tobacco seed oil methyl ester. Energy Conversion and Management. 2005;46:2373-2386.

366. Vamosi SM, Heard SB, Vamosi JC, et al. Emerging patterns in the comparative analysis of phylogenetic community structure. Mol Ecol. 2009;18:572-592.

367. Van Aken B. Transgenic plants for enhanced phytoremediation of toxic explosives Current Opinion in Biotechnology. 2009;20:231-236.

368. Van Aken B, Agathos SN. Biodegradation of nitro-substituted explosives by white-rot fungi: a mechanistic approach. Adv Appl Microbiol. 2001;48:1-77.

369. Van Aken B. Yoon JM, Just CL, et al. Metabolism and mineralization of hexahydro-1,3,5-trinitro-1,3,5-triazine inside poplar tissues (Populus deltoides xnigra DN-34). Environ Sci Technol. 2004;38:4572-4579.

370. Van Dillewijn P, Couselo JL, Corredoira E, et al. Bioremediation of 2 , 4, 6-trinitrotoluene by bacterial nitroreductase expressing transgenic aspen. Environ Sci Technol. 200842:7405-7410.

371. Van Dillewijn P, Caballero A, Paz J, et al. Bioremediation of 2,4,6trinitrotoluene under field conditions. Environmental Science \& Technology. 2007;41:1378-1383.

372. Varma A, Palsson BO. Metabolic flux balancing -basic concepts, scientific and practical use. Bio-Technology. 1994;12(10):994-8.

373. Vasudevan P, Padmavathy V, Tewari N, et al. Biosorption of heavy metal ions. J Sci Ind Res. 2001;60:112-120.

374. Veljkovic VB, Lakicevic SH, Stamenkovic OS, et al. Biodiese production from tobacco (Nicotiana tabacum L.) seed oil with a high content of free fatty acids. Fuel. 2006;85:2671-2675.

375. Via SM, Zinnert JC. Impacts of explosive compounds on vegetation: a need for community scale investigations. Environ Pollut. 2016;208(Pt B):495-505.

376. Via SM, Zinnert JC, Young DR. Multiple metrics quantify and differentiate responses of vegetation to composition B. Int $J$ Phytoremediation. 2017;19(1):56-64.

377. Vila M, Lorber-Pascal S, Laurent F. Fate of RDX and TNT in agronomic plants. Environ Pollut. 2007a;148(1):148-154

378. Vila M, Mehier S, Lorber-Pascal S, et al. Phytotoxicity to and uptake of RDX by rice. Environ Pollut. 2007b;145:813-817.

379. Viswanath Buddolla, M Subhosh Chandra, K Praveen Kumar, et al. et al. Fungal Laccases and Their Biotechnological Applications with Special Reference to Bioremediation. Dynamic Biochemistry, Process Biotechnology and Molecular Biology. 2008;2(1):1-13.

380. Waisner S, Hansen L, Fredrickson H, et al. Biodegradation of RDX within soil-water slurries using a combination of differing redox incubation conditions. J Hazard Mater. 2002;B95:91-106.

381. Walton JD. Horizontal gene transfer and the evolution of secondary metabolite gene clusters in fungi: a hypothesis. Fungal Genet Biol. 2000;30:167e171.

382. Wang GY, Laidlaw RD. Metabolic engineering of fungal secondary metabolite pathways. Handbook of industrial mycology. Marcel Dekker; 2005. p. $635-651$.

383. Wang Chen, Helin Huang, Benjamin R Bunes, et al. Trace Detection of RDX, HMX and PETN Explosives Using a Fluorescence Spot Sensor. Sci Rep. 2016;6:25015.

384. Wang D, Boukhalfa H, Marina O, et al. Biostimulation and microbial community profiling reveal insights on RDX transformation in groundwater. Microbiology Open. 2016;6:e423.

385. Wayne LG, Brenner DJ, Colwell RR, et al. Report of the ad hoc committee on reconciliation of approaches to bacterial systematics. Int $J$ Syst Evol Micr. 1987;37:463-464.

386. Wenzl P, Wong L, Kim KW, et al. A functional screen identifies lateral transfer of B-Glucuronidase (gus) from bacteria to fungi. Mol Biol Evol. $2005 ; 22: 308 \mathrm{e} 316$

387. Wendt TM, Cornell JH, Kaplan AM. Microbial degradation of glycerol nitrates. Applied and Environmental Microbiology. 1978;36:693-699.

388. Webb CO, Ackerly DD, McPeek MA. et al. Phylogenies and community ecology. Ann Rev Ecol Syst. 2002;3:475-505.

389. Weisburg WG, Barns SM, Pelletier DA, et al. 16S ribosomal DNA amplification for phylogenetic study. J Bacteriol. 1991;173:697-703.

390. Wiechert W. Modelling and simulation: tools for metabolic engineering. J Biotechnol. 2002;94(1):37-63.

391. Wong JWC, Li KL, Zhou LX, et al. The Sorption of Cd and Zn by Different Soils in the Presence of Dissolved Organic Matter from Sludge. Geoderma. 2007;137:310-317.

392. Winfield LE, Rodgers JH, Jr D'Surney. The responses of selected terrestrial plants to short ( $<12$ days) and long term $(2,4$ and 6 weeks $)$ hexahydro- 1,3,5-trinitro- 1,3,5-triazine (RDX) exposure. Part I: growth and developmental effects. Ecotoxicology. 2004;13:335-353.

393. White GF, Snape JR. Microbial cleavage of nitrate esters: defusing the environment. J Gen Microbial. 1993;139:1947-1957.

394. Whitehouse CJ, Bell SG, Wong LL. P450 (BM3) (CYP102A1): connecting the dots. Chem Soc Rev. 2012;41:1218-1260.

395. Wilson KH, Blitchington RB, Greene RC. Amplification of bacterial 16 S ribosomal DNA with polymerase chain reaction. Clinical Microbiol. 1990;28:1942-1946.

396. Williams RE, Bruce NC. The role of nitrate ester reductase enzymes in the biodegradation of explosives," Biodegradation of nitroaromatic compounds and explosives. Jim C. Spain, Joseph B. Hughes, and HansJoachim Knackmuss, ed., Lewis Publishers, New York; 2000.

397. Williams RT, Ziegenfuss PS, Sisk WE. Com posting of explosives and propellant contaminated soils under thennophillic and mesophillic conditions. J Indust Microbial. 1992;9:137-144.

398. Wu H, Lai C, Zeng G, et al. The Interactions of composting and biochar and their implications for soil amendment and pollution remediation: a review. Crit Rev Biotechnol. 2017;37(6):754-764.

399. Xiao P, Mori T, Kondo R. Biotransformation of the organo-chlorine pesticide trans-chlordane by wood-rot fungi. New Biotechnol. 2011;29 (1):107-115.

400. Xu M. Fluorescence Ratiometric Sensor for Trace Vapour Detection of Hydrogen Peroxide. ACS Appl Mater Interfaces. 2014;6: 8708-8714.

401. Yadav Jagjit S, John C Loper. Cloning and Characterization of the Cytochrome P450 Oxidoreductase Gene from the Zygomycete Fungus Cunning hamella. Biochemical and Biophysical Research Communications. 2000;268(2):345-353.

402. Yang G, Wagg C, Veresoglou S, et al. How soil biota drive ecosystem stability. Trends Plant Sci. 2018;3:1057-1067.

403. Yanovich Y. Biodegradation of RDX in the Vadose Zone above Israel Costal Aquifer. Ben Gurion University of the Negev. Israel; 2018.

404. Yinon J, Zitrin S. Modern methods and applications in analysis of explosives. Wiley. Chichester; 1993

405. Young DM, Unkefer PJ, Ogden KL. Biotransformation of hexahydro1,3,5-trinitro-1,3,5-trinazine (RDX) by a prospective consortium and its most effective isolate Serratia marcescens. Biotechnology and Bioengineering. 1997a;53:515-522. 
406. Young DM, Kiits CL, Unkefer PJ, et al. Biological breakdown of RDX in Slurryreactors proceeds with multiple kinetically distinguishable paths. Biotechnology and Bioengineering. 1997b;56:258-267.

407. Yoon JM, Oliver DJ, Shanks JV. Plant transformation pathways of energetic materials (RDX, TNT, DNTs). In: Eaglesham A, Bessin R, Trigiano R, Hardy RWT, editors. Agricultural biotechnology: beyond food and energy to health and the environment. National Agricultural Biotechnology Council Report 17. National Agricultural Biotechnology Council, Ithaca, NY, USA; 2005. p. 105-116.

408. Yoon JM, Van Aken B, Schnoor JL. Leaching of contaminated leaves following uptake and phytoremediation of RDX, HMX, and TNT by poplar. International Journal of Phytoremediation. 2006;8:81-94.
409. Zhang CL, Hughes JB. Biodegradationpathways ofhexahydro- 1,3,5trinitro-1,3,5-triazine (RDX) by Clostridium acetobutylicum cell-free extract. Chemosphere. 2003;50:665-671.

410. Zhao JS, Paquet L, Halasz A, et al. Metabolism of octahydro-1,3,5,7tetranitro-1,3,5,7-tetrazocine by Clostridium bifermentans strain HAW1 and several other H2-producing fermentative anaerobic bacteria. FEMS Microbiol Lett. 2004a;237:65-72.

411. Zhao JS, Spain J, Thiboutot S, et al. Phylogeny of cyclic nitraminedegrading psychrophilic bacteria in marinesediment and their potential role in the natural attenuation of explosives. FEMS Microbiol Ecol. 2004b;49:349-357. 